DOE/CE/15307--TI - TI

DE93 002802

\title{
A Waterjet Mining Machine for Use in Room and Pillar Mining Operations
}

in fulfillnent of

Contract DOE DE FG01 87CE 15307

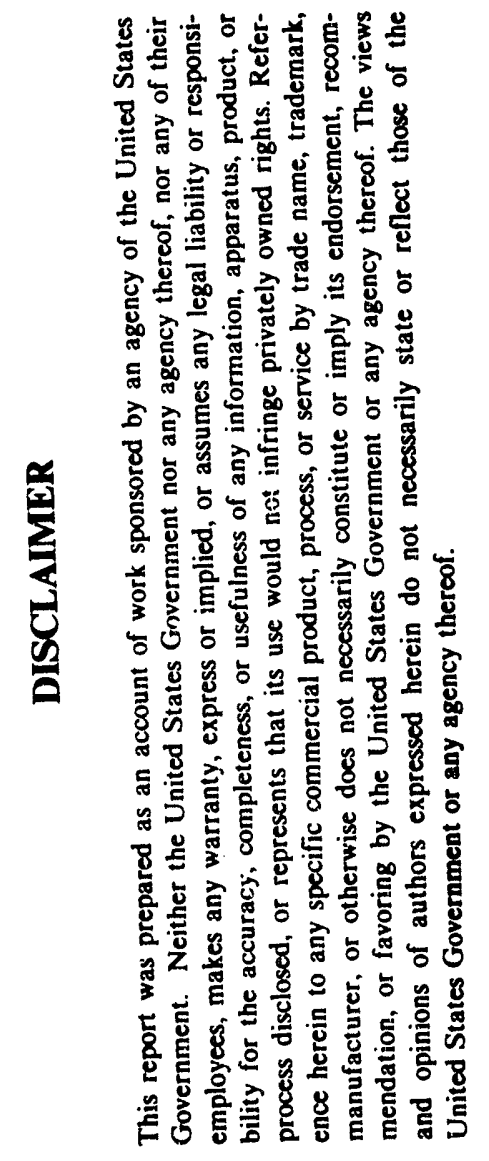

for the

U.S. Department of Fnergy

1000 Independence Avenue, S.W.

Washington, D.C. 20585

\author{
by \\ Dr. David A. Summers \\ University of Missouri-Rolla \\ High Pressure Waterjet Laboratory \\ Rolla, MO. 65401
}

June, 1990 


\section{TABLE OF CONTENTS}

CHAPTER I. BACKGROUND .......................................................

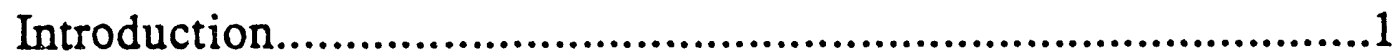

Historical Background ................................................................

Proposed RAPIERS Method of Operation........................................4

Jet Cutting Parameters .....................................................................7

CHAPTER II. EQUIPMENT CONSTRUCTION..................................14

Irtroduction................................................................................14

Gathering Arm Loader Apron.......................................................15

Shield Support ............................................................................20

Computer Operated Slot Cutting Arm ............................................24

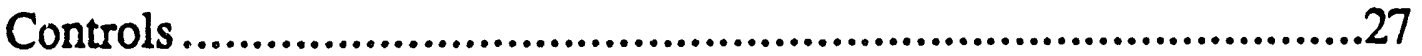

Hyaraulic Circuitry and System Hardware .....................................34

CHAPTER III. EQUIPMENT CONSTRUCTION .................................37

Introduction..................................................................................37

Prototype Evaluation ......................................................................38

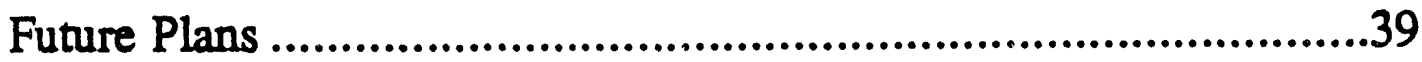

Acknowledgements.......................................................................40

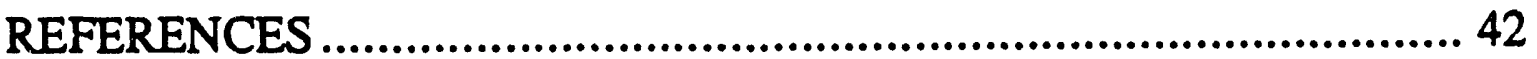




\begin{abstract}
A new mining machine is constructed for use in room and pillar mining operations. This machine uses the action of computer controlled, centrally located high pressure cutting lances to cut deep slots in a coal face. These slots stress relieve the coal ahead of the machine and outline blocks of coal. The movement forward of the machine then wedges up the lower block of coal.

This wedging action is assisted by the gathering arms of the loader section of the machine, and by underlying oscillating waterjets which create a slot ahead of the loading wedge as it advances. Finally the top section of coa! is brought down by the sequential advance of wedge faced roof support members, again assisted by the waterjet action from the central cutting arms.

The machine is designed to overcome major disadvantages of existing room and pillar mining machines in regard to a reduction in respirable dust, the creation of an immediate roof support, and an increase in product size, with concomitant reduction in cleaning costs.
\end{abstract}




\section{CHAPTER I. BACKGROUND}

\section{Introduction}

In 1987 the University of Missouri Rolla undertook the design and construction of a room and pillar coal mining machine. This final report documents the original concept which was proposed and the modifications made as the design avolved during the construction of the first prototype. The report concludes with discussion of the projected future plans to develop this equipment.

\section{Historical Background}

Coal has been a major fuel source for the United States for the whole of the 20th Century. Current declining production of domestic oil suggests that it will retain this role well into the 21 st Century. Production of coal is largely from underground operations in the Eastern and Western United States. The majority of the coal excavated from underground workings is extracted by continuous mining machines (Figure 1).
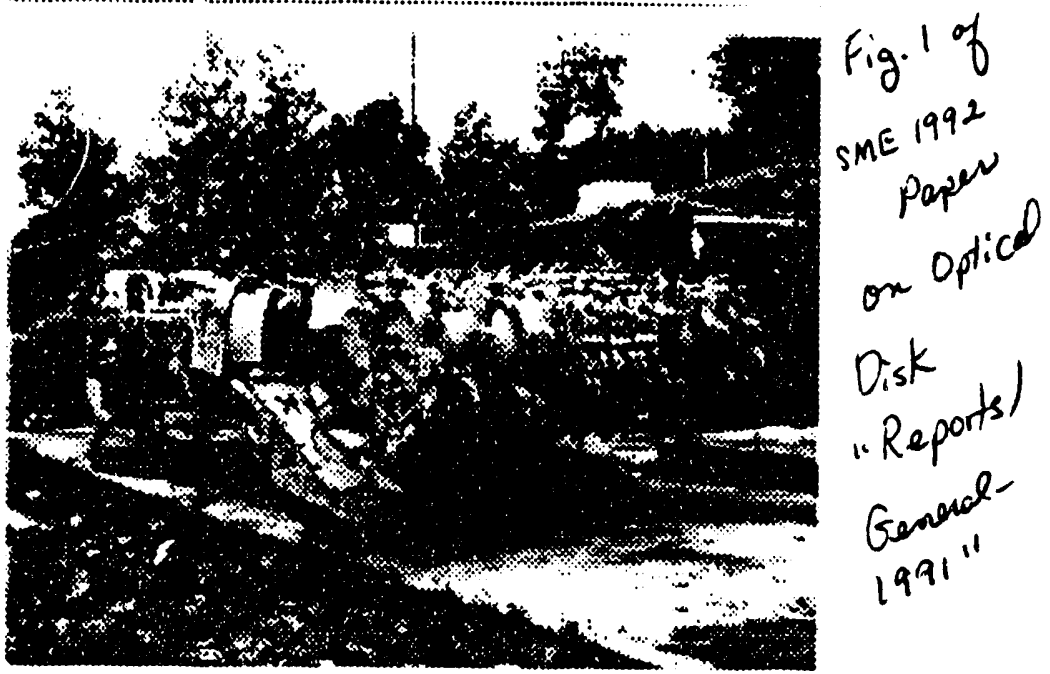

Figure 1. Continuous Mining Machine.

Figure 1. Continuous Mining Machine

These miners are fitted with a large rotating drum into which high strength steel picks are arranged in one of a variety of patterns. As the drum rotates against the coal face, these picks penetrate into the coal, grinding it from the solid. Under the drum 
the continuous miner has a wedge shaped apron upon which two gathering arms are mounted. These arms push the fallen coal towards the center of the machine where a conveyor is located. As the coal passes onto the conveyor it is carried through the machine to a boom projecting out of the back of the continuous miner. The most common method of moving the coal from this point is to use shuttle cars. These are small, generally electric powered trucks which collect the coal from the back of the continuous miner and carry it to the face end of a continuous belt conveyor. This conveyor is then used to carry the coal away from the working panel on its way out of the mine.

Although productivity from a continuous miner can be quite high on an instantaneous basis, overall production rates on a daily basis can be disappointingly low. This is because of two major requirements which must be implemented during the cycle. As the mining machine grinds the coal from the surface, the cutting action of the individual picks generate considerable volumes of very fine coal dust. This dust easily becomes airborne and provides a respirable dust hazard for the continuous miner operator and any other workers in the vicinity. To overcome this environmental problem it is necessary to keep a clean air supply feed close to the working face. This is often done by moving a length of ventilation line towards the face after every 10 feet of machine advance. This will obviously slow the production rate of the machine since it is generally not operating when this is done.

The second problem creates a significantly greater cutback in production. The roof over most coal seams is made up of rock which can be quite weak and may itself comprise a number of very thin layers of material. In order to hold the roof in place and prevent its collapse on the mining crew, artificial supports must be used. Over the years, the most popular of these has become what is known as a roof bolting system. In essence, this requires that holes be drilled into the roof typically upward over a distance of approximately 7 feet. The holes are spaced on 4 to 5 foot intervals apart both across and along the tunnel. Once each hole has been drilled, a metal rod, known as a roof bolt, is installed in the hole. These are attached to the rock in one of several ways, each of which serves to hold the rock layers together and to prevent their collapsing into the working space.

The machine which drills the holes and places the bolts in them is itself quite large. Thus, in order to bolt the area of roof which has been exposed by the operation of the continuous miner, that machine must first be withdrawn out of the tunnel. In a normal mining plan a machine will work in several different tunnels in sequence to give time 
for the roof bolters to support the roof. At the same time, this pattern of extraction is planned so that the continuous miner will drive a series of normally perpendicular tunnels. As these intersect they will outline, between them, a series of coal pillars which will be left standing in the seam to provide stronger support for the more permanent stability of the excavation.

This need to provide an immediate support of the roof, before the continuous miner operator is required to work under it, limits the advance of the machine to a distance of perhaps only 20 feet in any one tunnel at one time. The resulting intermittent cutting action of the machine significantly reduces the overall daily production which can be obtained from the working section.

One additional problem of increasingly significant economic importance has developed with the use of the continuous miner. The grinding action of the drum and picks against the coal face produces very small coal. As an approximate rule more than $80 \%$ of the coal produced will be less than 1 inch in size. The cost for cleaning this material to remove dirt and other impurities can be as high as $\$ 6.50 /$ ton. Cleaning these impurities from the coal is becoming mandatory before it can be sold to many current buyers, particularly for power generation.

One can therefore summarize some of the working disadvantages of the common continuous miner as being:

that it produces large quantities of respirable dust, that mining must be stopped to provide support of the roof, that too much small coal is produced which is expensive to clean.

As a result, it is appropriate to look at a different excavation philosophy which might overcome these disadvantages.

The University of Missouri-Rolla has worked with the Jet Propulsion Laboratory of Pasadena, CA to develop a mining machine which would overcome some of these disadvantages (Reference 1). The design which has been developed was based upon the successful testing of a longwall mining machine which used high pressure waterjets as a cutting tool to replace the impact of the hard metal picks. Trials of the longwall unit had shown that the waterjets mine coal without genera ting respirable dust and in significant quantities and that the coal produced by the combined waterjets and mechanical system was significantly larger in size (Reference 2). Because large coal 
can cost as little as $\$ 1.50 /$ ton to clean, this suggests an economic advantage of cleaning cost alone of up to $\$ 5.00 /$ ton with a change in the tool used.

After considerable evaluation the design of a continuous miner version of the hydrominer, as this earlier machine was known, has been developed. This design sought to include the advantages of the longwall machine adapted to the type of room and pillar mining most common in the United States. In order to provide a simple reference to the machine during the course of this report, an acronym has been developed for the machine. This is RAPIERS (standing for Room And Pillar In-seam Excavator and Roof Supporter).

\section{Proposed RAPIERS Method of Operation}

The machine which has been developed has been designed to produce more coal with less energy and with less environmental and safety problems than existing equipment. To trace the development of the machine, the original method of excavation proposed will be initially described. Following this the modifications required as the machine was constructed will be reviewed.

Very simply put, RAPIERS (Figure 2) operates by first of all cutting a slot in the middle of the coal face, which can be considered as a wall across the end of the access tunnel. After cutting this slot which is approximately 2-3 inches wide, the overlying rock pressure on the coal ahead of the machine will be transferred to adjacent coal, since the slotted material can no longer support this thrust. The cual therefore, at this time, is much easier to break since it is no longer under confinement and pressure.

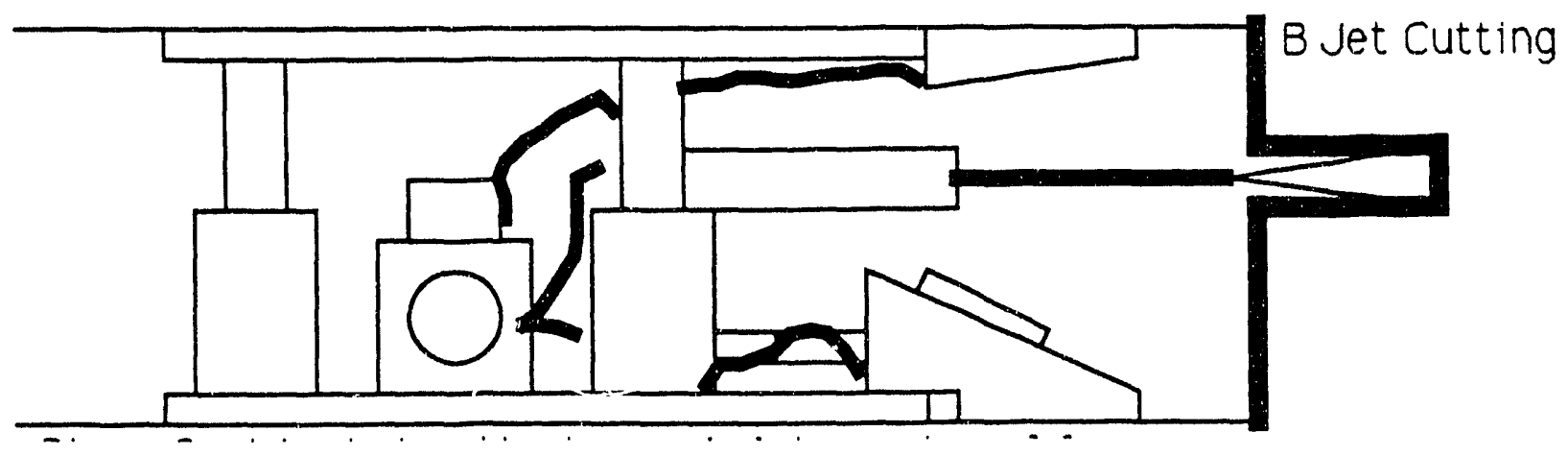

Figure 2. Schematic showing Side View of RAPIERS at a coal face. 
Once the initial central cut has been taken, two vertical relieving cuts are made at the edges of the tunnel. This isolates the block of coal which is to be mined. The bottom wedge at the front of RAPIERS is then moved forward. As it moves forward into the coal, an oscillating waterjet nozzle traverses underneath the leading edge cutting a slot ahead of the blade. Two jets issue from this nozzle, and can cut a slot up to three feet deep ahead of the wedge, two inches high. The interaction of the wedge and the waterjet together enhance the performance of both since the uplifting force generated by the wedge is concentrated at the back of the slot which the waterjet is cutting. This opens any cracks which might be present and puts the coal in tension making it easier for the waterjet to cut the coal.

As the wedge moves forward it will break the overlying coal upwards, fragmenting it into pieces, and at the same time moving it back up the wedge. In order to help this movement and to load the coal mined from the face, the machine uses the same principal as is currently used in the conventional continuous coal mining machines, namely two rotating gathering arms, located one on either side of the top of the wedge. These arms rotate and move the coal from in front of the machine towards the center of the apron, where a small transfer conveyor is located. This conveyor carries the coal up the apron and back through the machine to a protruding boom were the coal can be loaded onto a shuttle car. By using an already existing gathering arm it is possible to eliminate the requirement for developing a new method of loading the coal from the coal face. Further, the wedge shape of the existing continuous miner aprons can be used to help break the coal from the solid.

Once the bottom wedge has been pushed forward into the coal to its full extent, a block of coal cut to the width of the tunnel,, measuring half the seam in height and some 2-3 feet deep will have been extracted. At this time, a second wedge and oscillating waterjet will be activated at the top of the seam. this will similarly push forward, breaking down the top half of the coal and causing it to fall onto the apron which is located underneath it. The gathering arms will then move this upper half of the coal back to the transfer conveyor. After all the coal has been mined in the block ahead of the machine, then the main body of the machine will be moved forward ready to restart the process. (This sequence of events is illustrated in Figure 3). 


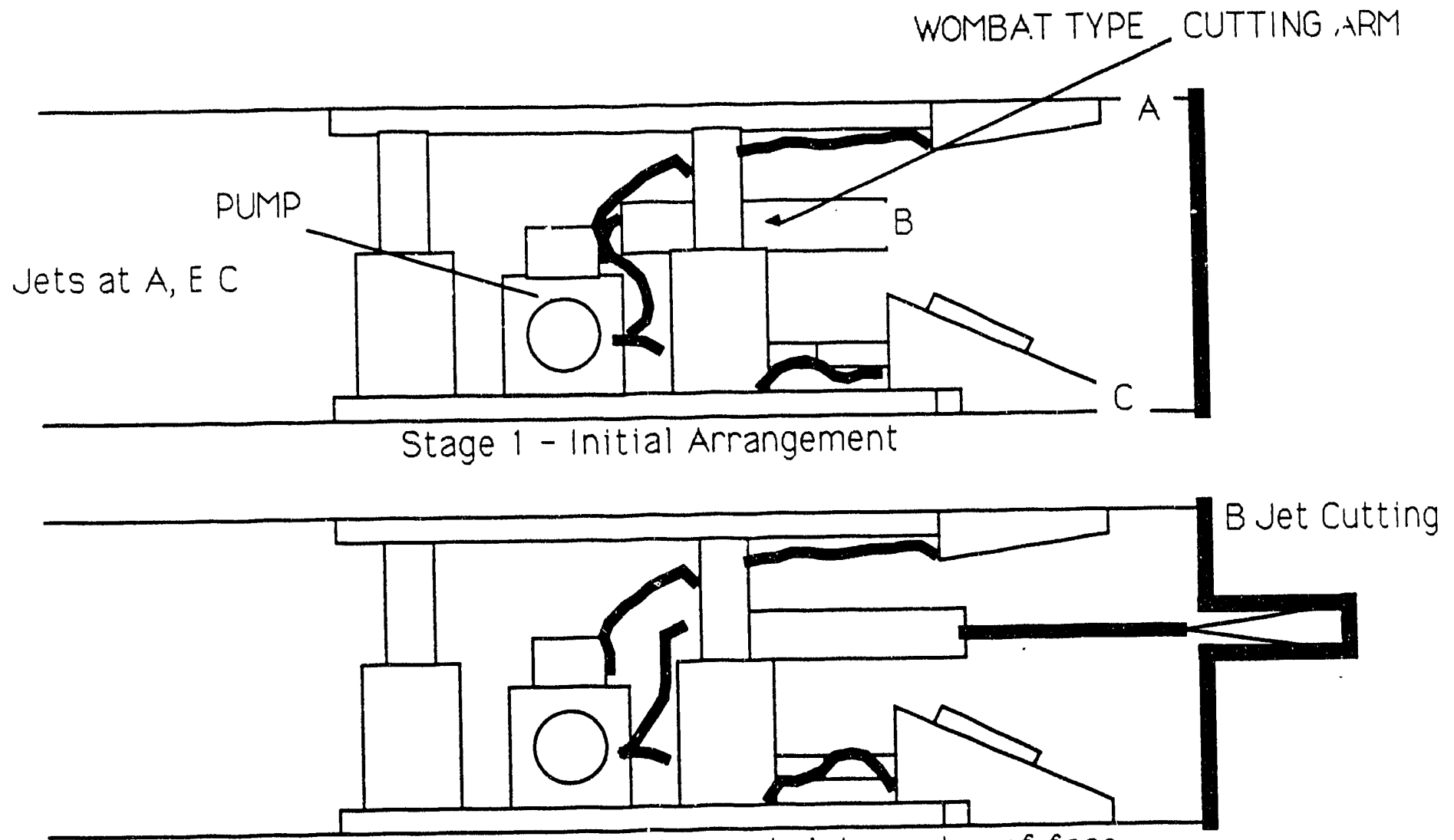

Stage 2 - Wombat activates and slots center of face

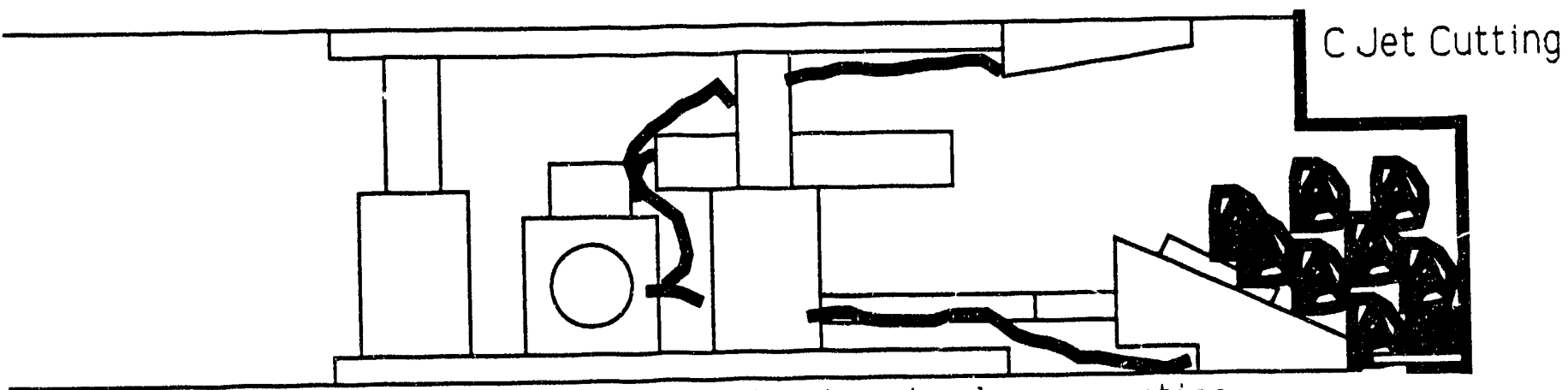

Stage 3-Lower wedge activates to mine lower section

A Jet Cutting

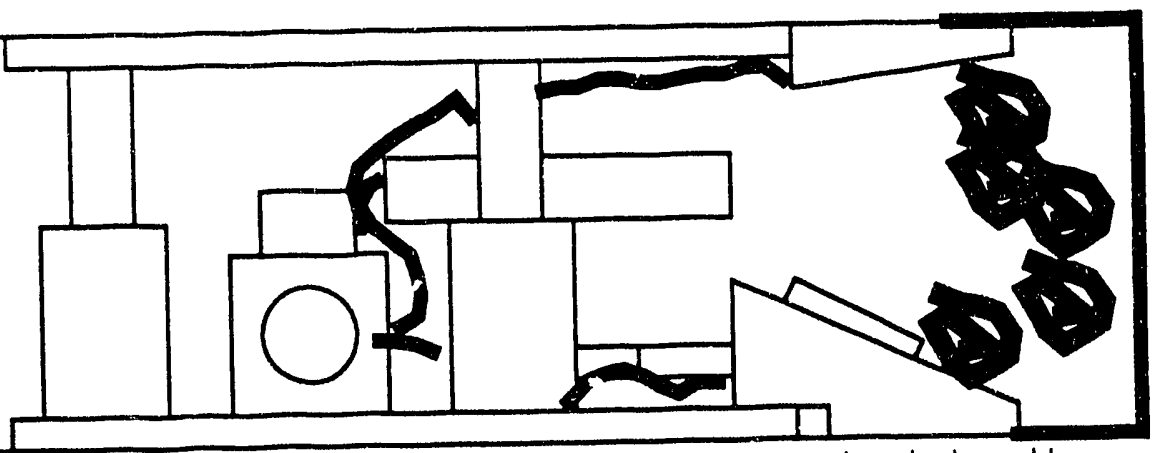

Stage 4 - Upper wedge activates and chock moves forward mining the rest of the coai in the block.

Figure 3. Schematic representation of operation of RAPIERS. 
In order to provide a strong base against which the wedges can be thrust forward, it is necessary to create a strong, yet moveable support. This is achieved by extending two pistons, from cylinders located on either side of the apron. These pistons brace between the roof and floor of the mine, through steel plates. Similar devices are commonly used in mining to provide temporary roof support along the mining face in the method known as longwall mining, and are referred to as chocks or shields.

The large force required to hold the roof up also provides a ccnsiderable frictional force, which is sufficient to hold the main body of the machine in place, while the wedges are advancing forward. Once the machine has extracted both the upper and lower sections of the coal seam, then the piston on one of the shields is lowered, and it is advanced, by reversing the push ram used earlier to advance the lower wedge and loading apron. After this shield is fully forward, then it will be raised into position, so as to provide a brace for the apron, while the second shield is lowered and advanced. When the complete machine has been moved forward then roof bolts will be installed by a machine operating behind the coal excavator. These hold the tunnel open during the remainder of the mining process.

The relatively small size of the machine, and the immediate support that is provided to the machine operator by the hydraulic cylinders make it easier to use a roofbolter behind the machine. At the same time the machine operator is always working under a supported roof, as provided by the hydraulic cylinders on the machine.

\section{Jet Cutting Parameters}

Coal is a rare rock in that it contains a large number of flaws which normally lie in perpendicular planes. The horizontal planes are usually referred to as the bedding planes of the seam, while the vertical planes are known as the cleat of the coal. These weakness planes provide an ideal avenue for waterjets to exploit the coal and excavate it.

The simple way to describe the cutting of coal by a high pressure waterjet is to examine the sequence of events as a jet impacts the surface. In the initial instants of impact the first water to arrive on the surface will penetrate into the surface cracks, filling them with fluid. The next segment of the water jet to arrive will then pressurize these fluid wedges in the coal, causing them to extend the cracks to the point that they coalesce, removing material from the solid. For the greatest effect this requires that there 
is a pressure differential between adjacent cracks, so that the block of coal which is surrounded by fluid has a relative force on it, making it move out of the solid.

The method of coal removal requires that the most effective use be made of he flaws already in the coal. This is the same principal of material removal which is effective in cutting may rocks. Early experiments in the waterjet removal or rock were directed at finding the best way of using the jet horsepower to remove the greatest volume of rock, as fast as possible.

Jet horsepower is derived from two main sources, the volume flow of the water, and the pressure at which it is driven. Experiments have shown that the greater the pressure that the water is driven at, so the deeper the slot that is cut. However, the most effective use of a waterjet in cutting coal for this application is not restricted to the depth of the slot achieved. Nor is higher pressure alone a necessarily advantageous option.

As waterjet pressures increase, so the size of the equipment required to generate and deliver the water must increase. This is needed to safeiy contain the pressure and it makes the resulting machine heavier, more cumbersome, and more expensive. Greater demands on better water quality become necessary, and, for equivalent horsepower, the volume of water available is reduced. This had several disadvantages. These come about because, as the water pressure increases, so the velocity of the water coming from the nozzle also goes up. This means that, with the reduced volume of water travelling faster, the cross-sectional area of the jet must be reduced even further.

The faster the jet travels as it moves through the air from the nozzle to the coal face, then the greater the difference in speed between it and the air. This increases the rate at which the outer edges of the jet are disrupted. If at the same time the jet diameter is smaller, then the amount of jet available becomes less. The result is that the distance over which the jet is able to cut into the coal becomes shorter.

The second problem relates to the width of the slot which the jet will cut. The narrower the jet is, then the smaller the width of cut that will be made. As a simple approximation the jet will cut a slot about twice the width of the impacting jet. While this is not a great problem in surface cutting or in applications where the jets cut materials in factories, it is very significant in underground applications. This is because all rock underground is under pressure. Most of this pressure comes from the weight of the rock lying on top of the tunnel. Pressure can also be present as a result of nearly 
other tunnels, and geological movements which might have ocurred since the rock was deposited. These pressures can be quite high, and result in the rock becoming compressed by the load. When a waterjet or other mining machine now cuts this rock the first result is that the load on that coal is removed. This is a useful ability of the RAPIERS since it makes the coal easier to break out and load if is is under no pressure from the surrounding rock. However, when the slot is made, the removal of pressure from the coal above and below the slot allows them to expand. If the slot cut by the waterjet is very narrow, then the expansion may be sufficient that the slot is completely closed. In which case pressure will again build up in the coal and it will become as hard to break out and load as before.

The third problem is along the same lines as the first two, and relates to the mechanism of coal removal. The jet penetrates by getting into the flaws in the coal surface. The higher the pressure and the smaller the diameter of the jet, then the smaller the number of flaws that will be found under the jet impact area at one time. Thus the cutting operation will be less efficient.

These considerations had been evaluated in the development of the original longwall waterjet mining machine (the HYDROMINER). Experiments with the development of that machine showed that while cutting depth was increased, as jet pressure was increased (Figure 4) the specific energy of cutting did not improve. This is the amount of energy required to remove a unit volume of coal from the surface.

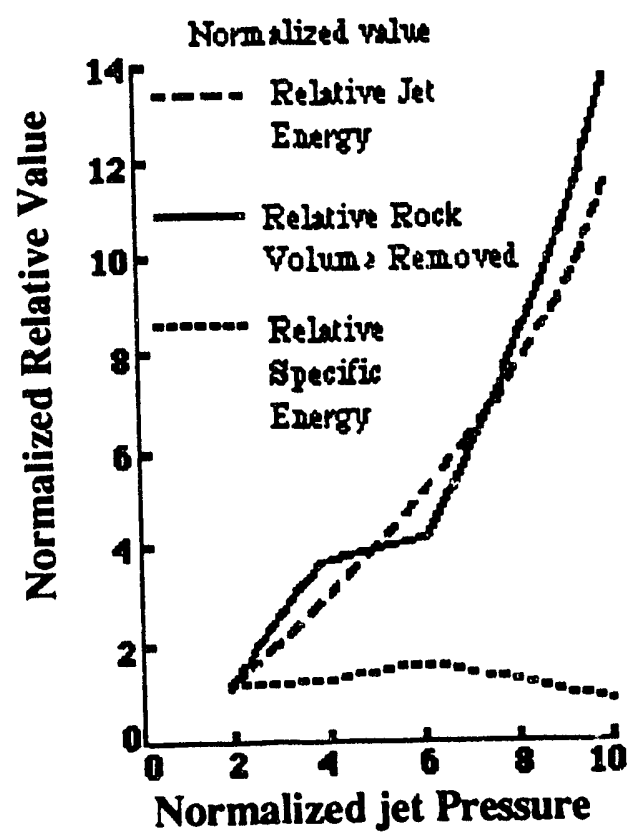

Figure 4. Reiationship between volume and energy of removal and jet pressure (after Reference 3). 
If however, additional horsepower was given to the water by increasing the flow volume, or the jet diameter, then (Figure 5), not only did the depth of the slot cut increase, but the volume of material increased faster, so that the specific energy of cutting dropped significantly.

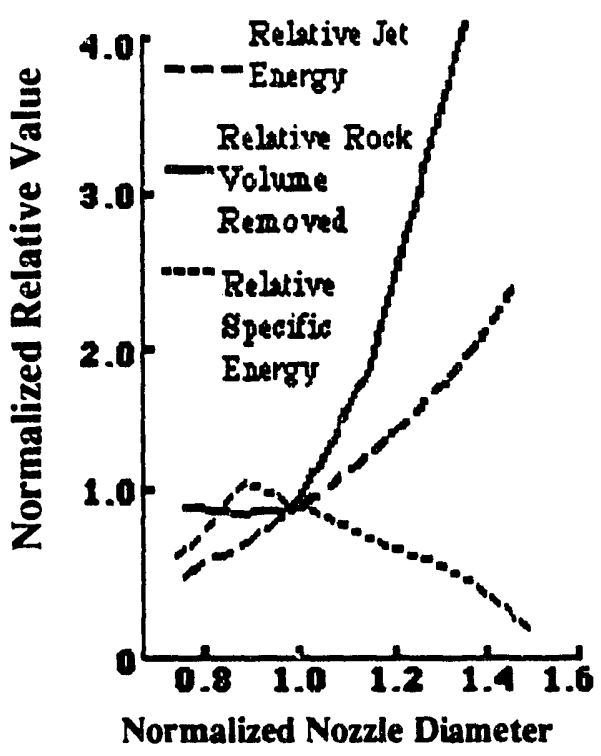

Figure 5. Relationship between volume and energy of removal and jei diameter (after Reference 3).

Those experiments concluded, and subsequent machine testing verified, that the most effective cutting conditions ocurred where the jets were at higher volume but lower pressure. Within that constraint there are additional bounds. The coal found underground is often surrounded by softer shales. These often provided the soil of the primeval forest from which the coal was formed. Subsequent pressure has turned this material into a shale. It is, however, very sensitive to the presence of a lot of water. A mining machine therefore cannot use vast quantities of water without the floor being destroyed, making mining more difficult, and reducing the stability of the excavation.

In order to reach a compromise on the quantities of water to be used, the Hydrominer standardized on the approximately $50 \mathrm{gpm}$ of water used on most conventional mining machines as a means of suppressing the respirable dust generated by the typical conventional continuous miner. However, the Hydrominer was used in a longwall mining operation. In such an operation almost immediately after the coal is taken out the roof is allowed to collapse into the empty space. In conventional room and pillar mining, where RAPIERS will be used, this is not so. The tunnels made by the machine will continue to be used to carry coal away as the tunnel grows longer. Men, materials and machines may use any one tunnel for several weeks, and thus floor and stability con- 
cerns are much more important. For this reason it is prudent to consider using a smaller volume flow than that used with the Hydrominer.

The machine design for the Hydrominer used four sets of dual-orifice nozzles at one time to cut out the coal ahead of the machine. That machine continuously moved. The RAPIERS instead is a machine with sequential operation. Instead of four nozzles therefore, the machine can be operated satisfactorily with only two in operation at one time. This reduces the water quantity required to approximately $22 \mathrm{gpm}$. When this is integrated with the performance data evaluated from Hydrominer, a jet pressure of 10,000 psi has been found to be satisfactory at this flow rate.

The choice of 10,000 psi is dictated by considerations which go beyond just the ability to cut the coal. As mentioned in the earlier discussion on the need and costs of cleaning coal, there is a considerable amount of dirt and other impurities in natural coal. This often takes the form of layers of other rock in the coal seam 1.. These are usually harder than the coal, and the jets must be able to cut througin them if the machine is to be a success. Tests in a surface mine of the Hydrominer prototype indicated that a 10,000 psi jet system would be able to do this at an effective rate for most of the rocks found in the coal.

A dual orifice design (Figure 6) was chosen in order to ensure that the slots cut would be wide enough to totally relieve the surrounding pressure and to leave a large enough gap for the cutting heads to enter the slot. This is important since the performance requirements for RAPIERS need a deep slot, projected as being about 18 inches deep.

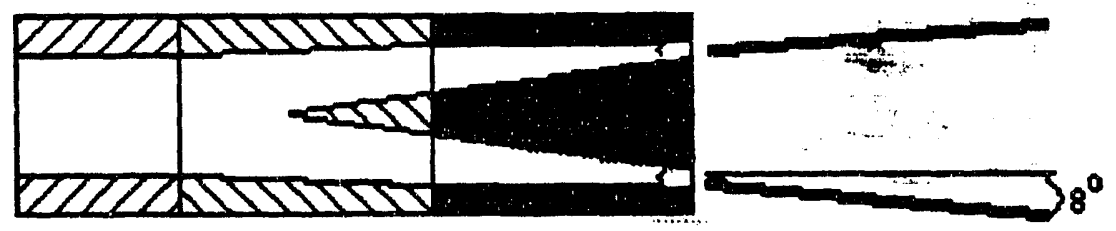

Figure 6. Dual Orifice design (after Reference 4).

A single waterjet will not be able to cut this deep on a single pass, but the depth can be achieved using multiple passes of a dual orifice combination. The design chosen takes advantage of the structure of the coal. Because of the many bedding and cleat planes in coal it has relatively little strength in tension. Thus two jets, inclined slightly outwards, and traversed vertically, cut not only the coal immediately under the jets, but also will penetrate along the weakness planes in the intervening material and break it from the solid. On the next pass of the nozzle the jets will now not encounter coal 
until they reach the back of the previous slot, as shown in Figure 7, and the process is repeated.

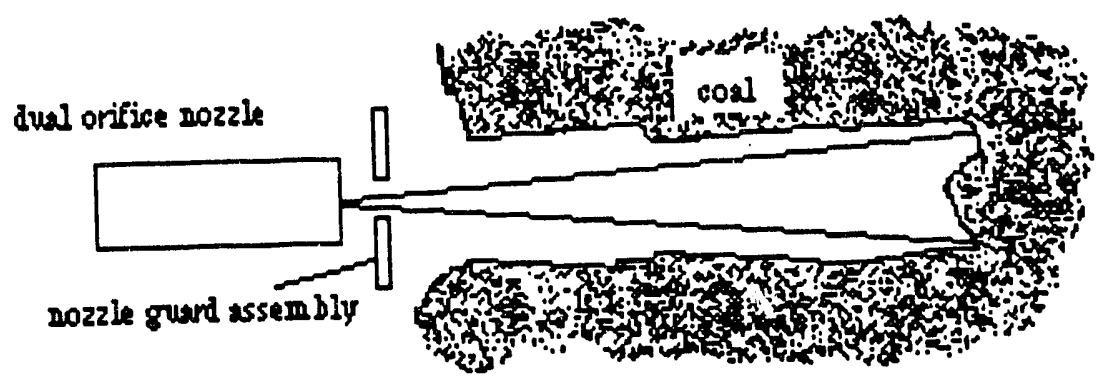

Figure 7. Jet passage through a slot cut by a dual orifice, showing the lack of wall contact.

This has the additional advantage over a single nozzle design that the jet effectiveness is not reduced by contact with the sides of the previously cut slot, until the jet hits the back of the previous cut. In this way it became relatively simple to cut a slot roughly two inches wide over the required depth of cut ahead of the machine. The result enables the cutting nozzle to establish a deep slot ahead of the machine, and in this way to break the cantilever carrying the surrounding ground stress. This moves the stress away from the coal to be excavated, making it easier to cut and to break out from the solid. Further,by minimizing the number of cuts which need to be made in the face, the majority of the coal will be removed in large blocks of coal with relatively little force being required.

The cutting action of these jets is sufficiently powerful that the slot can easily be established, however, the amount of force required on the machine to hold the cutting nozzles is still quite small. In contrast to the thousands of pounds required to hold a continuous miner head in position, not only to counter the thrust required but also to support its weight. The cutting forces from a dual orifice nozzle flowing $10 \mathrm{gpm}$ at 10,000 psi can be approximated by the equation:

$$
\text { Force }=0.052 . \text { Flow }(\mathrm{gpm}) \sqrt{\text { Pressure (psi) }}
$$

This gives a force of approximately $52 \mathrm{lb}$. The nozzle assembly on the lance weighs less than $10 \mathrm{lb}$. In consequence a much smaller, and thus lighter, more maneuverable and less expensive system can be developed. 
With these parameters as the preliminary basis for the de:iign of the machine, and working with equipment donated by two manufacturers of mining machines, it was now possible to design and assemble a first prototype of the equipment. 


\section{CHAPTER II. EQUIPMENT CONSTRUCTION}

\section{Introduction}

The University of Missouri-R.olla was fortunate, at the beginning of this contract, to be receive donations of two used pieces of equipment from their manufacturers which could then be used as the basic components for RAPIERS. The first of these was the gathering arm loader from a Joy Cuntinuous Miner. This comprised the front apron together with the gathering arms and the drive and channel for a central 30 " wide scraper conveyor used to carry the coal away from the cutting drum (Figure 8).

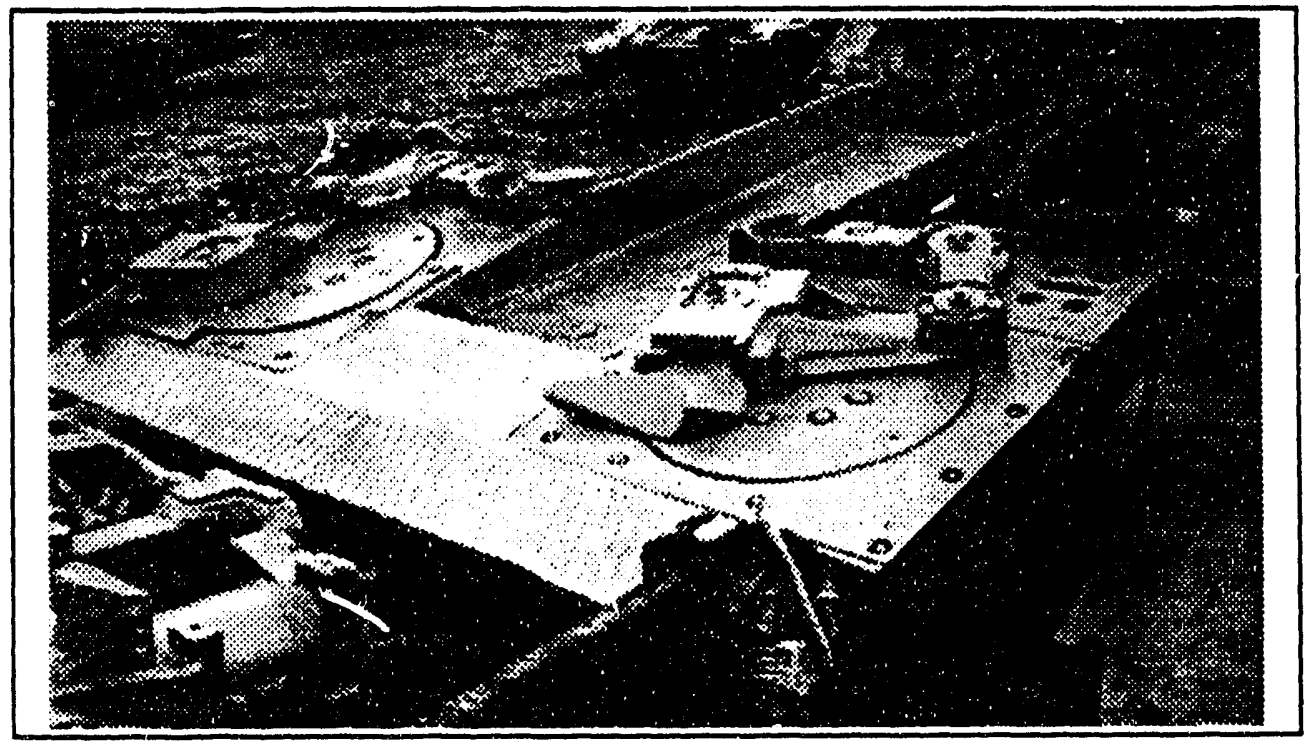

Figure 8. The Gathering Arm and Apron of a continuous Miner

The second component which was donated was a longwall hydraulic roof support or shield (Figure 9). This comprised two large hydraulic cylinders connected together and fitted with a hydraulic pushing ram. The hydraulic cylinders push between floor and roof plates to support the overlying roof, while underneath it. At the same time large steel plates mounted at the back of the frame prevented rock from entering behind the machine.

The initial design for the RAPIERS system had conceived that two roof supports would be used, one on each side of the gathering arms. However, the machine is designed to cut only to the width of the loading apron-which, in this case, restricted the operational width to 110 inches. The use of a shield on each side of the conveyor would place the outer half of each shield out considerably beyond this width. A decision was therefore made to modify the equipment design. Fortunately, the shield obtained was largely symmetric. Thus, it would be possible to cut a single shield in half and mount one half on either side of the loading conveyor. This would allow the machine to fit within the required width. 


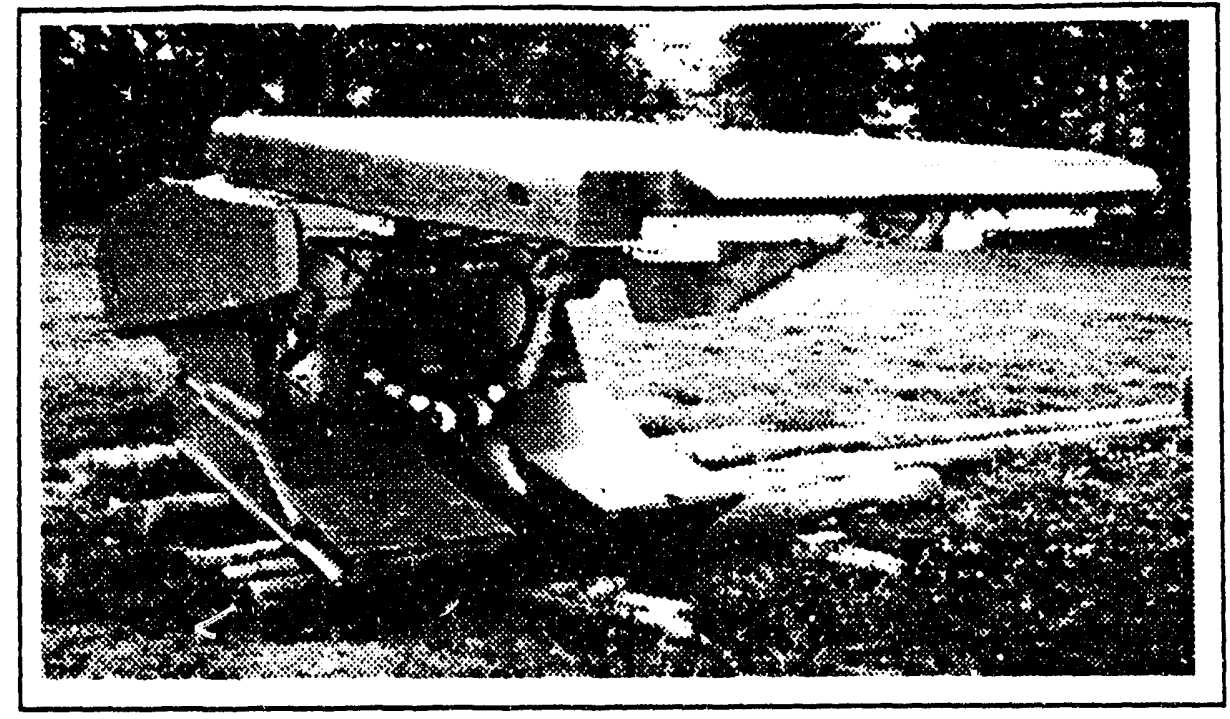

Figure 9. Original Shield Support System

In the description of the assembly of the unit which follows, particular problems encountered in each stage of the operation will be described, together with their solution. Although this solution is simply described, it should be recognized that these were often the result of false starts and other proposed solutions which were found to be less effective in the final analysis.

\section{Gathering Arm Loader Apron}

The method of collecting coal produced by a conventional continuous miner is relatively simple and with little modification can be adopted for the RAPIERS System. In essence the mechanism, commonly known as a gathering arm loader, is made up of a loading ramp or apron, which is simply a sloped metal surface. On this surface, two hinged arms are constrained to sweep out a path which pushed the coal intercepted towards the center of the ramp. As the coal enters and moves up this central section of the ramp it falls onto a contained scraper conveyor section. The conveyor carries the coal out of the working area.

The gathering arm apron thus already has the wedge shape required for RAPIERS in order to break out the lower section of the coal seam after the initial slotting of the face has occurred. The loading wedge will be thrust forward during this part of the mining cycle so that its leading edge enters the slot cut in the bottom of the coal seam (Figure 3). The wedge will be pushed forward with sufficient force that the leading edge will elevate and break the overlying segment of coal into fragments which the gathering arms can then load out. During the development of the earlier Hydrominer, discussions were carried out with coal plow manufacturers in Germany (Reference 5). 
A major aspect of those discussions was to determine, based on their extensive experience, the angle of the wedge which would give best loading conditions. The information obtained at that time, suggested that, at the speeds to be used with RAPIERS, the wedge angle required to break and elevate the coal was not a critical value. In other words provided that extreme values were not selected, variations in the angle between 30 and 60 degrees would have little effect on machine performance. This was an important preliminary finding and was an encouraging development. Because of the lack of importance of this angle, it could be increased at little cost. This would allow the existing apron to be simply modified to accept the waterjet cutting equipment required to cut the underlying slot of the coal seam.

Rather than modify the internal construction of the gathering arms, a separate wedge shaped framework 3" high on its leading edge, 10" high at its backward edge, and 4' 5 " deep was constructed (Figure 10). This ran the full width of the loading apron. Once the cutting arm mechanism had been assembled and mounted in this frame, the loading apron could then be mounted on top and would thus provide the top housing for the slotting arm drive. The whole piece was bolted to the bottom of the gathering arm apron, so that it could be easily disassembled easily when necessary for repair.

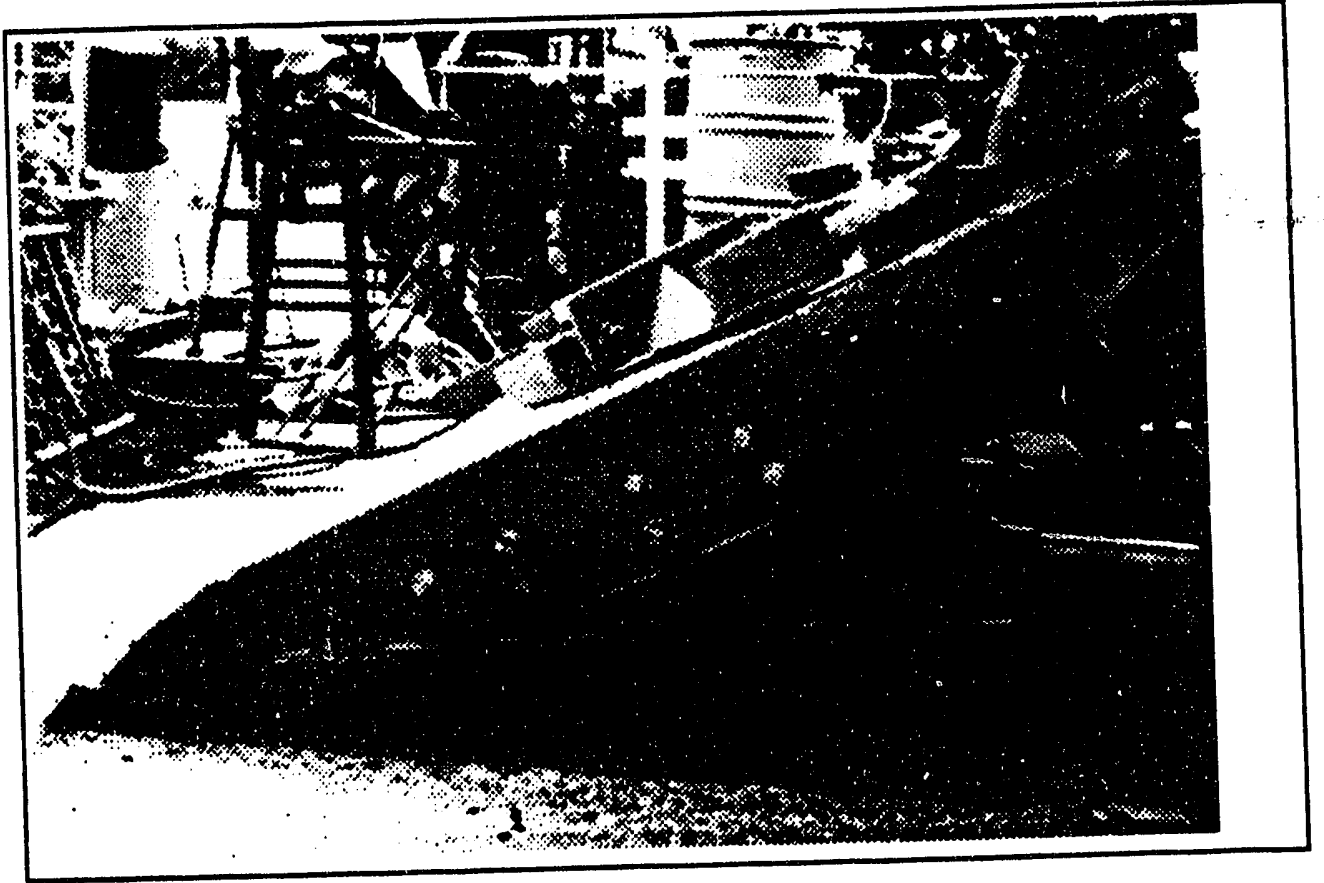

Figure 10. Separate wedge shaped framework constructed to hold the lower cutting arm mechanism.

A hydraulic drive was chosen to move the cutting arm over the required slot width. This has the inherent advantage of being a relatively safe system for use in the possible dangerous environments at the working face of the coal mine. The bi-directional hydraulic motor drove a screw thread, in turm moving a platform to which the jet 
cutting lances were mounted (Figure 11). Guidance for the nozzles is provided by a steel guide pipe.

HIGA PRESSURE WATER

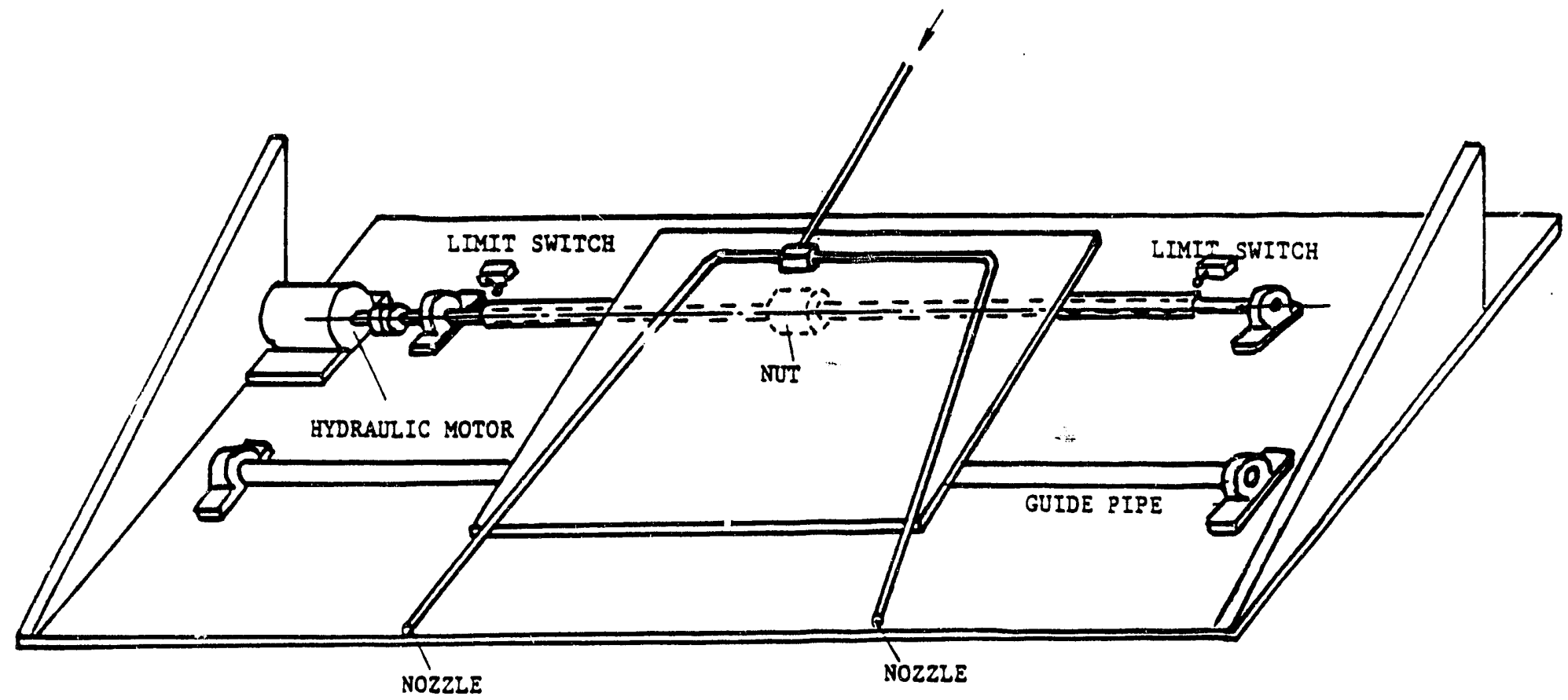

Figure 11. Schematic Representation of lower arm drive mechanism

The maximum traverse speed of the nozzles was set at 8 inches/second. This provided a sweep speed of 7 seconds a pass, or a maximum cscillation speed of 8.5 passes a minute. At a slot cutting speed of more than 2 inshes/poss, as determined by field experience during the first trials of the Hydrofitiner, this would give an advance speed of 17 inches/minute. For an 18 inch step for each advance, this would give a time of roughly one minute for the lower wedge to advance. For a 36 inch "bite" the advance time would be some 2 minutes. It should be noted that this does not consider the beneficial action of having the wedge head applying tensile pressure to the root of the slot being extended by waterjet action. In trials of the Hydrominer the slot at the bottom of the coal could be kept effectively open ahead of the machine while it was advancing at $10 \mathrm{ft} /$ minute. A similar machine in Germany achieved an advance rate of $60 \mathrm{ft} /$ minute (Reference 6). The potential performance of this machine is thus already practically demonstrated to be significantly above that which is being predicted in this report.

It was decided to use two lances mounted on either side of the machine centerline to cut the underlying coal slot. This decision was based on the amount of time that 
would be required to cut the slot in contrast with the desire for a machine which would be at least as competitive in production rate as existing equipment.

After considerable debate, it was decided to use dual orifice nozzles which would not rotate to produce the waterjets coming from the waterjet lances. These were chosen over self rotating nozzle assemblies because of the smaller space which they would require allowing them to fit close to the leading edge of the cutting slot. The nozzle design also gained from the previous work with Hydrominer. That experience had shown that the egress slot allowing the jets to flow out of the apron onto the coal also provided access for coal particles. By reducing the slot width to about $1 / 4 \mathrm{inch}$, and putting the two diverging jets adjacent rather than vertically above one another so that they could use the narrow slot this was avoided.

The method of drive for these lances is different from that which was used in the Hydrominer. In that earlier machine, the lances were oscillated over an arc by a hydraulic motor through a camshaft design. However, the arms had only to swing over a range of approximately 2 feet. Thus, the standoff distance of the arm from the coal did not increase significantly from the center to the extremities of the stroke. In the case of the RAPIERS machine each lance must sweep out a length of approximately 55". Were this to be done by oscillation, the standoff distance of the nozzles from the coal face at the extremities of the sweep, relative to that in the center, would have a significant effect on jet cutting performance. For this reason the slightly more complicated screw feed mechanism was adopted because it would provide a linear drive moving the nozzle pair along the inner face of the apron.

In order to simplify operation, electric limit switches at the ends of the lance path were used to reverse the motion (Figure 12). These switches feed into a directional flow contro: valve within the servo controlled hydraulic drive to the slotting motor.

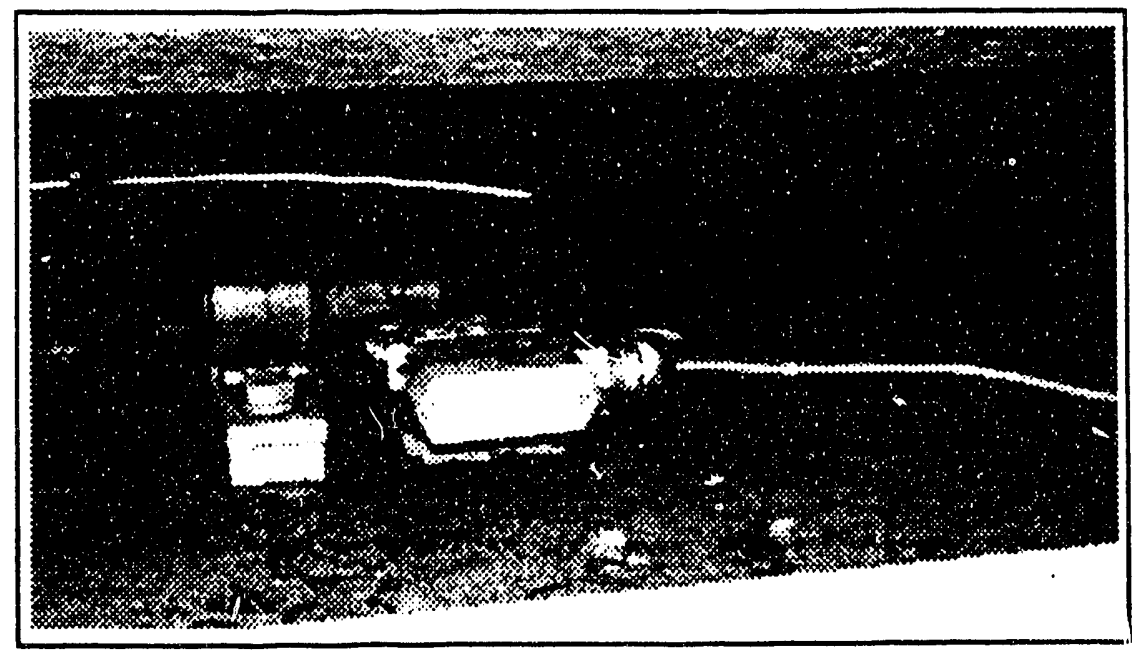

Figure 12. Location of electrical limit switch on lower arm traverse.

Page 18 
The high pressure lances were built from sections of high pressure stainless steel tubing and were manifolded together at the back of the traverse platform to simplify the supply of high pressure water to the system through a single line from the high pressure pump (Figure 13).

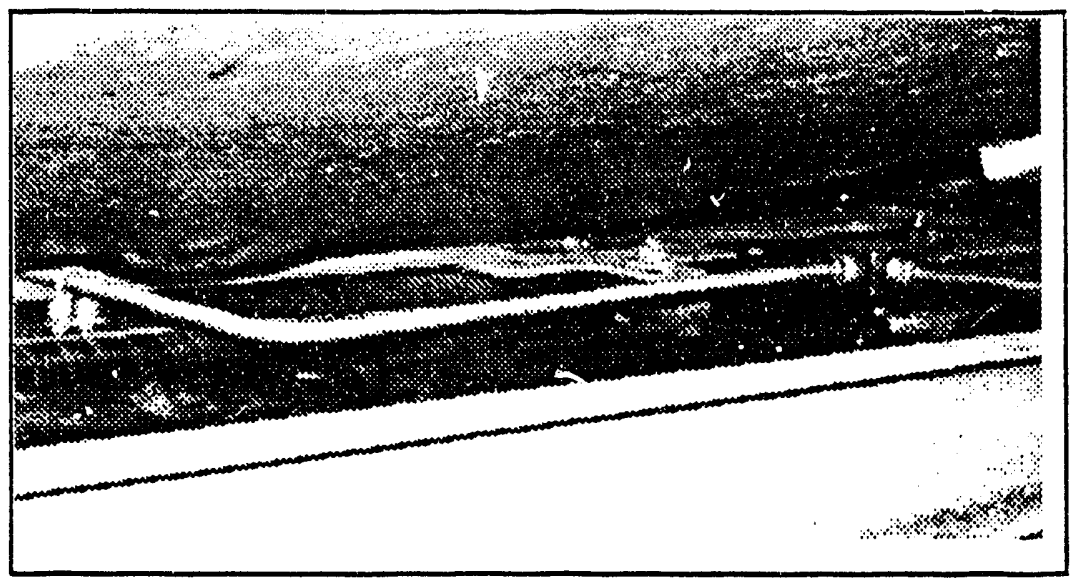

Figure 13. Feed lines to the two lower cutting nozzles

When the apron had been acquired, no thought had been given to the power and primie mover that would be required for the operation of the gathering arms. In the machine for which this component was designed, this power comes through a drive linkage from the main machine motors. In this instance, all those motors which lie in the center of the continuous miner were not available. To replace them and to provide power for the gathering arms, a $15 \mathrm{hp}$ electric motor and a replacement gearbox were mounted on a bearing plate and oriented to drive the transmission rods operating the gathering arms (Figures 14 \& 15).

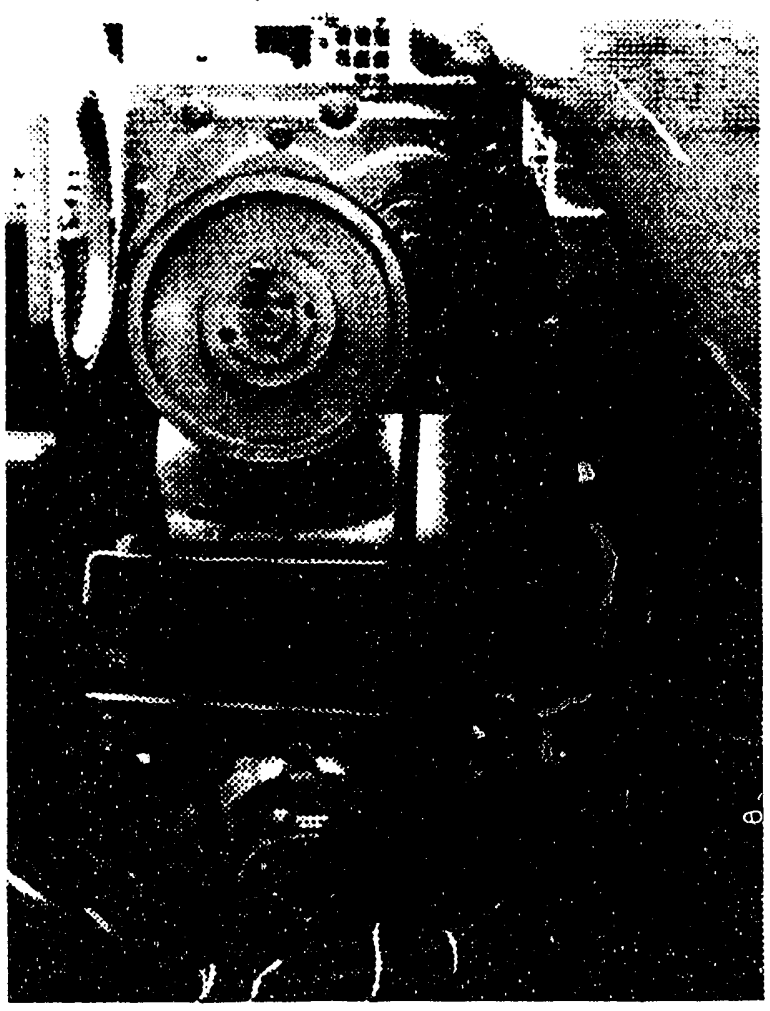


It was found necessary to completely rebuild this assembly in order to make it work effectively in this new configuration. The gearing was chosen to rotate the gathering arms at a speed of $12 \mathrm{rpm}$. The operation of this system required a considerable effort in cleaning and replacing worn and failed components in order to bring the equipment into working order.

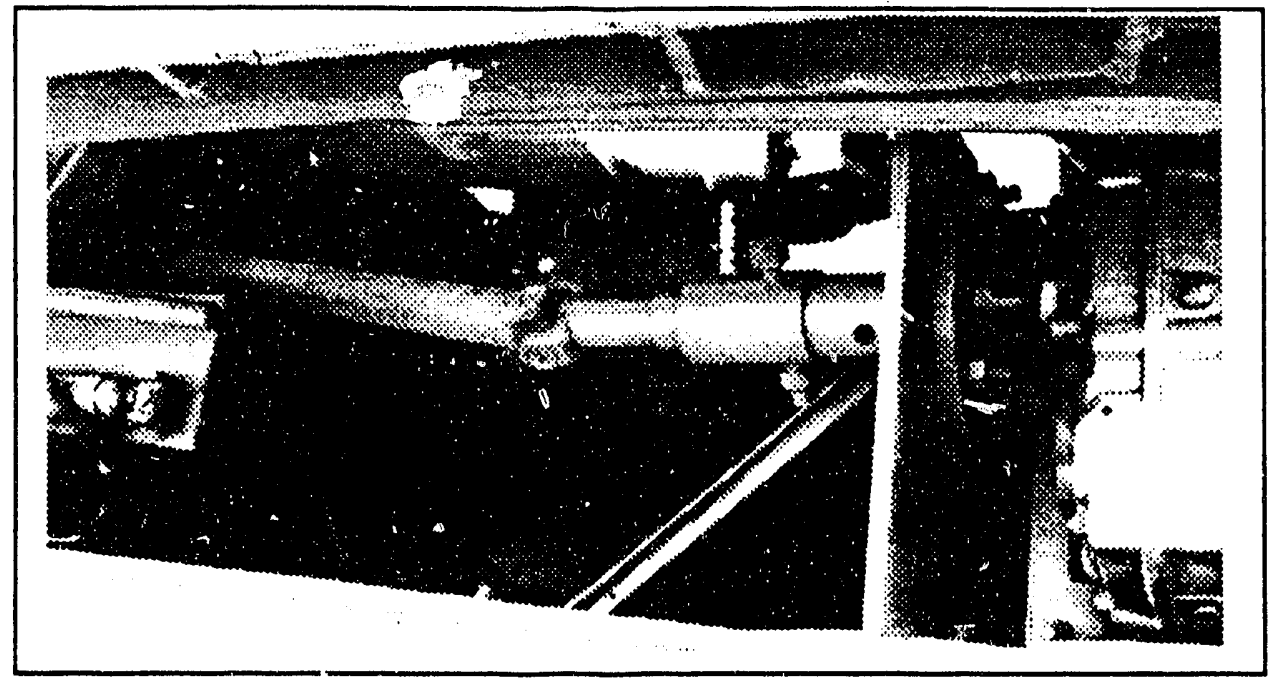

\section{Shield Support}

Figure 15. Replacement gearbox and Drive to Gathering Arms

The roof support obtained had been initially constructed as a single unit. However, in its assembly almost all the components were duplicated on each side of the central axis of the support. The major exception to this was the main bearing plate which would be pressed up against the roof of the mine in order to hold it in place. This component was therefore removed from the frame and the remaining components separated into two halves. The roof beam was then cut in half using a low pressure $(5,000 \mathrm{psi})$ high volume flow rate $(22 \mathrm{gpm})$ abrasive lacien waterjet using garnet as the abrasive (Figure 16). The system gave an acceptable cut through the steel with the exception of 4 rib locations which were subsequently cut with a flame torch. This was only done because of some difficulty in orienting the cutting nozzle to access the remaining metal.

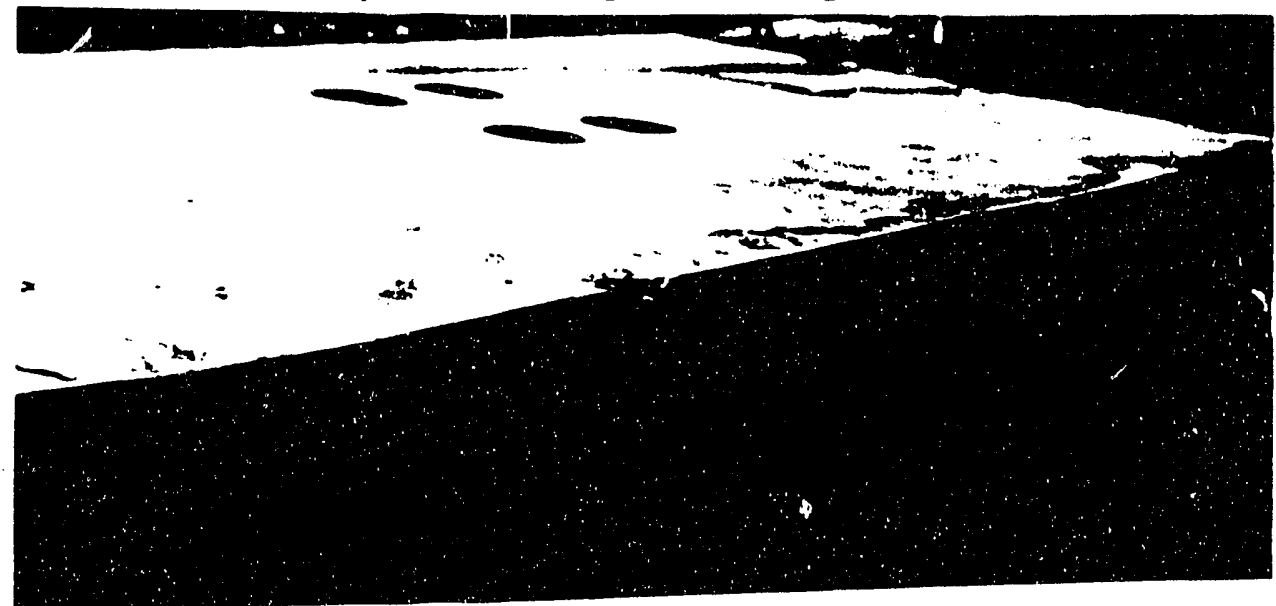

Page 20 Figure 16. Edge Cut along the Shield Roof with a DIAjet System. 
Each roof section was then remounted on the appropriate chock half which was in turn placed on either side of the gathering apron (Figures $17 \& 18$ ). In order to connect the chock to the apron, a double acting hydraulic cylinder was attached to the base plate of each chock half (Figure 19). The piston ram from the cylinder was connected through a hinge point mounted on the back of the apron. In this way, either the apron could be pushed forward under the thrust from both rams on the roof supports or alternately, one of the supports could be lowered from the roof and pulled forward to the apron position in sequence.

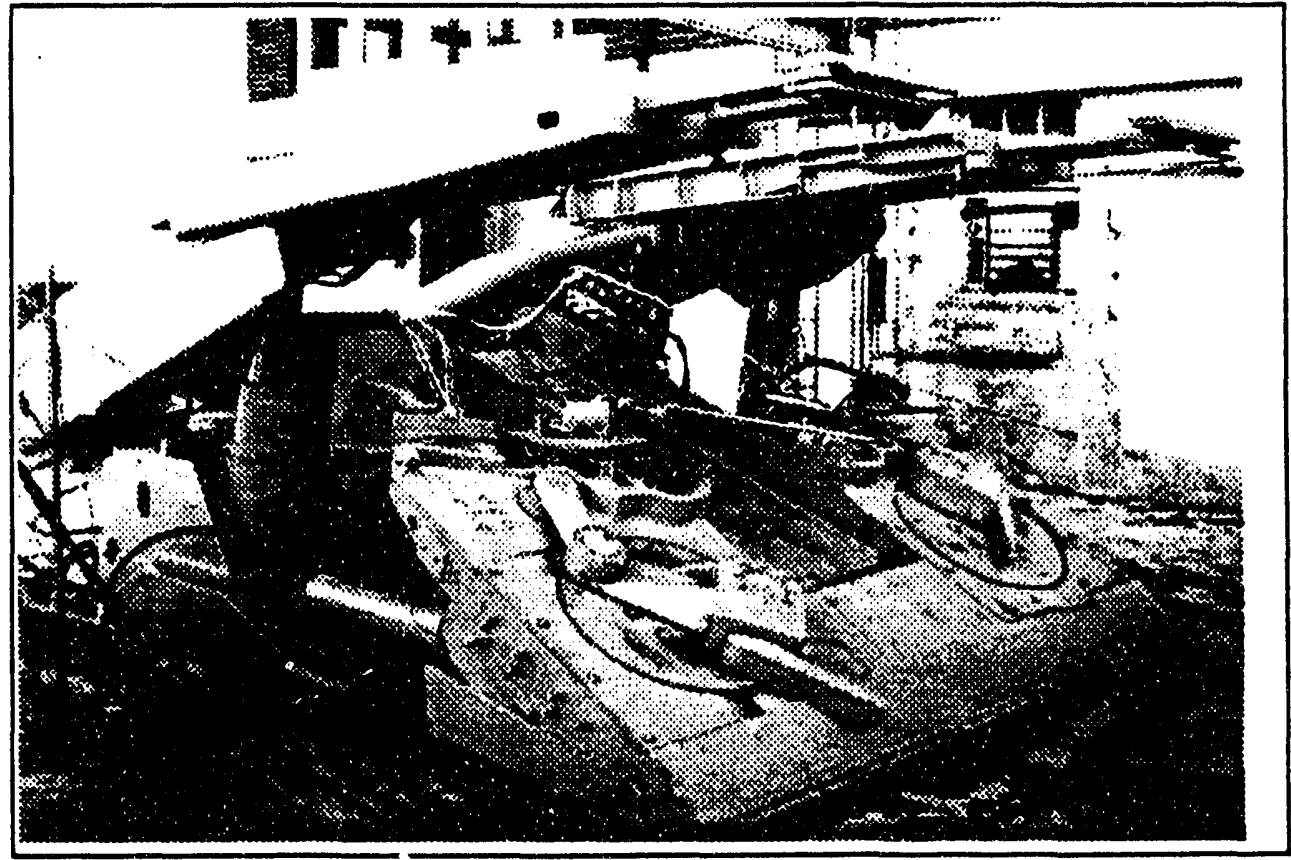

Figure 17.Side View of the RAPIERS machine

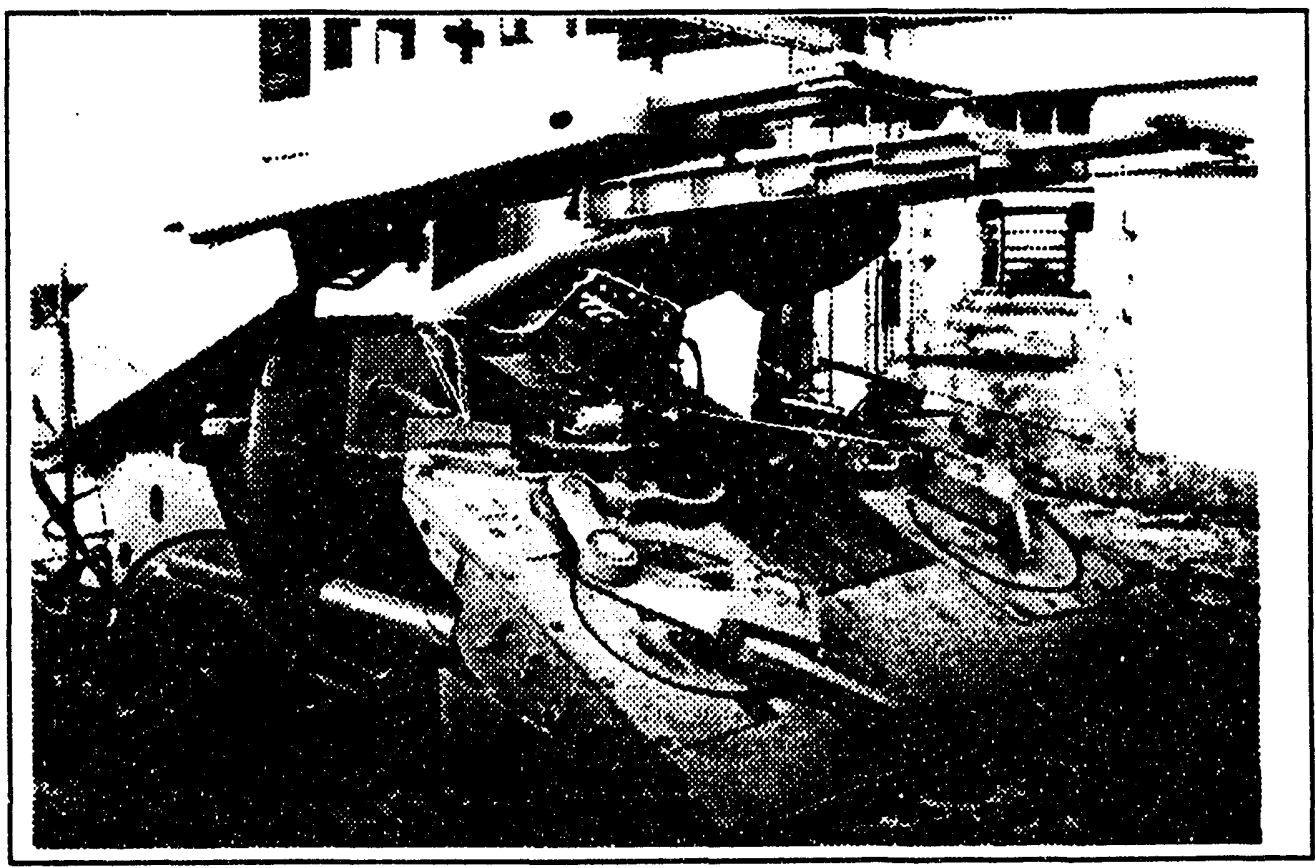

Figure 18. Front View of the RAPIERS machine. 


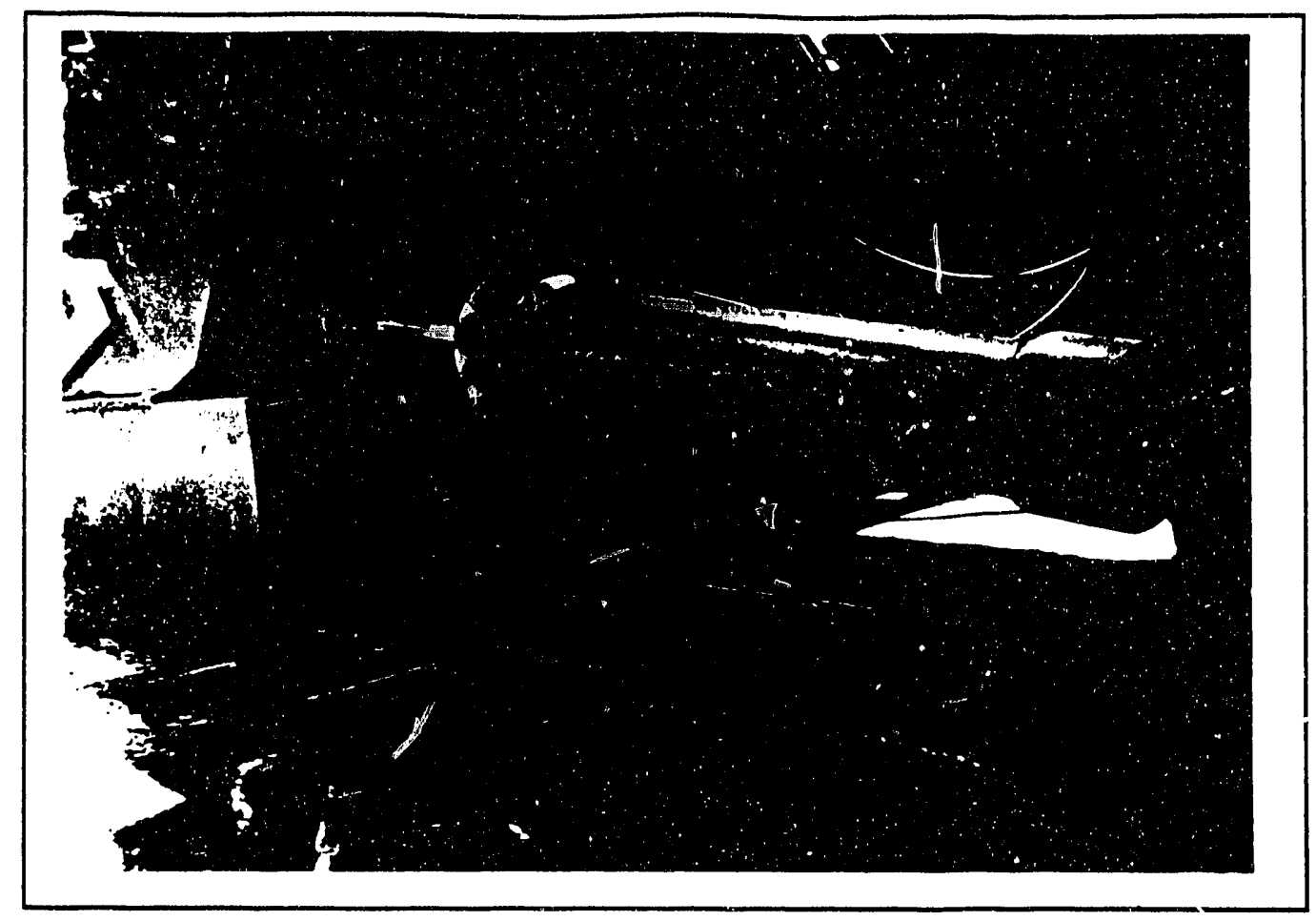

Figure 19. Hydraulic Ram for Apron and Shield Movement

Hydraulic controls to operate the 4 cylinders (the two pushing cylinders and the two roof support cylinders) were through servo control valves mounted on the machine (Figures $20 \& 21$ ) and were themselves controlled by the software in the MACSYM computer (Appendix I).

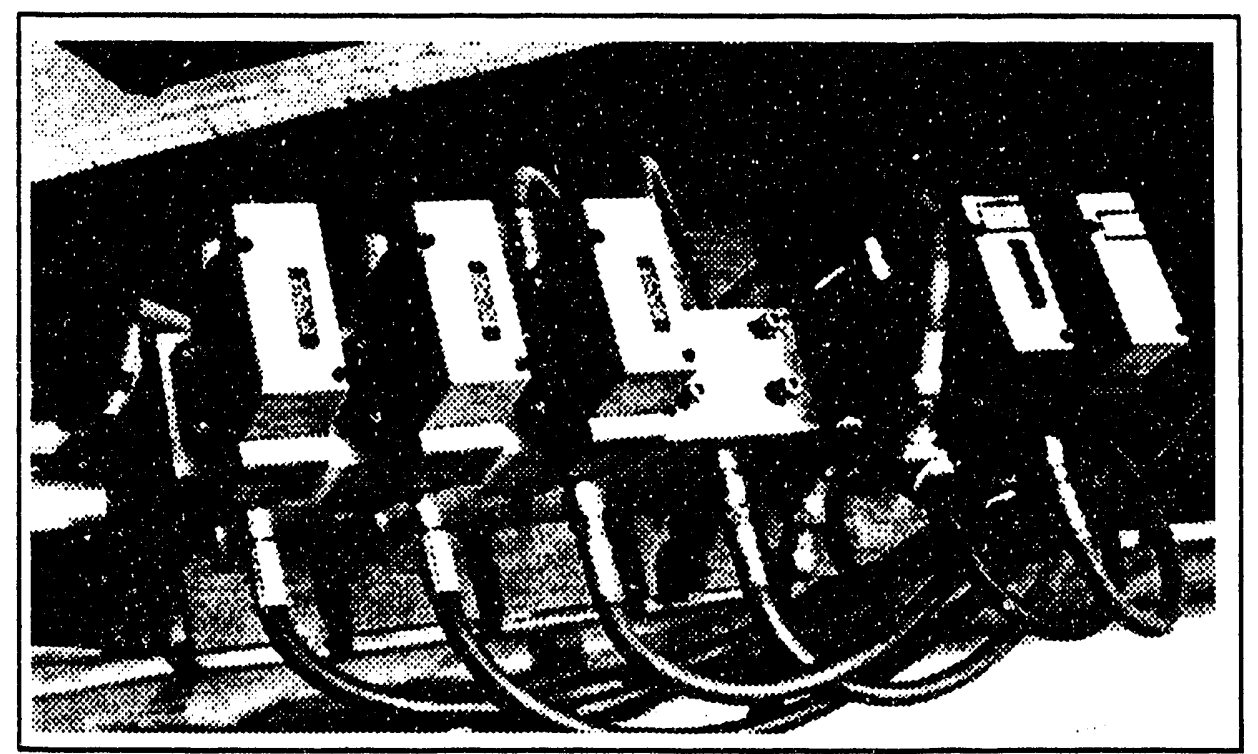

Figure 20 Initial Assembly of the bank of Servo Control Valves used to control RAPIERS 


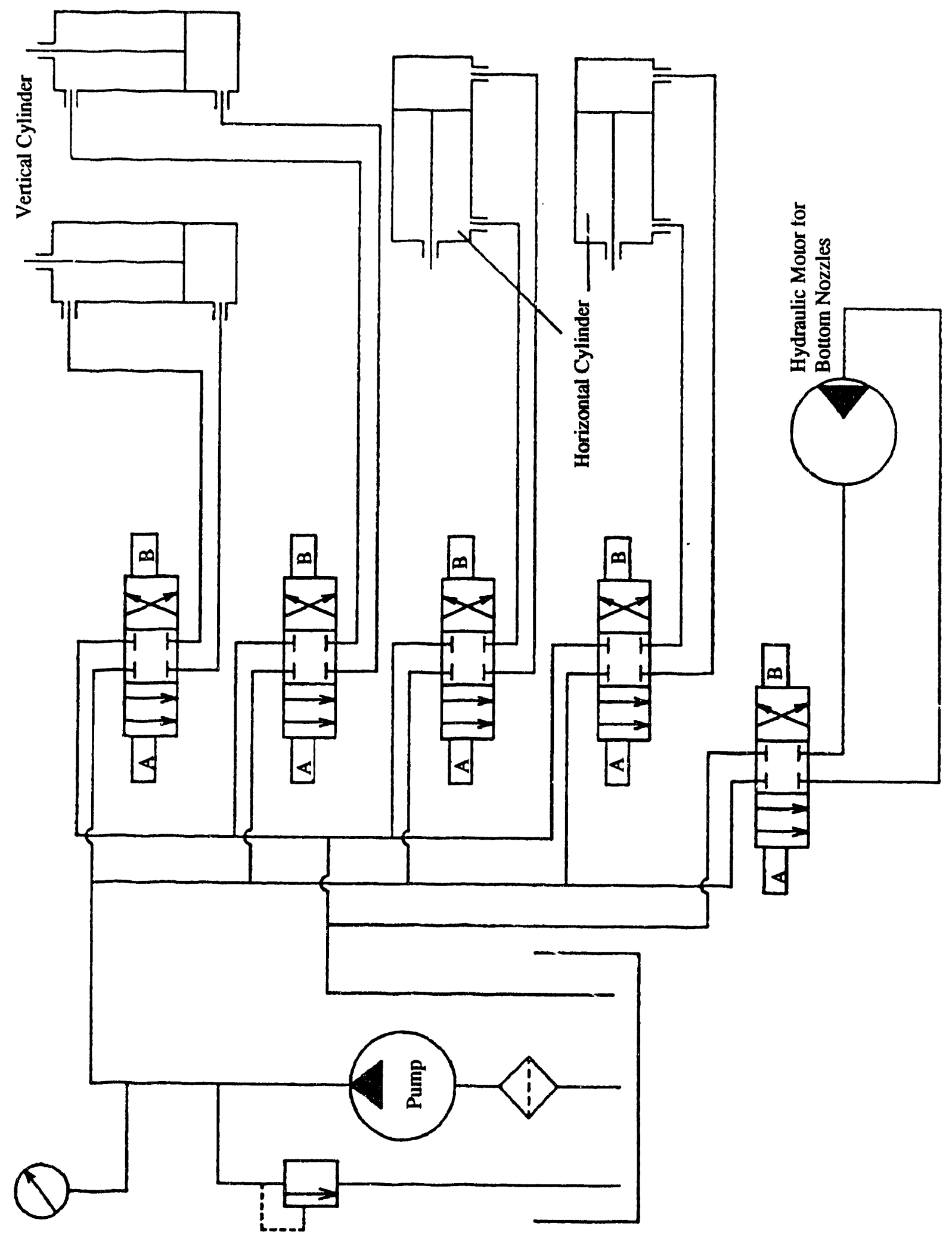

Figure 21.Schematic of the Hydraulic Control Circuitry 


\section{Computer Operated Slot Cutting Arm}

The first cut in the coal face is made to provide stress relief to the coal ahead of the machine (Figure 3). At the same time, the slot must be wide enough to allow the coal which will then be wedged out a free space into which to move during the fragmentation process. For these purposes, the original machine was conceived so that a waterjet would move to cut a slot approximately 18 " deep ahead of the machine in the form of an "H" (Figure 22). Such a shape would provide a central horizontal cut which would give a free surface for the lower wedge which it defined to move into. The two vertical cuts would be at the edge of the opening and would free the coal in the RAPIERS path from the surrounding solid making it easier to extract.

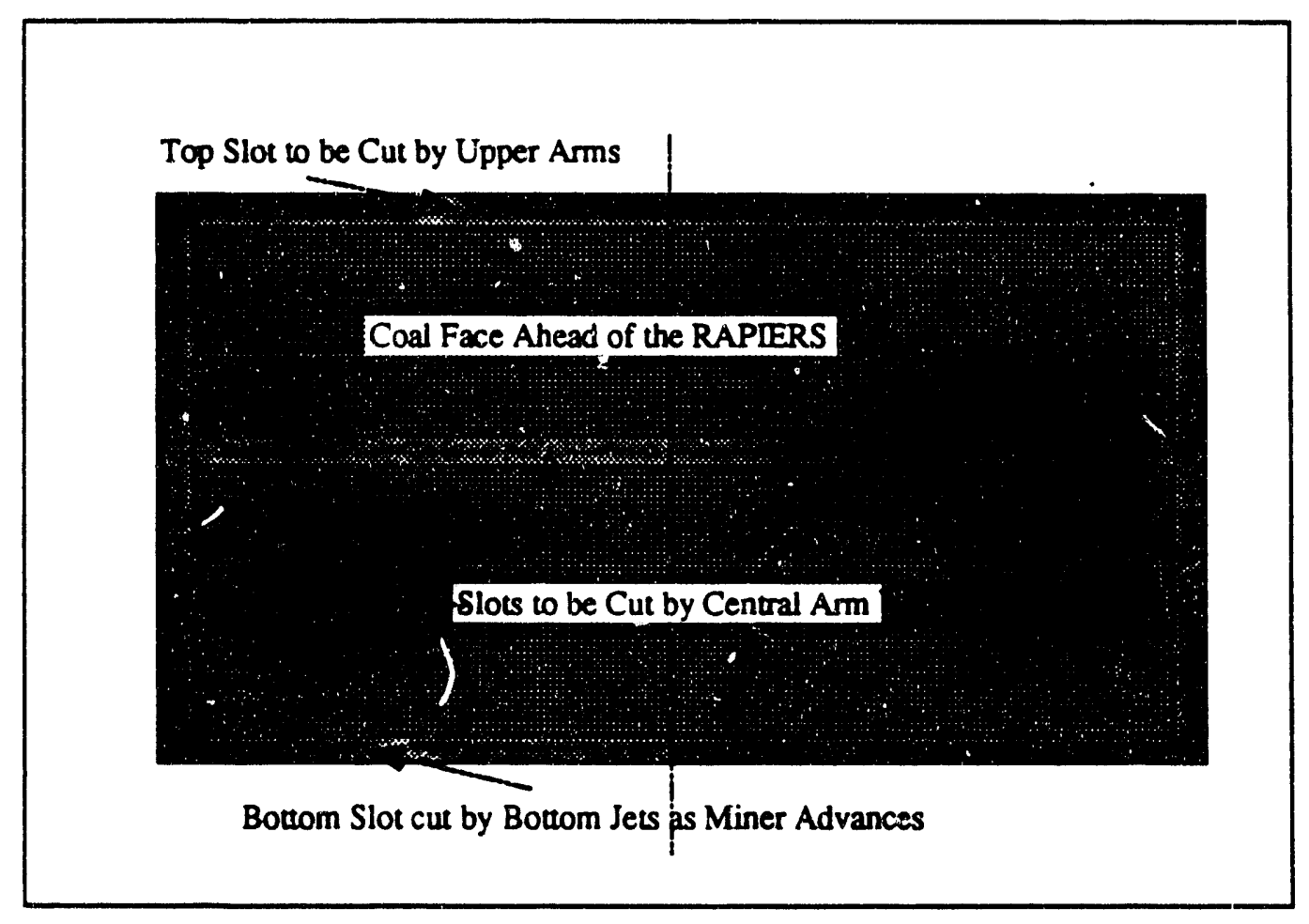

Figure 22. Original Pattern of Slots to be cut in the Coal Face.

The original conception of the cutting arm to cut this first slot was that a single lance cculd be used (Figure 23). A practical evaluation of the limited time available to make the cut and the logistics of the cutting process suggested that a two-lance system would be more effective. 


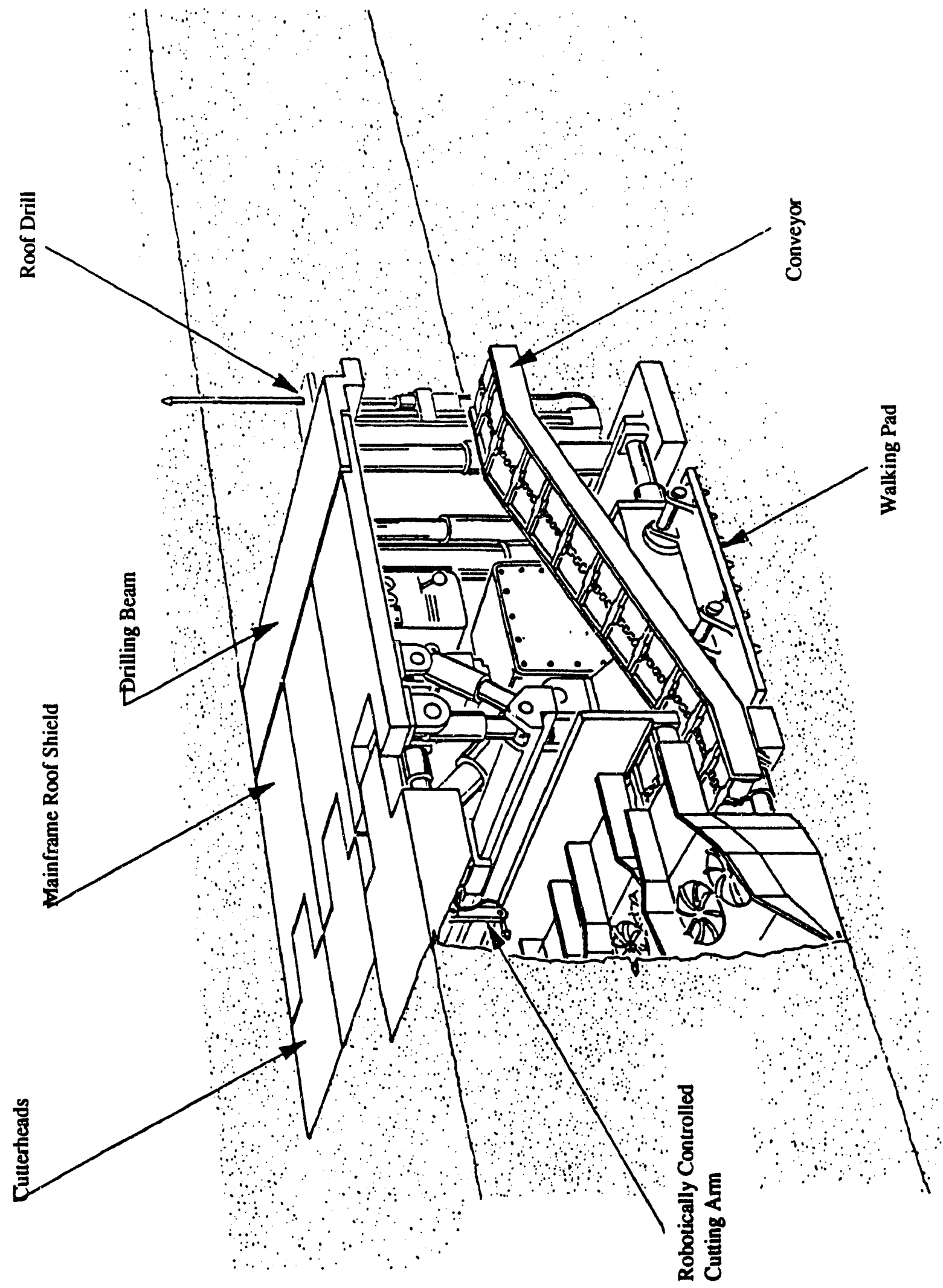

Figure 23. Design Concept proposed by JPL Report 
A rigid and stable mounting location was required as a base plate for the slotting arm drive unit. Examination of the possible mounting surfaces in the assembled unit indicated only a limited set of options The most practical point was just outside the frame of the scraper conveyor where this crossed the upper surface of the gathering arm.(Figure 24). This location had many benefits and would allow the cutting arms to be retracted out of the way during the removal of the coal. The problem with this location was that it made it very difficult to reach the outer edges of the coal seam and even more difficult to direct the lance to cut a slot along this perimeter. For this reason, the pattern of relief slots to be cut was changed.

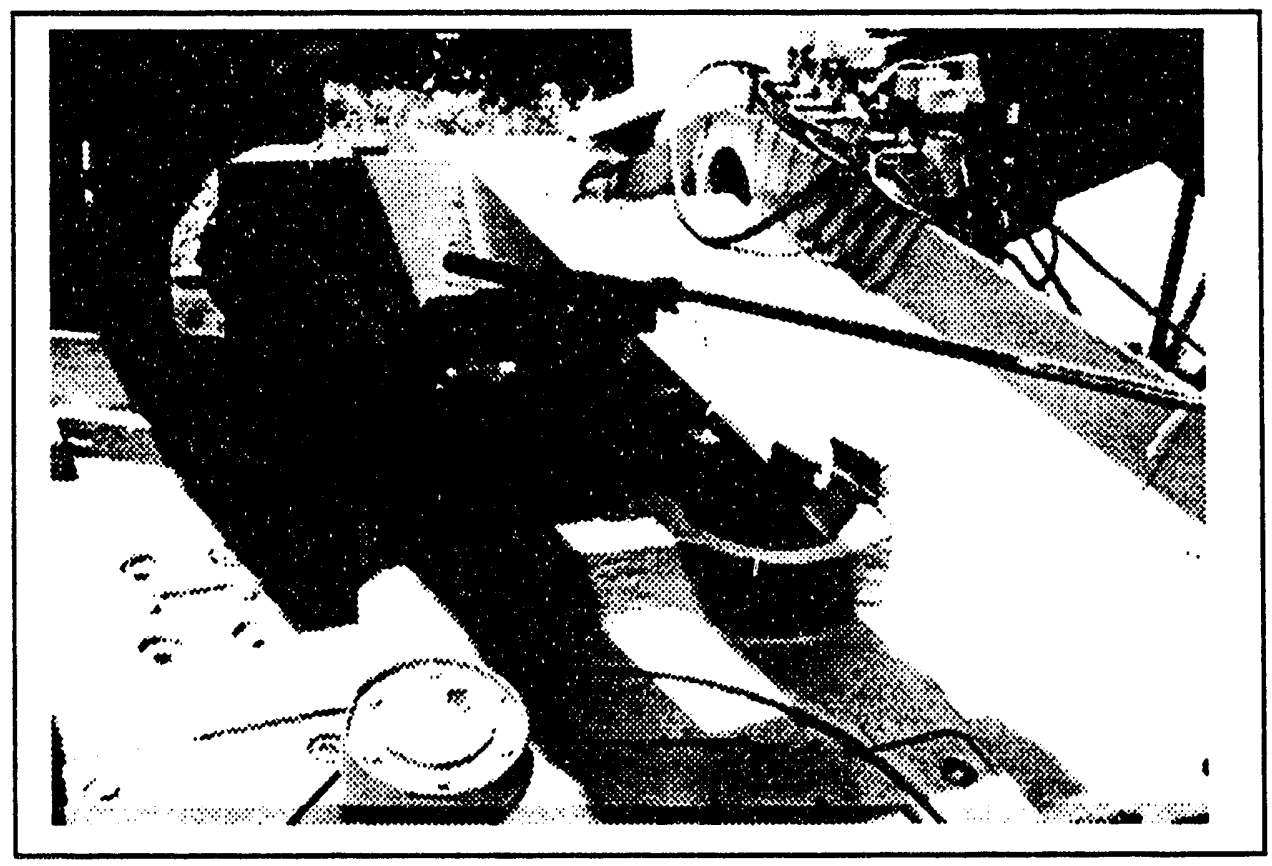

Figure 24. Location of the Central Cutting Arm Assembly

Instead of cutting the slot horizontally and then along the edges of the proposed tunnel, the design was modified to cut the vertical slot in the center of the machine ahead of the face. This would still provide the stress relief and access for unloading and fragmenting the main coal mass ahead of the machine. It would also provide a more rapid method of cutting the slot. The experiments which had previously been carried out with Hydrominer indicated that providing the slot was wide enough and of sufficient depth this would be sufficient to allow the coal to be removed from the solid by the wedging action of the apron as it moved forward. 


\section{Controls}

The robotic cutting arm had, by now, been designed to make all the cuts in the coal face except the bottom slot.

\section{a) Structural considerations}

The dimensions of the coal face which this prototype machine would excavate were considered to be an average of 5.5 feet in height and 9 feet 2 inches in width. In reality the height of the coal is likely to vary as the machine advances, and the flexibility of the design will allow for some considerable variation in this height. The nozzle head should be able to reach any point along the face. One option to get this purpose is to adopt the scheme proposed by Jet Propulsion Laboratory of California Institute of Technology in the report on the design of hydro-mechanical system for underground coal mining. In that report the robotic cutting arm was rail-mounted and able to move horizontally. The rail was supported hydraxlically by cylinders placed at each end, and was designed to move up and down and skew at an angle as shown in Figure 23.

While this idea was a good starting point it required that both the supporting structure and the driving system would be quite complicated. When this complexity was considered in light of the harsh conditions which exist in the vicinity of the underground working face, it was decided it would create too many problems. Instead it was decided to modify the design following the principles of simplicity and rigidity.

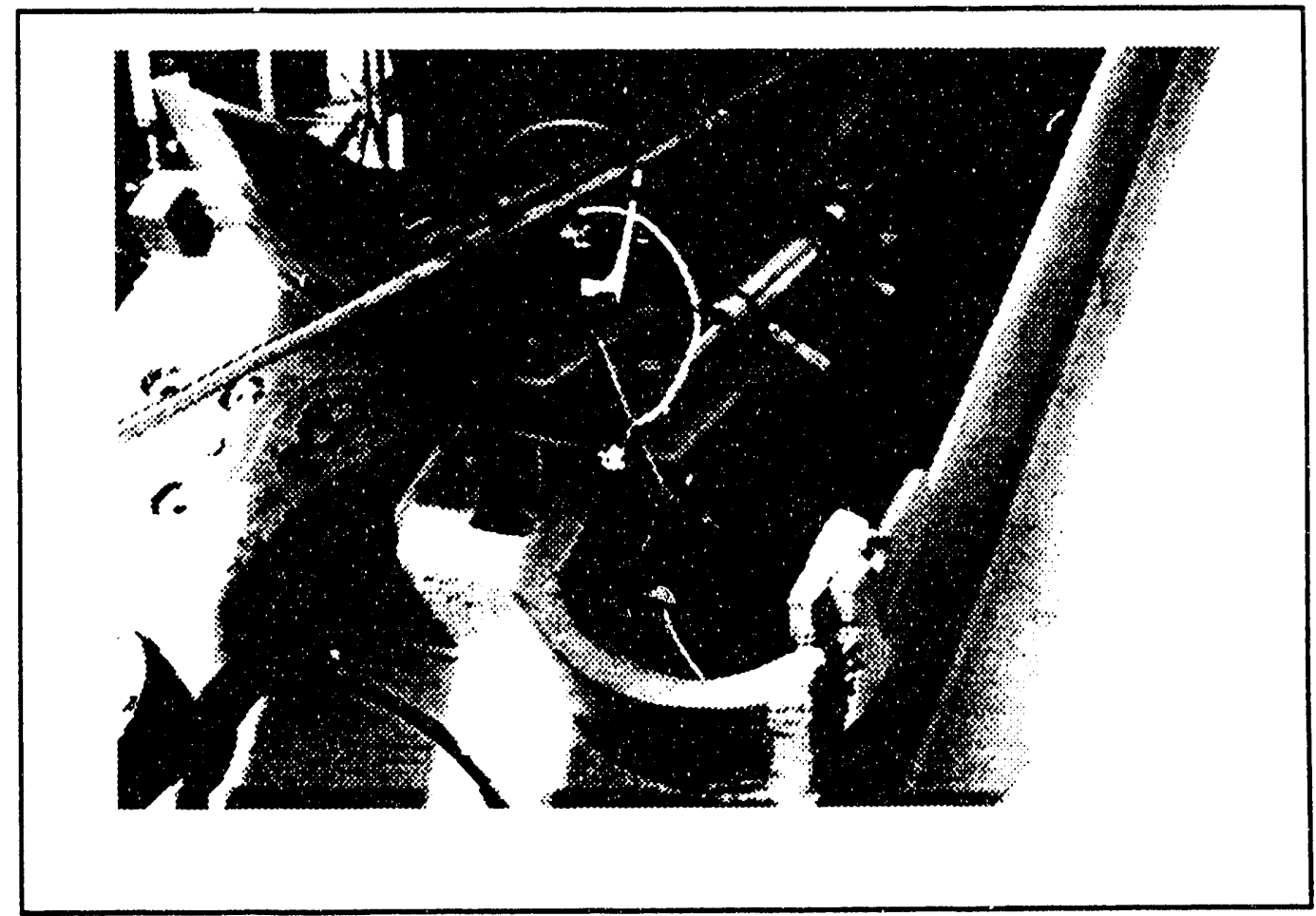

Figure 25. Detail of the cutting arm showing the horizontal pivoting ram 
Figures 24, 25 and 26 show the position and arrangement decided for the robotic cutting arm. Because the working range over which each jet can act is limited by the dimensions of the arm, two arms were chosen for use. These were mounted on either side of the conveyor channel and each arm was arranged so that it could cut slots in the facing half of the coal seam (5.5 feet in height and 4.5 feet in width).

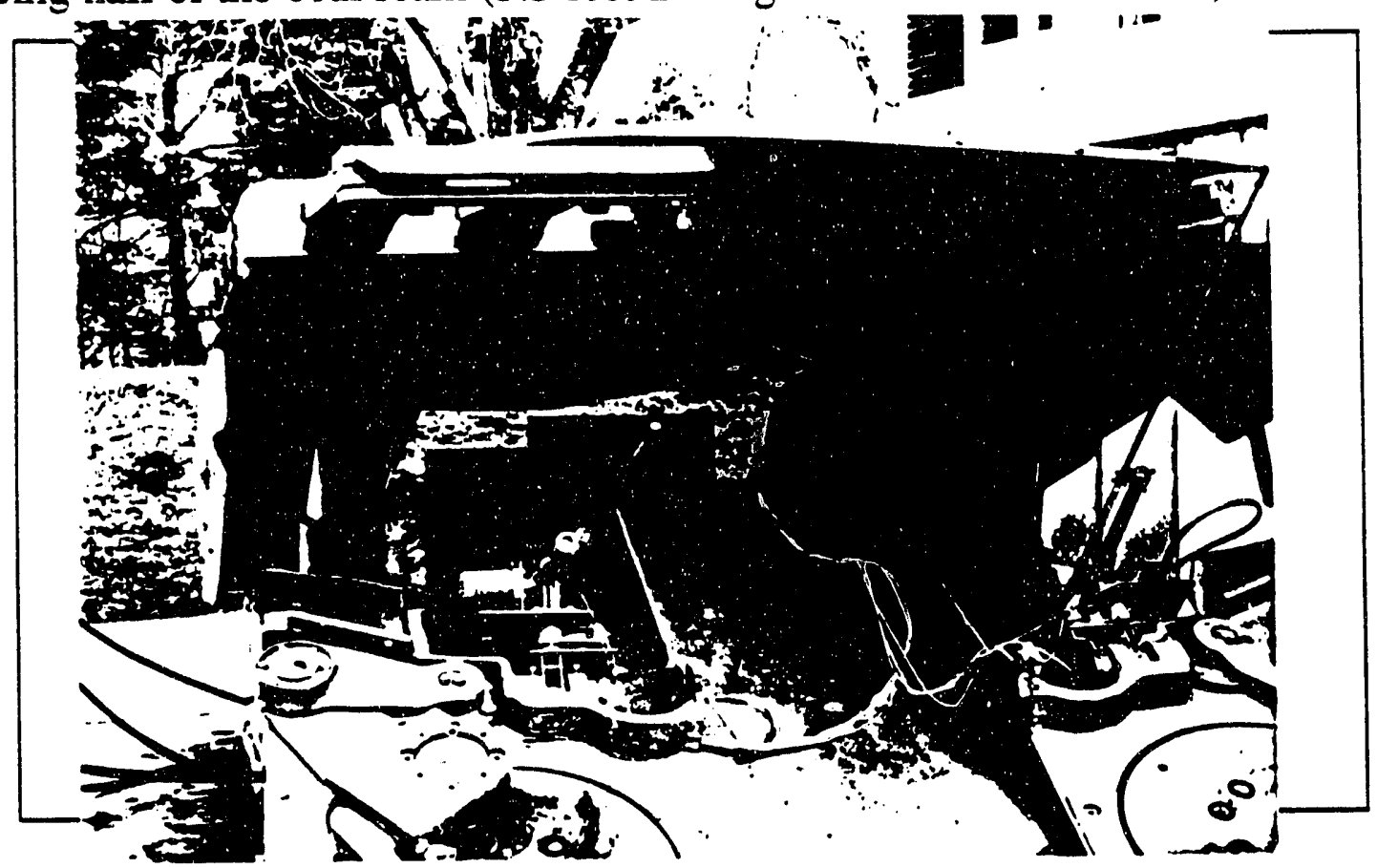

Figure 26 Front View of the Assembled RAPIERS

A schematic diagram of the cutting arm is shown in Figure 27. The movements required of the arm could be achieved with just three degrees of freedom. Rotation joint 1 will allow the nozzle to move in the vertical direction, while rotation joint 2 lets the cutting head travel across the face in the horizontal direction. Both joints are to be driven by hydraulic cylinders. The third freedom is a linear motion and is used to compensate for changes in the distance between the nozzle and the coal face and to advance the nozzle into the face as the slot is deepened. This is intended to keep the stand-off distance as a constant. This feed mechanism is provided by a pair of gears and a rack and pinion and is driven by a hydraulic motor.

A considerable period of discussion arose over the choice of the cutting arm motions. It was necessary to evaluate the benefits and disadvantages of this three freedom arm in comparison with the more generally accepted robotic arms which have a greater number of degrees of freedom. The advantage of an arm with a greater number of degrees of freedom, such as for example an arm with 5 degrees of freedom, is that the attack angle of the nozzle to the coal face can be kept at 90 degrees or, if needed, can also be adjusted. However the structure required to allow this freedom, and the controls which it would require to sense the position and to ensure the correct motions, 


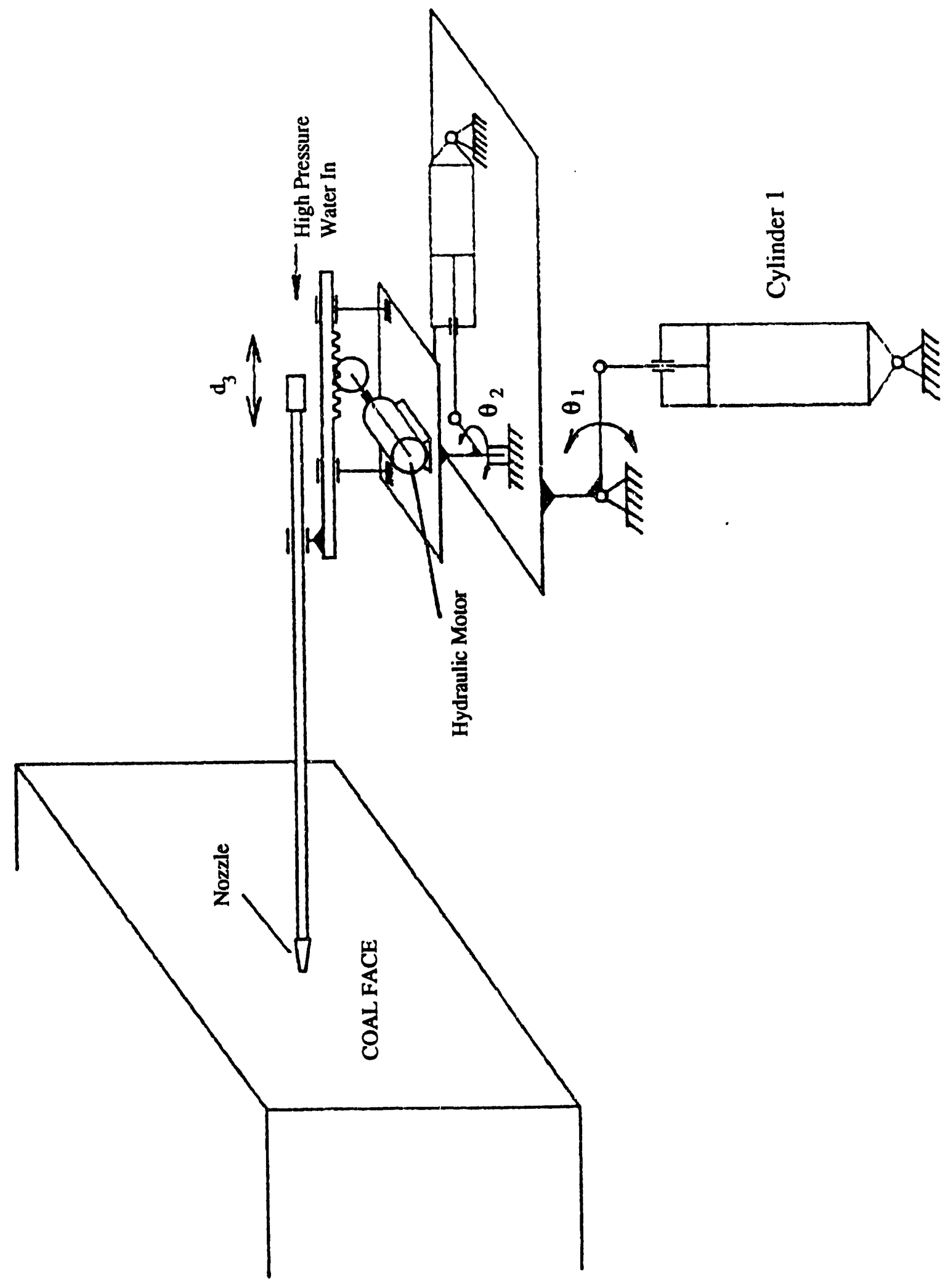

Figure 27. Overall System Co-ordinates for Operation of the Cutting Arm

would be complicated and the cutting lance would have to be lighter for the addtional equipment to be able to move it effectively. This would make the equipment more fragile. 
In contrast, the three motion arm is simple to operate. Because of its simplicity greater weight can be given to the arm, which will thus become more rigid. The major disadvantage of this system is that the attack angle cannot be adjusted. As the nozzle moves to the edge of the working range, the angle between the waterjet and the face will reduce to about 70 degrees. In this application this reduction can be accepted, because the purpose of the cuts is to isolate the coal block and relieve the surrounding stress. This will still be possible with the smaller angle.

b) Kinematic solution

Figures 27 and 28 show the basic coordinates of the robotic arm, in which the $\mathrm{X}$-Y plane is set parallel to the working face, and the positive $\mathrm{Z}$ direction is set perpendicular to and away from the face. Point $O$ is the intersection point of the axes of the two planes of rotation set by the joints. $\theta_{1}$ and $\theta_{2}$ are the parameters for the first and second rotation joints, and $\mathrm{d}_{3}$ is the parameter for third linear translation. Based on conventional robotic theory, the following equations can therefore be established:

$$
\begin{aligned}
A 1 & =\left|\begin{array}{cccc}
1 & 0 & 0 & 0 \\
0 & \cos \Theta 1 & -\sin \Theta 1 & 0 \\
0 & \sin \Theta 1 & \cos \Theta 1 & 0 \\
0 & 0 & 0 & 1
\end{array}\right| \\
\mathrm{A} 2 & =\left|\begin{array}{cccc}
\cos \Theta 2 & 0 & \sin \Theta 2 & 0 \\
0 & 1 & 0 & 0 \\
-\sin \Theta 2 & 0 & \cos \Theta 2 & 0 \\
0 & 0 & 0 & 1
\end{array}\right| \\
\mathrm{A} 3 & =\left|\begin{array}{llll}
1 & 0 & 0 & \mathrm{a} 3 \\
0 & 1 & 0 & \mathrm{~b} 3 \\
0 & 0 & 1 & \mathrm{~d} 3 \\
0 & 0 & 0 & 1
\end{array}\right|
\end{aligned}
$$

\begin{tabular}{|c|c|c|c|c|}
\hline \multirow{3}{*}{$\mathrm{T}=\mathrm{A} 1 \triangle \mathrm{A} 2 \bigcirc \mathrm{A} 3=$} & $\mathrm{C}_{2}$ & 0 & S2 & $230 C 2+\infty 30 S 2$ \\
\hline & s10s2 & & $-\operatorname{sinc2}$ & b3 $\alpha C 1+a 3051052-d 030 S 1 \alpha C 2$ \\
\hline & - C1OS2 & s1 & $\mathrm{Cloc2}$ & b30S1-30C10S2+d30C10C2 \\
\hline
\end{tabular}

The total transformation $\mathrm{T}$ should be

where $\mathrm{S} 1, \mathrm{~S} 2$ means $\operatorname{SIN} \theta_{1}, \operatorname{SIN} \theta_{2}, \mathrm{C} 1, \mathrm{C} 2$ means $\operatorname{COS} \theta_{1}, \operatorname{COS} \theta_{2}$. 


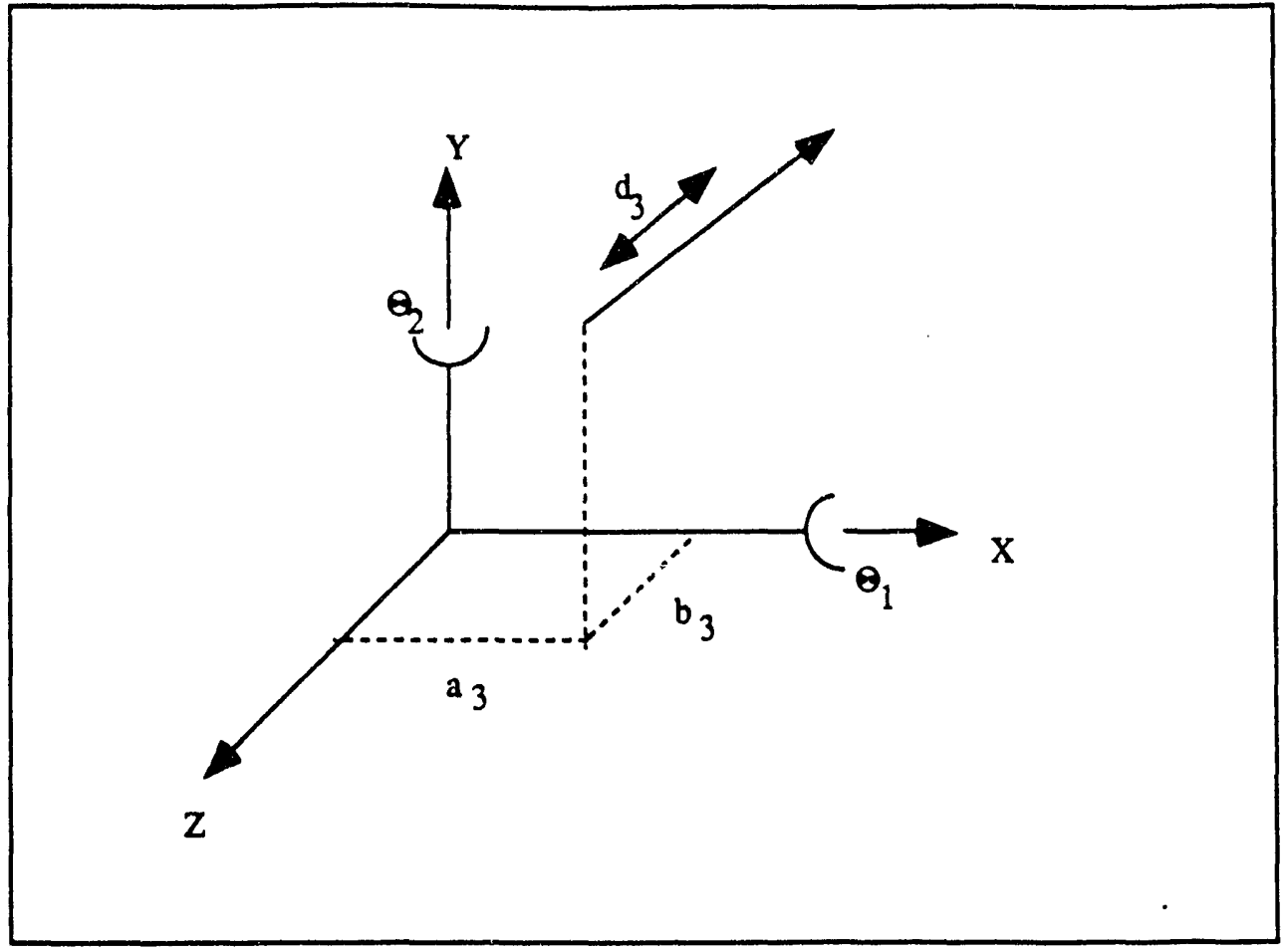

Figure 28. Base coordinate System for the Robotic Arm in which the $X . Y$ plane is parallel to the work face, and the positive $Z$ direction is away from the face.

Suppose that the end-effector, i.e., the cutting head, is located at $X, Y, Z$, then the equations become

$$
\begin{aligned}
& X=\mathrm{a} 3 \cdot \cos \Theta 2+\mathrm{d} 3 \cdot \sin \Theta 2 \\
& Y=b 3 \cdot \cos \Theta 1+\mathrm{a} 3 \cdot \sin \Theta 1 \cdot \sin \Theta 2-\mathrm{d} 3 \cdot \sin \Theta 1 \cdot \cos \Theta 2 \\
& Z=b 3 \cdot \sin \Theta 1-\mathrm{a} 3 \cdot \cos \Theta 1 \cdot \sin \Theta 2+d \mathrm{~d} \cdot \cos \Theta 1 \cdot \cos \Theta 2
\end{aligned}
$$

Solving the above equations, gives the results

$$
\begin{aligned}
& d 3=\sqrt{X^{2}}+Y^{2}+Z^{2}-a 3^{2}-b 3^{2} \\
& \Theta 1=\tan ^{-1} \frac{-b 3}{\sqrt{Y^{2}}+Z^{2}-b 3^{2}}-\tan ^{-1} \frac{Y}{Z} \\
& \Theta 2=\tan ^{-1} \frac{-X}{\sqrt{a 3^{2}}+d 3^{2}-X^{2}}-\tan ^{-1} \frac{a 3}{d 3}
\end{aligned}
$$

Once the kinetic solutions have been obtained, the position of the cutting head (X, Y, $Z$ ), can be controlled by controlling the values of the parameters $\theta_{1}, \theta_{2}$ and $d_{3}$. 
In order to control the traverse speed of the cutting head in the $\mathrm{X}, \mathrm{Y}$, or $\mathrm{Z}$ directions the Jacobian matrix. i.e., the relationship between the velocities of the nozzle and the three joint coordinates, $\theta_{1}, \theta_{2}$, and $d_{3}$, should be established. Then, once the required traverse speed is known, the joint speeds, $w_{1}$ and $w_{2}$ for the rotational joints 1 and 2 , and the linear velocity $\mathrm{v}_{3}$ for the translation joint 3 can be calculated as the cutting head moves through the different locations of the cutting path. Here, the derivation and the calculation of the Jacobian matrix are neglected. The location and speed control will be further explained later.

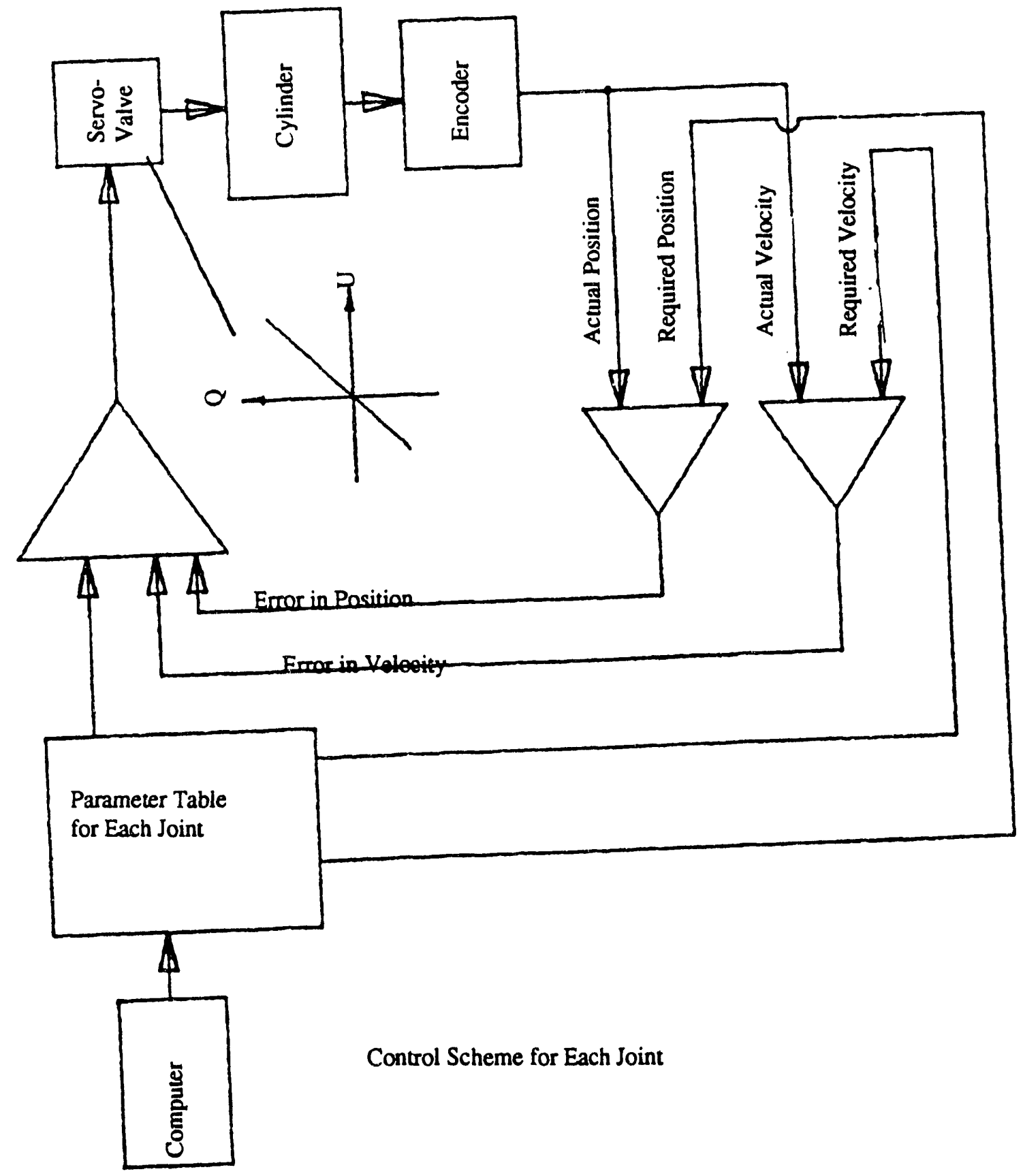

Figure 29. Representation of the Closed Loop Control System 


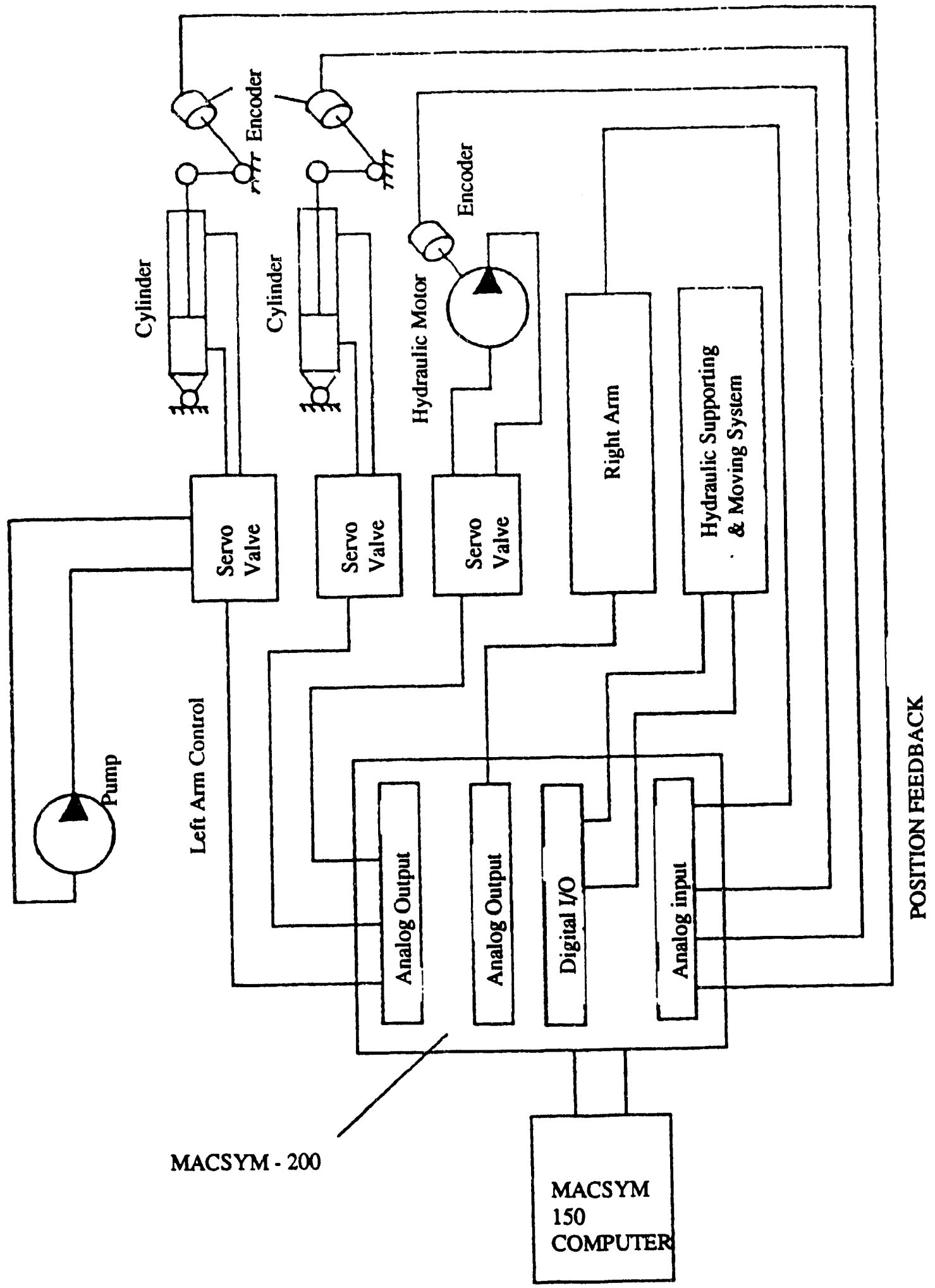

Figure 30. MOOG Model 22-131A and Model 32-187 Servo Valves 


\section{Hydraulic Circuitry and System Hardware}

A closed-loop control scheme was designed for use in the system, and is shown in Figure 29. The computer used in the system is a MACSYM-150, which was specially chosen its capabilities in dealing with analog input and output. The computer is connected to a MACSYM-200, expansion box, which holds one analog input board and one output board. Three hydraulic servo-valves are connected to the output board, and are used to direct and to control the flowrate of the hydraulic fluid to the various system controls. It is by controlling the opening and position of the spools in the servo-valves, that the direction of motion and the speed of the two cylinders and the one hydraulic motor can be controlled. Two rotational encoders are attached to the axes of the first and second rotary joints.

A third encoder is installed along the axis of the hydraulic motor. These encoders are connected to the input board of the MACSYM-200, and are used to feed back to the computer the actual position of the cutting head. When these signals are integrated with that of the system clock within the computer, the real-time velocities of the head in the three directions can also be derived, and compared, inside the computer, with that required. As a result any necessary positional and velocity changes required can be mandated from within the program.

The servo-valves used in this control system were produced by the MOOG Company. Two Model 22-131A valves were used to control the cylinder posditions. These cylinders each had a rated flowrate of 30 cubic inch per second. A model 32-187 valve was chosen to control the flow of fluid to the hydraulic motor and had a smaller rate of flow, of 2 cubic inch per second. Both valve types had close to equivalent characteristics, as shown in Figure 30. Theoretically the control flow is proportional to the input electric current. Because the control electric current is very small (rated currents are $15 \mathrm{ma}$ and $3.6 \mathrm{ma}$ respectively), no amplifier was needed in the control circuit and the controlling coils could be directly hooked up to the computer analog outputs.

The encoders used were all of the potential type, based on the same principle as a linear potential meter as shown in Figure 31. The output voltage indicates the position of the moving shaft of the encoder, which is fixed to the joint shaft of the cutting arm. The advantage of this type of encoder is that the output voltage correlates closely with the actual position of the arm, and no initialization is required before the unit can start to operate, as would be required with the photo type of encoder. This simplified the programming and operation of the unit considerably. 


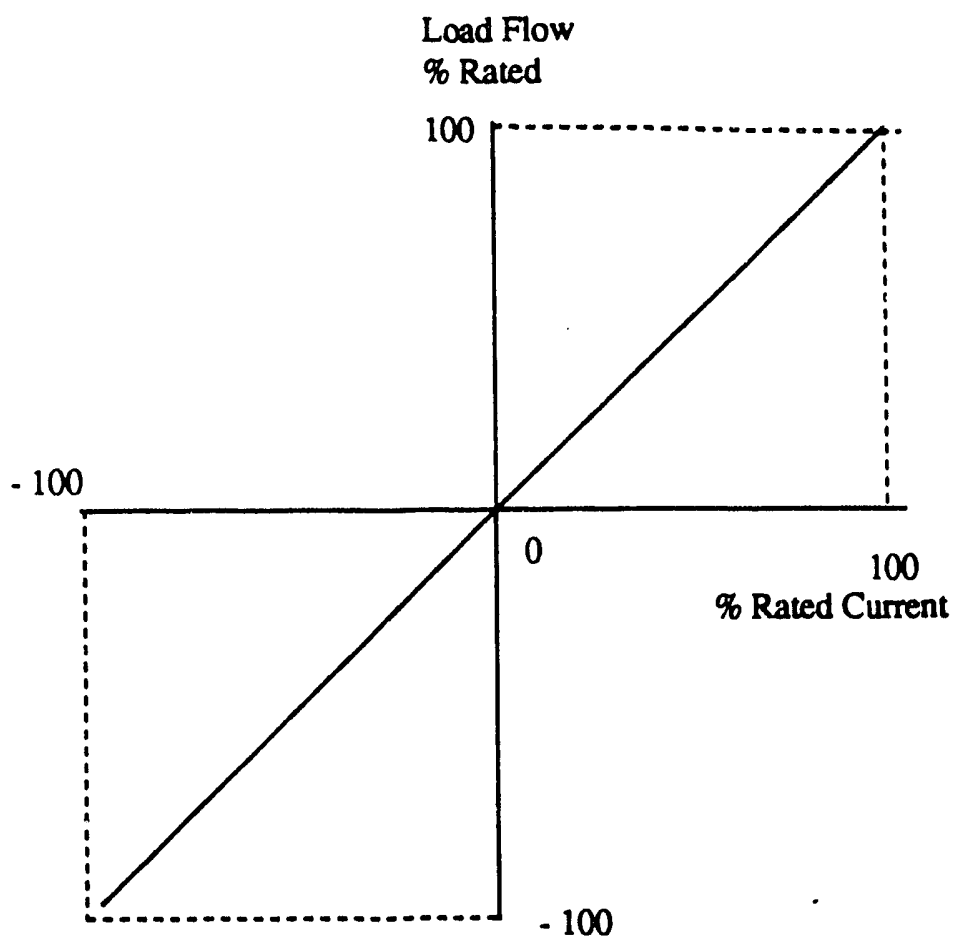

Figure 31. Load Flow - Control Current Characteristics

a) Programming

The MACSYM-BASIC language was used to write the operating computer program which is given in Appendix 1. The general idea used for controlling the movement of the cutting arm was as follows.

First, the program tests the analog input and output of the controlling system, and obtains the basic information on the condition of the cutting arm. Then the computer will request that the operator enter the required coordinates of the cutting path $\left(X_{0}, Y_{0}\right.$, $\mathrm{X}_{1}, \mathrm{Y}_{1}$ ) over the coal face, and the required traverse speed.

The program will then compute the kinematic solution for the movement of the robotic arm. As a part of this process the program calculates the joint parameters, $\theta_{1}$, $\theta_{2}, d_{3}$, and the joint velocities, $w_{1}, w_{2}$, and $v_{3}$ at different points all along the cutting path. The basis for the selection was designated to be at equal time intervals over the course of the path designated. The program will then establish a table, exemplified by that shown in table 1 . This table will list all the required parameters tied to their value at specific times along the path which the arm must sweep out. Based on the velocities given in the table, the computer will output a controlling voltage to the individual servo-valves. This voltage will be adjusted to the computed motion and will thus change as a function of the time during the arm motion. At the same time, the cur- 
rent actual locations and velocities of the cutting head will be measured from the readings of the encoders. These will be converted by the program into the acutal position and velocities. Then the program computes the individual errors between the actual values and those which the programmed motion requires. These errors are used to compute correcting values which are then output as compensating signals, which are proportional to the position error and velocity error. The computer will then integrate these signals to generate a new value for the controlling output voltage for each of the servo-valves. The program will continue to monitor and control the motion over the course of the movement.. Because of the close monitoring of the movement and the volocity, any errors in motion which occur can be detected while they are still small. In this way, the nozzle will closely follow th: required cutting path and moves at the specified speed. 


\section{CHAPTER III. EQUIPMENT CONSTRUCTION}

\section{Introduction}

The purpose of the award for the development of a room and pillar waterjet mining machine under this program was to move the technology toward commercial development. Investigations at UMR into the application of high pressure waterjets have been going on for almost 23 years. A number of developments have shown considerable commercial promise, but it has been difficult to find a reliable path to move novel ideas forward into the market place.

At the beginning of this project considerable hope was placed in the development of the Mining Excavation Research Institute (MERI). This program was funded by ASME during its formative period, and a considerable effort was directed toward this avenue to the ultimate user. Unfortunately, new ideas take some time to develop and although the MERI program is not dead, its development has been much slower and there has been much less industrial support than had been hoped when the program was started. This avenue, therefore, towards the future development of the machine has not been as successful to this point in time as had been hoped. The development of a research arm to the American Mining Congress and the Research Council for the Society of Mining Engineers had both been outgrowths of the MERI activity. These two organizations will hopefully allow a better method of communicating with potential licensees as they become better established.

It, thus, becomes necessary to find a way to reach and convince possible licensees of the potential of RAPIERS. Experience with earlier machines has shown that the simple presentation of papers at symposia and meetings of learned societies is not enough. A graphic visual presentation has been found to be much more powerful in demonstrating the capabilities of waterjets and short video presentations have become widely accepted as a means of demonstrating the capabilities of waterjet cutting systems.

The original proposal therefore called for a video tape to be made of the mining machine operation. The level of funding currently available when taken with the high costs of travelling and installing the mining machine underground, prohibited the actual demonstration of the machine in a field environment. The length of time to obtain certification and the cost that this would incur also mandated against this option. 
The decision was therefore made to manufacture the machine at UMR and to demonstrate the operation of its separate components both by using field footage shot of the longwall waterjet mining machine in use, and also by demonstrating the jet cutting ability against an artificial coal seam.

An artificial coal seam was therefore constructed in which particles of coal approximately $1 / 4$ " in size were bound into a coarse abrasive cement paste. It was necessary to use a minimum amount of water in the mixture to minimize segregation and also to control the cement strength. The resulting material was relatively friable in much the same way as was found in a conventional coal seam.

In order to give some indication as to the performance of the machine in an underground situation, two short cartoon segments were prepared using the Videoworks II Program on an Apple Macintosh II computer. The first of these segments used a simple black and white model to demonstrate the cyclic operation of a normal continuous miner panel. The second, which was colorized, demonstrated the basic operational parameters of RAPIERS. These two segments were integrated with linking videotape to form a short documentary. The script is presented in Appendix II.

\section{Prototype Evaluation}

There is not a great deal of complexity to the prototype RAPIERS which has been develope. Experience has shown that the simpler the mining machine is built then the more likely it is to succeed. Several questions have to be answered, however, with the cutting trials in the artificial coal.

The initial questions was the best novel considerations to use for the cutting arms and the best way to cut the coal ahead of the mining machine. The lower cutting arm placed inside the wedge section of the loading apron performed adequately without additional modification. The use of a dual orifice nozzle issuing through a narrow channel was demonstrated to be successful in the earlier longwall machine and proved again to be successful with this device.

The oreration of the sample slotting arms could use as a dual orifice fixed nozzles or self-rotating nozzle assemblies. The self-rotating nozzle designs have become increasingly aviiiable and reliable over the last three years. These devices sensibly comprise a dual nozzle assembly with the jets inclined not only radially but also tangentially to the axis of the feed pipe. Thus, as the jet is used from the nozzles the reaction force is sufficient to cause the nuzzle assembly to rotate about the feed line. This concept is of considerable benefit in that it allows the nozzle to be rotated with- 
out any additional external drive mechanism which would be complicated and which would make the assembly much heavier. Three different assemblies have been obtained at UMR. One from the Hammelmann Corporation, one from NLB, and one from the Stone Age Company of Durango, Colorado. Evaluation of the performance of the different systems indicated that although the Stone Age System was the lightest of the three, the Hammelmann device gave the best performance, and this unit was then used during tests of the cutting head.

The development of the prototype machine used a computer controlled system to operate an control the operations of the machine. Although the trend in machine operation is in this direction, this addition to the machine may well have been an overcomplicated addition at this stage in the program. The basic mechanical components of the unit are very simple. The addition of computer monitoring equipment and the integration of servo valves and feed back control made the unit much more sensitive and more complicated to operate.

This complexity was compounded by two factors. In order to reduce the cost of construction a bank of used servo control valves was obtained for use with the equipment. It transpired that several of these valves were faulty and the diagnosis and ultimate replacement of these units after a relatively lengthy and expensive attempt at repair, cost a lot of valuable time. Further, once the machine was operated the feedback controls for the motion of the arm did not initially give a smooth and stable path for the arm at the required speed and in the required direction. Again, a considerable amount of time was spent in debugging this problem. Since a partial objective of the program was to demonstrate the simplicity of the equipment the probletins generated by the attempt to use computer control were perhaps unnecessary at this stage of the program.

\section{Future Plans}

The presence of the RAPIERS prototype at UMR has drawn considerable and increasing interest from the visiting executives at mining companies. Interest has been expressed by two of these companies by having the machine operated in one of their mines. It is believed that this will be a significant step forward but it will require some additional funding to become practical. The present intention is to seek that funding through the Bureau of Mines Generic Center Program in 1991.

A problem with the introduction of waterjet equipment hass lain in its cost and its relatively unproven capabilities for the mining industry. This situation is changing as 
the capabilities of high pressure waterjets and abrasive waterjet systems become more apparent. Significant progress in the technology has been made.

The relative cost and size of RAPIERS makes it unlikely that this will be the first waterjet equipment that a company will install in a mine. Two other developments which are now moving forward will likely proceed it. The first of these is a waterjet drilling device, and the second is the small fine coal planing machine being developed under separate DOE funding.

The reason that these other two machines will likely enter the market first, is that they are smaller, cheaper, and are much more capable of being operated in a stand-alone mode that RAPIERS. Although much more independent of other equipment that a longwall unit, a room and pillar mining machine still must be integrated into existing mining operations. This requires a relatively expensive commitment on the part of mine owners. While that commitment appears to be on the horizon, it will be easier to introduce the independent equipment first.

RAPIERS has been found in many ways to be a simpler machine than was anticipated when it was originally conceived. As interest continues to build in new mining equipment, and the needs for inexpensive clean coal become more demanding, the role that this new machine will have to lay is likely to be significant. We are committed to move the development of this machine forward in the next few years as the opportunity increasingly arises to introduce its benefits to industry.

\section{Acknowledgements}

This program was funded under the Energy Related Inventions Program with Mr. Jack Aellen as Project Officer. His considerable patience and helpful advice as we struggled with many of the problems in the development of this machine is sincerely appreciated.

The concept for RAPIERS was developed in cooperation with the Jet Propulsion Laboratory, Pasadena, CA. with Mr. Jay Estus as co-inventor of the machine. The help that was provided by that organization and the forbearance which they displayed as we struggled to bring the machine to completion is also appreciated.

A considerable part of the final machine design was built by Mr. James Blaine and the electronic circuitry by Mr. John Tyler of the Rock Mechanics \& Explosives Research Center Staff. The reporting and financial monitoring of the contract was under the direction of Mrs. Jo Blaine, this support is also very gratefully acknowledged. 
Finally the video script was prepared with considerable advice from Dr Sam Geonetta, now at the University of Cincinnatti. His advice and the assistance of the Center for Media Studies at UMR in assembling the tape, and that of Mr Fossey who shot is is willingly acknowledged. 


\section{References}

1. Lavin M.L. et al, "Design and Evaluation of a Continuous , In-Place, Hydromechanical System for Underground Coal Mining" Final Report on Contract JO134054 for the US Bureau of Mines, Jet Propulsion Laboratory, JPL Publication 84-64. July 1984.

2. Summers D. A., Barker C.R. and Mazurkiewicz M. "Experimentation in Hydraulic Coal Mining", 1977 AIME Ann Mtg, Atlanta, GA, Mar 18, 1977.

3. Summers D.A. And Peters, J.L. "Preliminary Experimentation in Coal Cutting in the Pressure Range 500 to 2,000 Atmospheres", 2nd Int Symp Jet Cutting Tech, Cambridge, UK, April 1974, paper H-2.

4. Selberg B.P. and Barker C.R. "Dual-Orifice Waterjet Predictions and Experiments", pp 493-510, in Erosion: Prevention and Useful Applications, ASTM STP 664, October 1977.

5. Summers D.A. et al "Excavation of Coal Using a High Pressure Water Jet System", Final Report on Contract HO232064 to US Bureau of Mines, November 1974.

6. Henkel E. "Gewinnungs- und Strebfordertechnik", 25th Year Review, Gluckauf, 1983, pp30-34. 


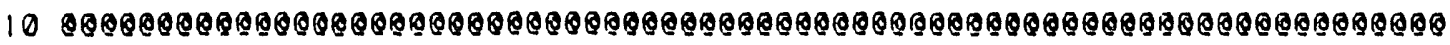

20

30

40

50

60

70 o日er

80

90

100 O THIS PROGRAM IS USED TO CONTROL THE HYORO-MINER. IT CONSISTS OF TIUO PA RTS ONE CONTROLS ROBOTIC CUTTING ARMS. THE OTHER CONTROLS THE BOTTOM WATERJET A ND THE MOUING OF MACHINE.
110 GOSUB 500
- CHECK COMMUNICATION CHANNELS \& ANALOG $1 / 0$
120 GOSUB 300
- maIN MENU
$12=$ END

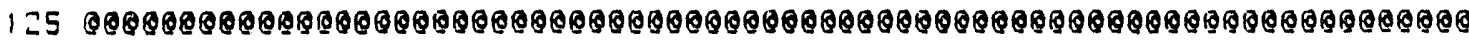
IIS SUBROUTINE FOR ROBOTIC ARM CONTROL
130 GOSUB 700 GET THE BASIC DATA FOR COAL FACE AND ROBOT:C ARMS
140 GOSUB 1000 GET THE REQUIRED PATH PARAMETRERS FOR THE CUTTING
150 GOSUB 1400
160 GOSUB 1600
170 GOSUB 2500
180 GOSUB $=800$
190 GOSUB 2900
200 GOSUB 3000
$=10$ GOSUB 3100
220 GOSUB 3200
230 GOSUB 3300
240 GOSUB 3500
250 GOSUB 2700
260 GOSUB 4100
270 GOSU8 4400
290 RETURN
290

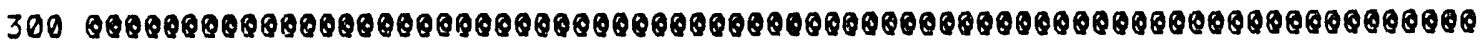
310 SUBROUTINE FOR MIAN MENU
320 PAGE 0 CLS DISPLAY 0
$330 \div 1$ !
$340 !$ TAB (10) "PRESS 'R' TO CONTROL ROBOTIC ARMS"
350 ! TAB(10) "PRESS "M' TO CONTROL MACHINE MOUING"
360 ! TAB (10) "PRESS ' $Q$ ' TO QUIT"
370 INPUT $X s$
380 IF $X \$=" M$ " THEN GOSUB 10000 GOTO 320
390 IF $X \$=" R "$ THEN GOSUB 125 GOTO 320
400 IF $X 9=" Q "$ THEN RETURN
410 GOTO 370
420 .

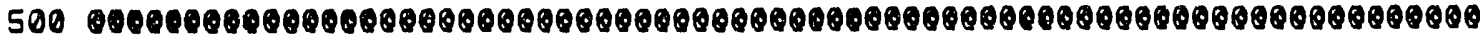

510 SUBROUTINE FOR CHECKING COMM. CHANNEL AND ANALOG I/O

520 PAGE 0 CLS DISPLAY 0

530 ON ERROR ERRNUM' 580

$540 \mathrm{~A}^{\prime}=1$ XRESET NOMODE 1 " CHECKING SERIAL I/O \& ANALOG I/O." !

550 AOT $(1,0)=0 \quad A O T(2,0)=0 \quad B=A I N(0,12,0,0) \quad A=D I N(3,12,13) \quad \operatorname{DOT}(3,0,10)=0$

$560 ; " X R E S E T$ SUCCESSFUL, MACSYM IS READY FOR ANALOG I/O." ! "PRESS ANY

KEY TO CONTINUE." INPUT XS

570 OFF ERROR RETURN

580 IF ERRNUM' $=23$ THEN ! " COMM. CHANNEL TIMEOUT, CHECK CABLE BETWEEN MACSYM 150 AND MACSYM 200." 1 " IF CABLE IS OISCONNECTED, RECONNECT IT AND RESTART $P$ 


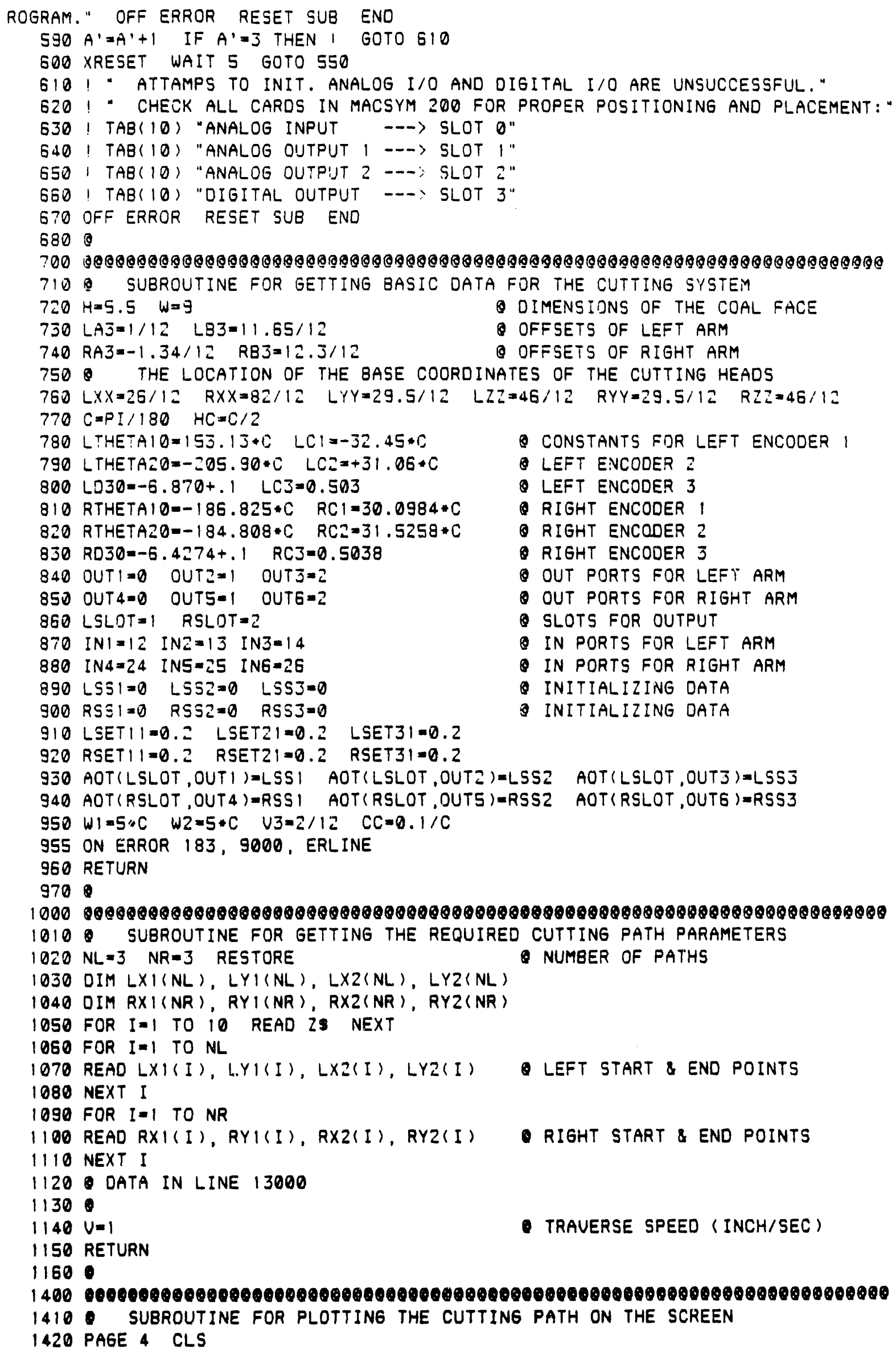




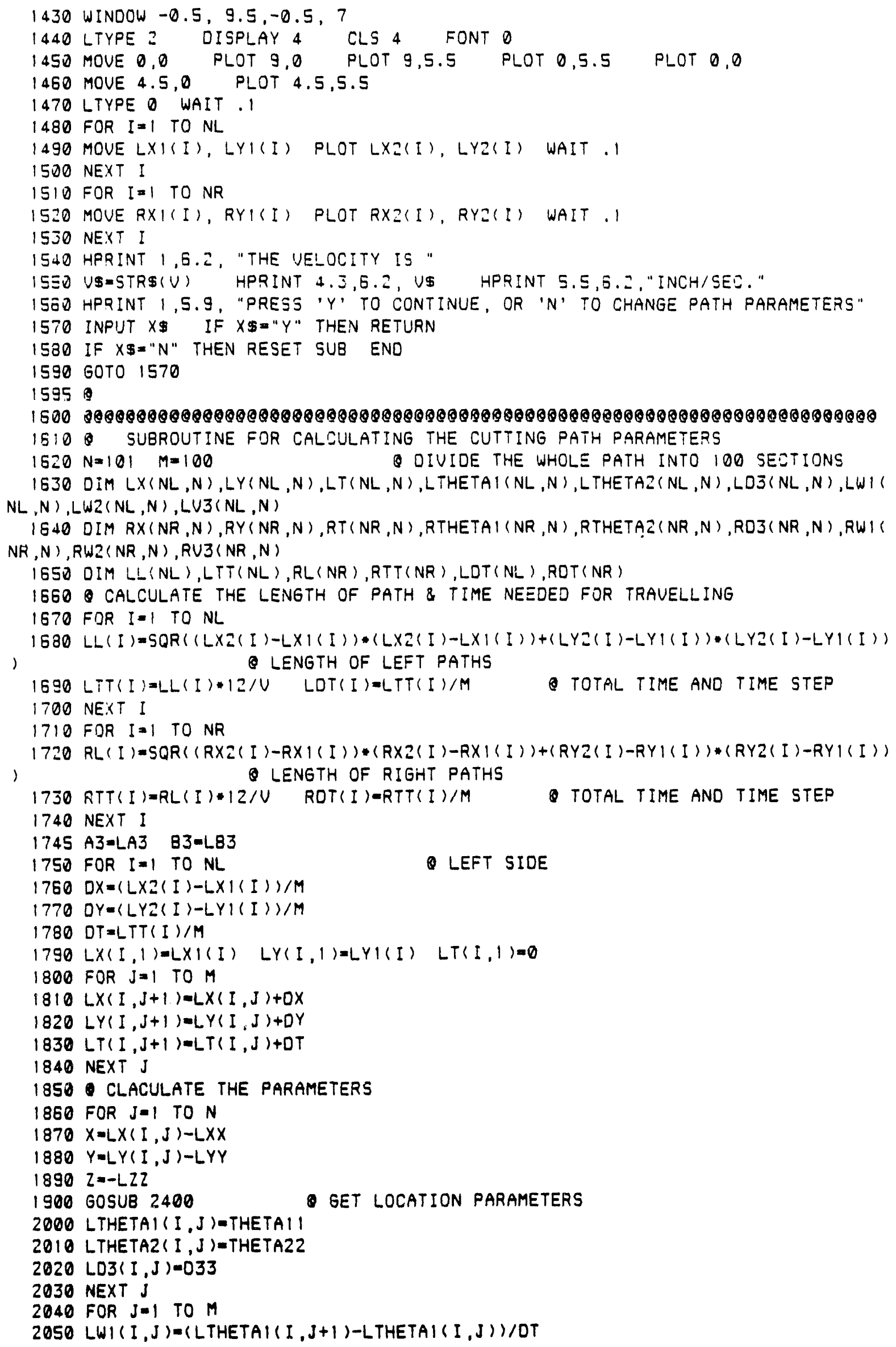




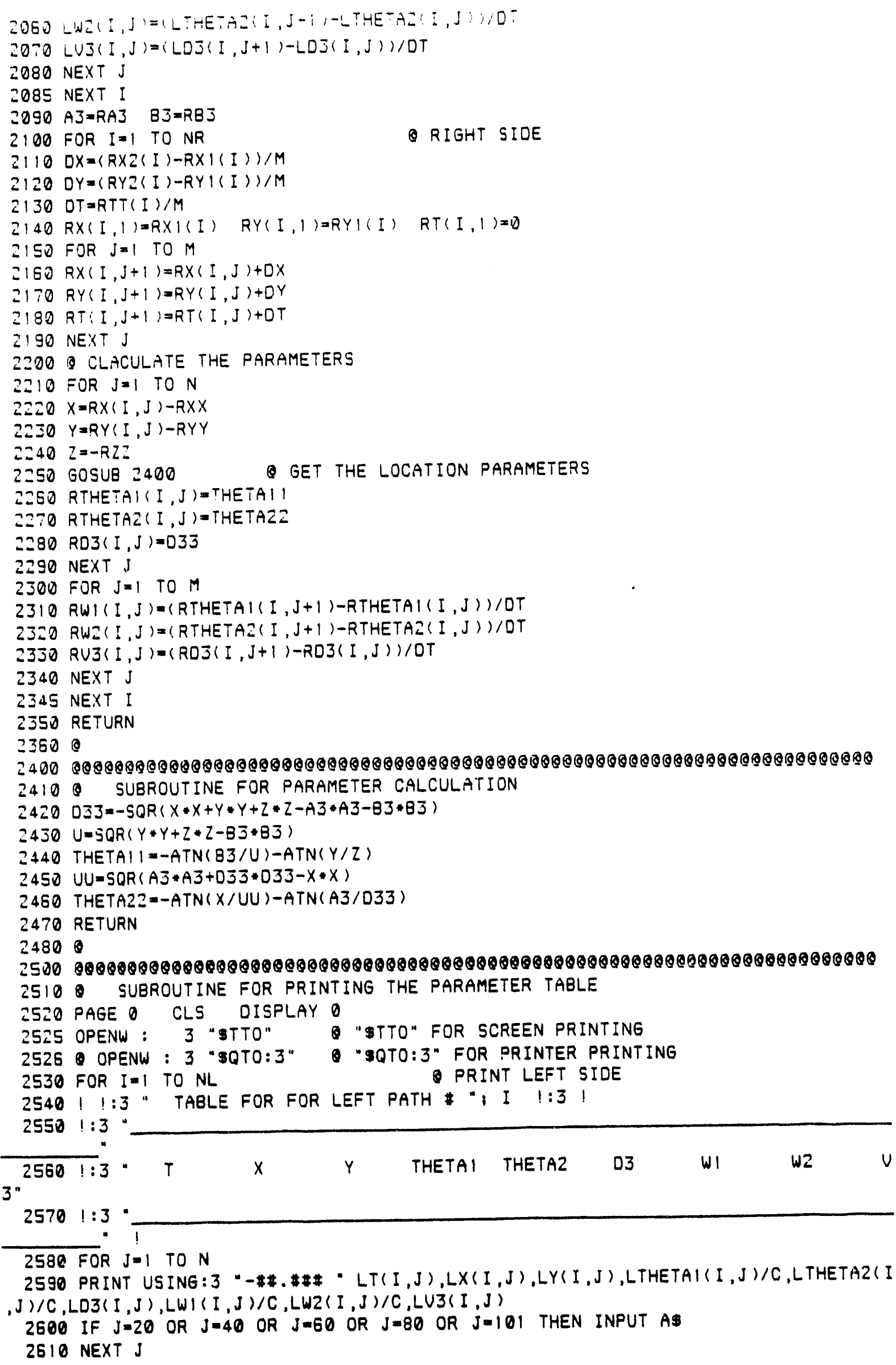




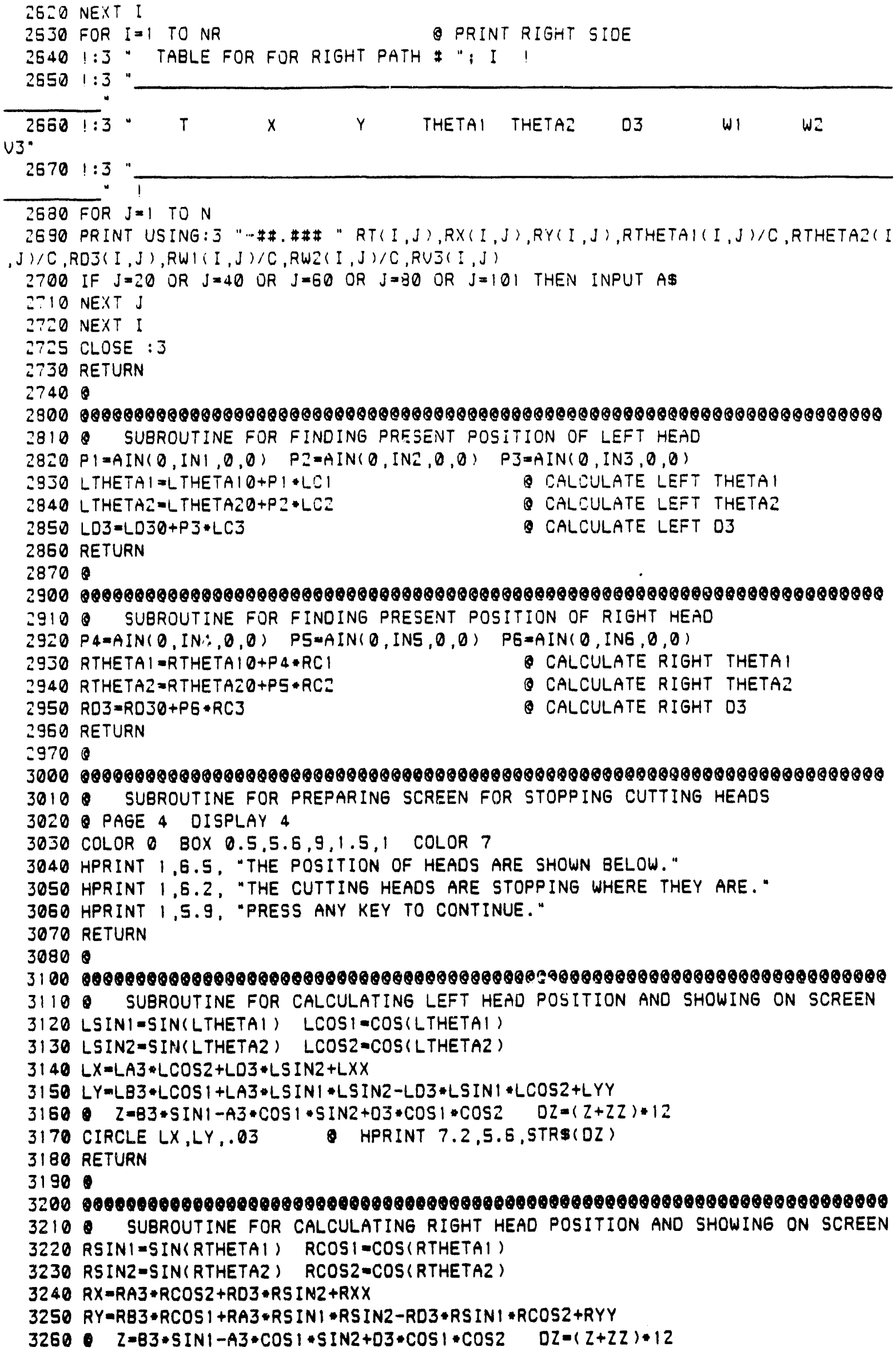




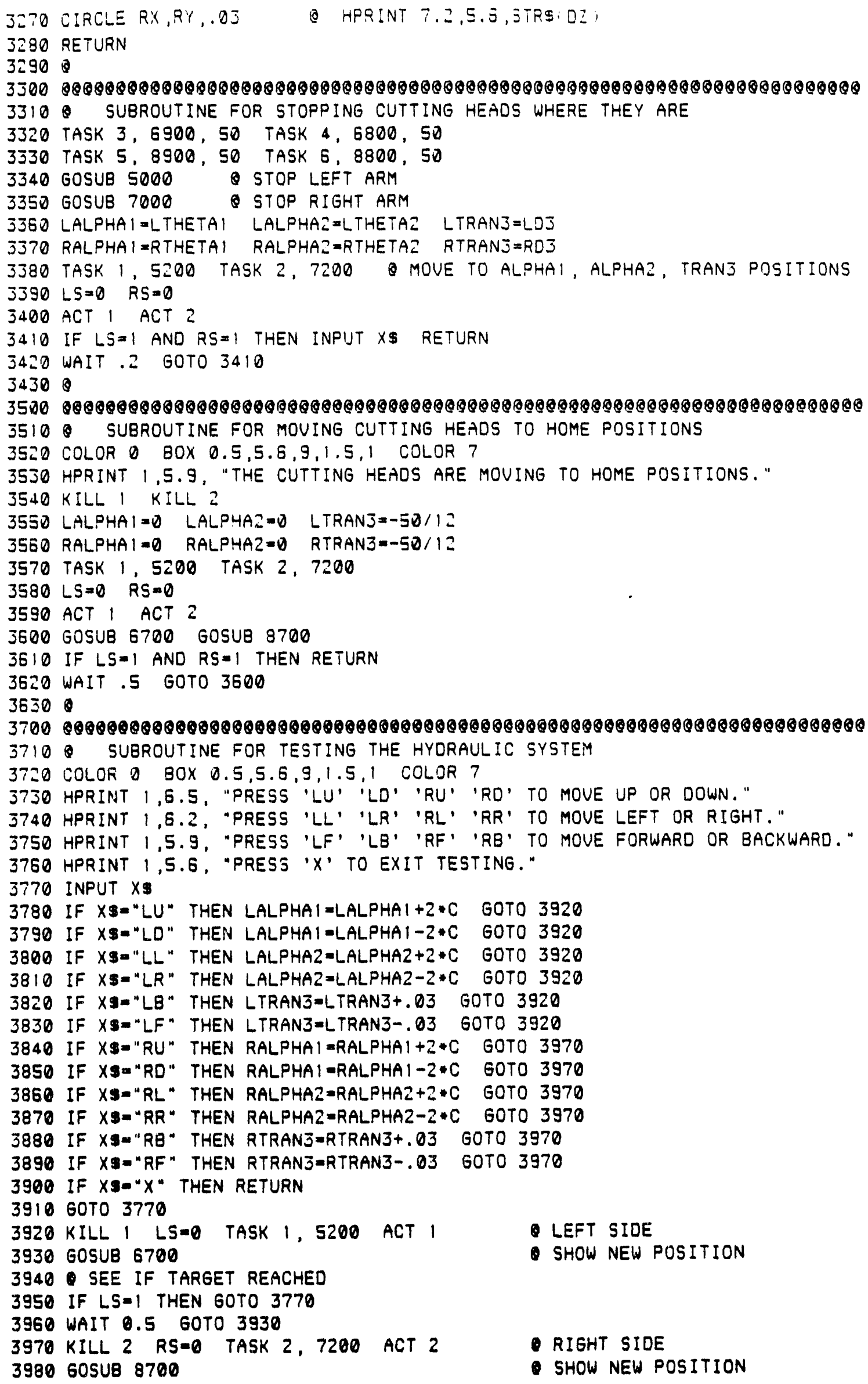

- SHOW NEW POSITION

- SHOW NEW POSITION 


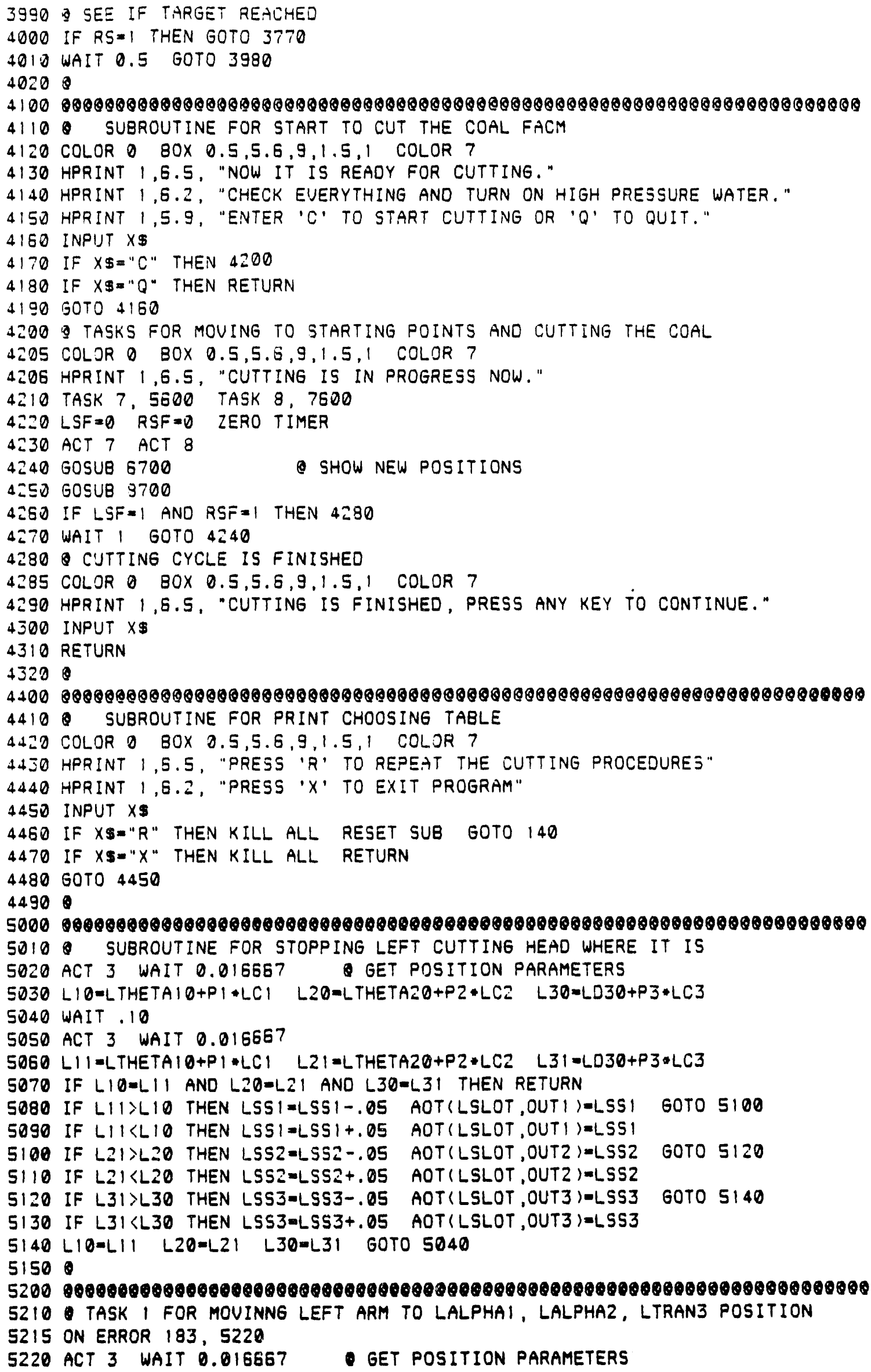




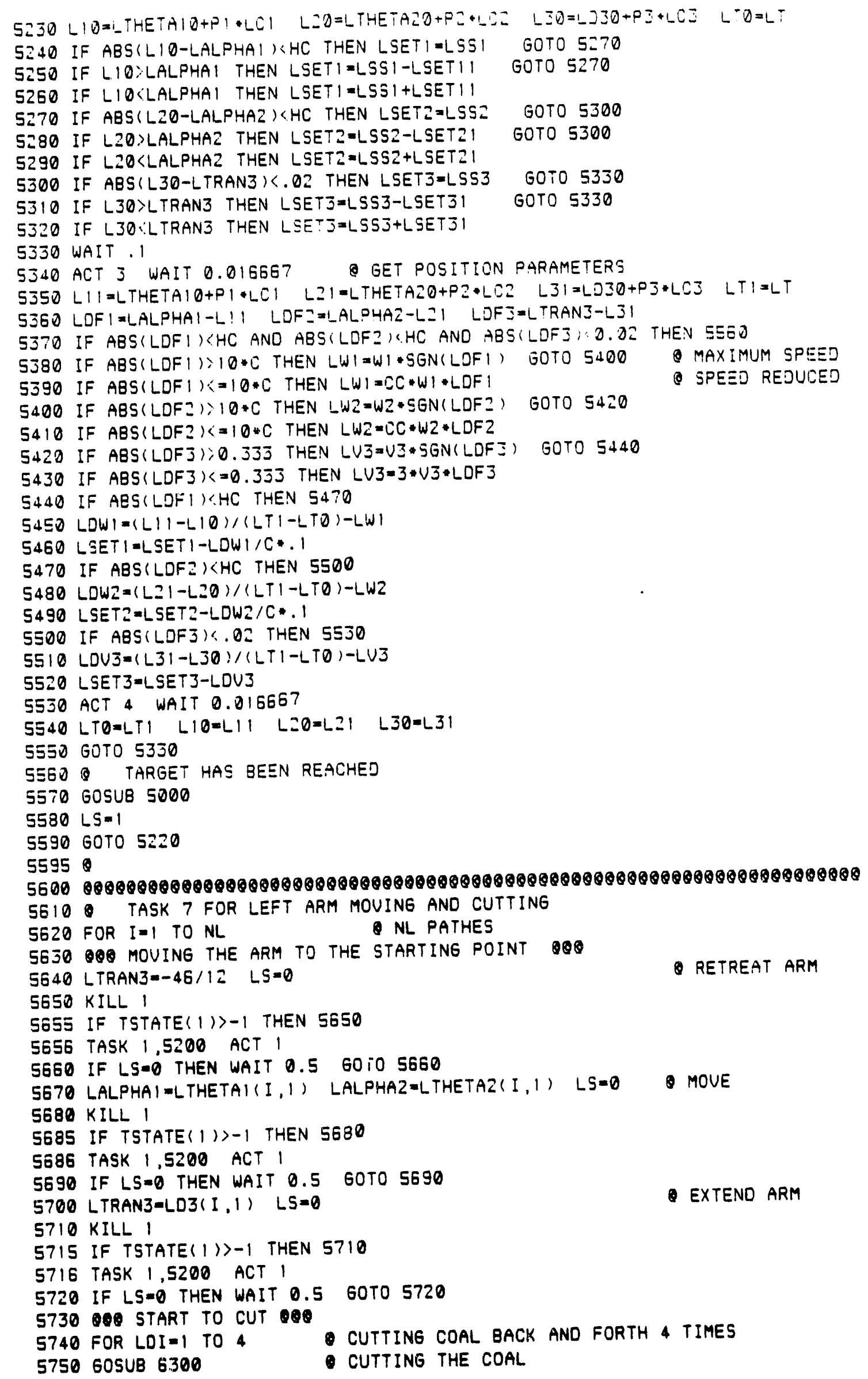




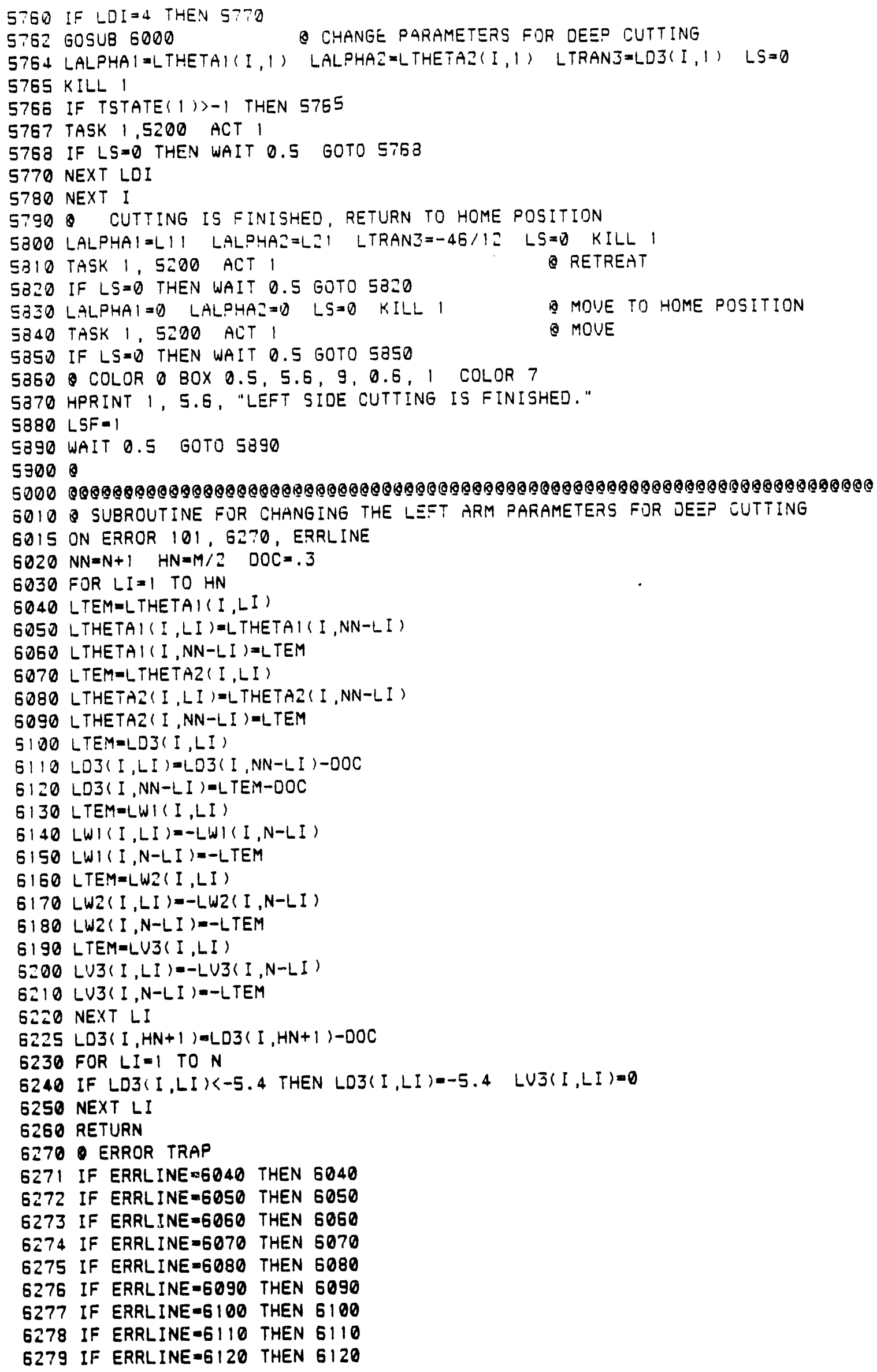




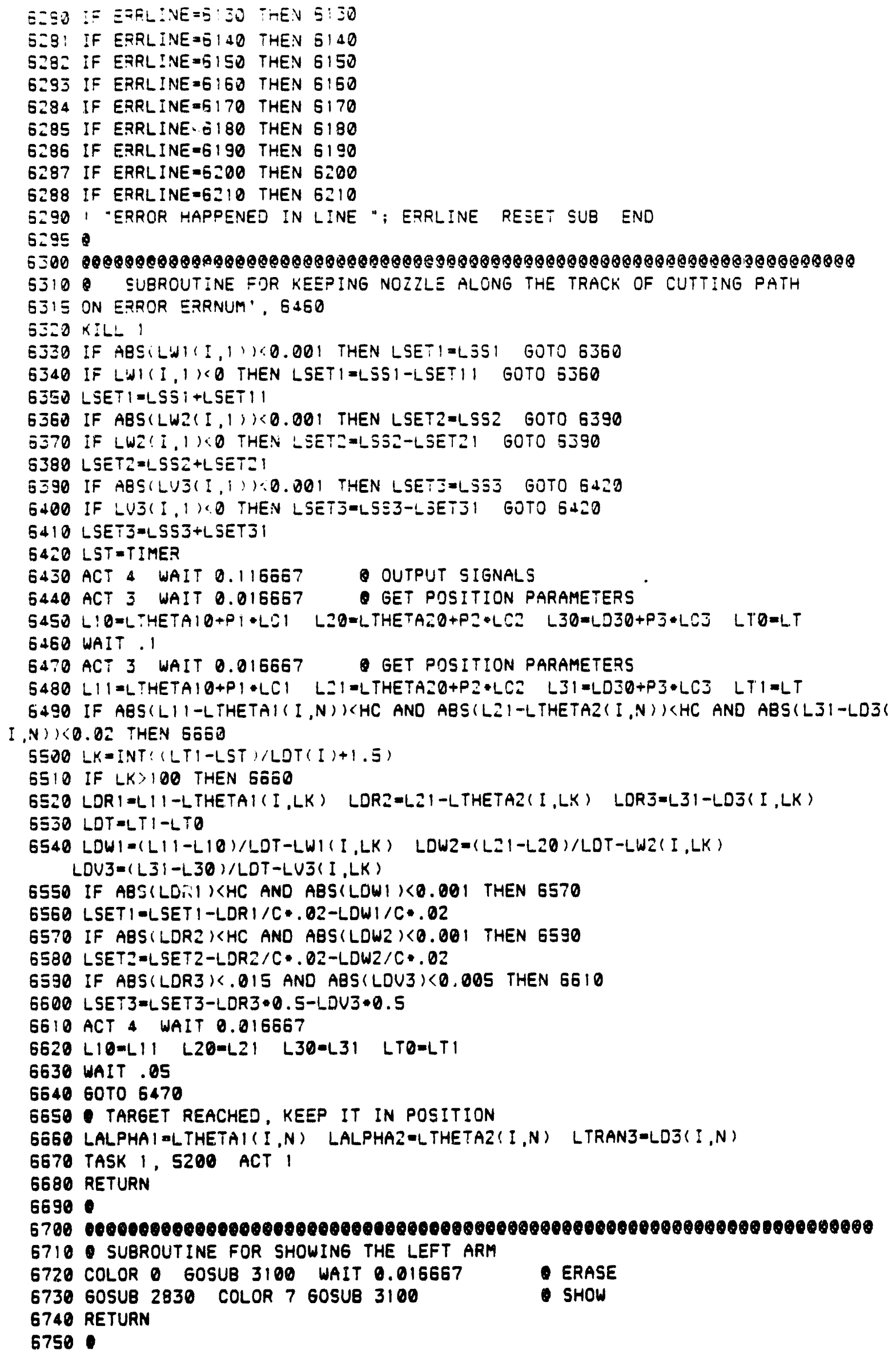




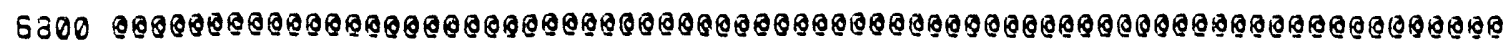

5810 THSK 4 FOR OUTPUTING LEFT CONTROLLING SIGNALS

6820 AOT(LSLOT, OUTI)=LSETI AOT(LSLOT, OUT2)=LSETI AOT(LSLOT,OUTJ) $=L S E T 3$

6830 SUSP SELF

6840 GOTO 6820

68500

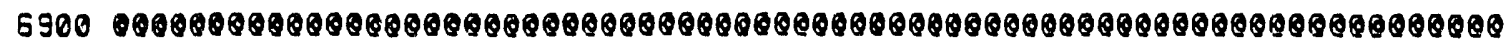

6910 TASK 3 FOR GETTING POSITION PARAMETERS FOR LEFT ARM

6920 L.T $=$ TIMER

$6930 P I=A I N(0, I N 1,0,0) \quad P 2=A I N(\theta, I N 2,0,0) \quad P J=A I N(\theta, I N 3,0,0)$

5940 SUSP SELF

$695060 T 06920$

6960

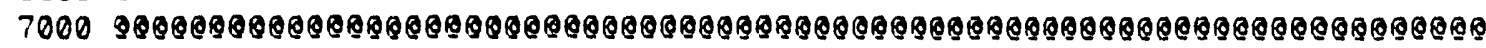

7010 SUBROUTINE FOR STOPPING RIGHT CUTTING HEAD WHERE IT IS

7020 ACT 5 WAIT 0.016667 GET POSITION PARAMETERS

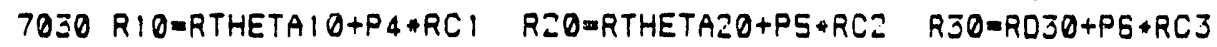

7040 WAIT . 10

7050 ACT 5 WAIT 0.016667

$7060 R 11=R T H E T A 10+P 4 * R C 1 \quad R 21=R T H E T A 20+P 5 * R C 2 \quad R 31=R D 30+P G * R C J$

7070 IF RIO=RII AND R20=R2I AND R30=R3I THEN RETURN

7080 IF RII>R10 THEN RSSI=RSS1-.05 AOT(RSLOT,OUT4)=RSS1 GOTO 7100

7090 IF RII RIO THEN RSSI=RSS1+.05 AOT(RSLOT,OUT4)=RSSI

7100 IF R21>R20 THEN RSS2=RSS2-.05 AOT(RSLOT, OUTS) $=R S S 2$

7110 IF R21 $\angle R 20$ THEN RSS2=RSS2+.05 AOT(RSLOT, OUTS) =RSS2

7120 IF R31>R30 THEN RSS3=RSSJ-.05 AOT(RSLOT, OUTE) $=R S S 3$

7130 IF R3I R 30 THEN RSS3=RSS3+.05 AOT(RSLOT, OUTE) $=R S S 3$

7140 RIO=RII R20=R2I R30=RJI GOTO 7040

7150

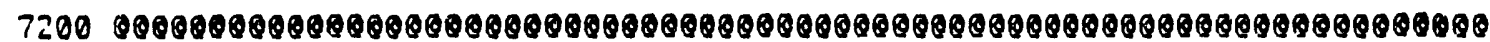

7210 TASK 2 FOR MOUINNG RIGHT ARM TO RALPHA1, RALPHA2, RTRANJ POSITION

7215 ON ERROR 183,7220

7220 ACT 5 WAIT 0.016667 GET POSITION PARAMETERS

T230 R10=RTHETAI0+P4*RCI R20=RTHETA20+P5*RCZ R30=RD30+PS*RC3 RTO=RT

7240 IF ABS (RIO-RALPHAI) $\angle H C$ THEN RSETI=RSSI GOTO 7270

7250 IF RIO>RALPHAI THEN RSETI-RSS1-RSETII G0TO 7270

7260 IF RIOLRALPHAI THEN RSETI=RSS1+RSETII

7270 IF ABS(R20-RALPHA2) $<H C$ THEN RSET2=RSS2 GOTO 7300

7280 IF R20>RALPHA2 THEN RSET2-RSS2-RSET21 G0TO 7300

7290 IF R20<RALPHA2 THEN RSET2-RSS2+RSET 21

7300 IF ABS (R30-RTRAN3)<.02 THEN RSET3=RSS3 GOTO 7330

7310 IF R3O>RTRAN3 THEN RSET3-RSS3-RSET31 GOTO 7330

7320 IF R30 LRTRAN3 THEN RSET3=RSS3+RSET3!

7330 WAIT . 1

7340 ACT 5 WAIT 0.016667 GET POSITION PARAMETERS

7350 RII=RTHETA10+P4*RC1 R21=RTHETA20+P5*RC2 R31=RO30+P6*RC3 RTI=RT

7360 RDF $1=R A L P H A 1-R 11$ ROF2-RALPHA2-R21 RDF3=RTRAN3-R31

7370 IF ABS(RDF1) $\angle H C$ AND ABS(RDF2) $\angle H C$ AND ABS(RDF3) $<0.02$ THEN 7560

7380 IF ABS(RDFI) $>10 * C$ THEN RWI $=W 1 * S G N(R D F 1)$ GOTO 7400

7390 IF ABS(RDF) $<=10 * C$ THEN RW $1=C C * W 1 * R D F 1$

7400 IF ABS(ROF2)>10*C THEN RWZ=W2*SGN(RDF2) GOTO 7420

7410 IF $A B S(R D F 2)<=10 * C$ THEN RW2 $=C C+W 2 * R D F 2$

7420 IF ABS(RDF3)>0.333 THEN RU3=U3*SGN(ROF 3$)$ 60T0 7440

7430 IF $A B S(R D F 3)<=0.333$ THEN RU $3=3.0 *$ U $3 *$ RDF 3

7440 IF ABS(RDFI) $<H C$ THEN 7470

$7450 R D W 1=(R \mid 1-R 10) /(R T 1-R T O)-R W)$

7460 RSET I-RSETI-ROW I /C* . I

7470 IF ABS(RDF 2 ) $\angle H C$ THEN 7500

7480 ROW2 $=(R 21-R 20) /(R T 1-R T O)-R W 2$

7490 RSET2=RSETZ-RDW2/C*.I 


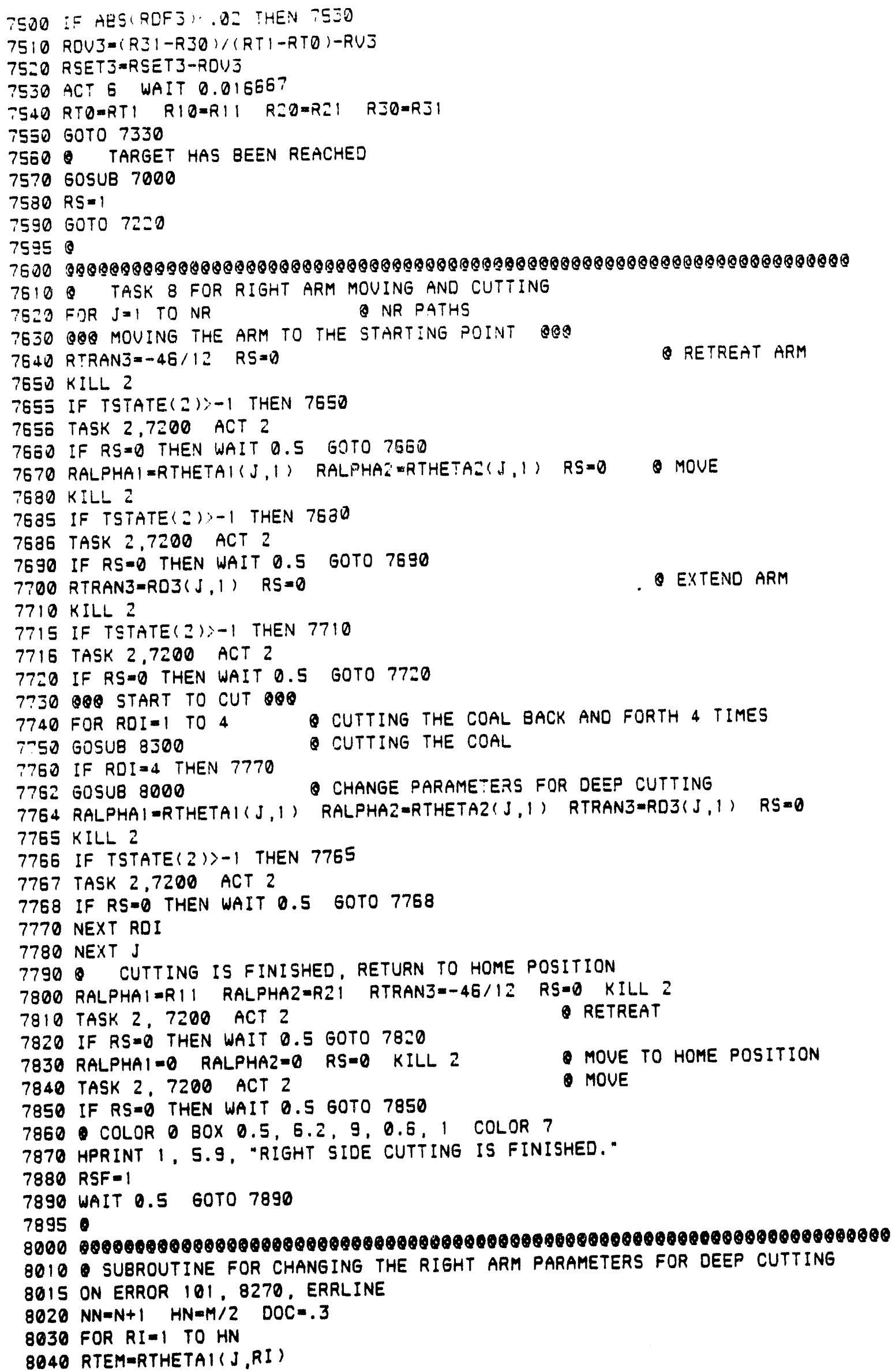




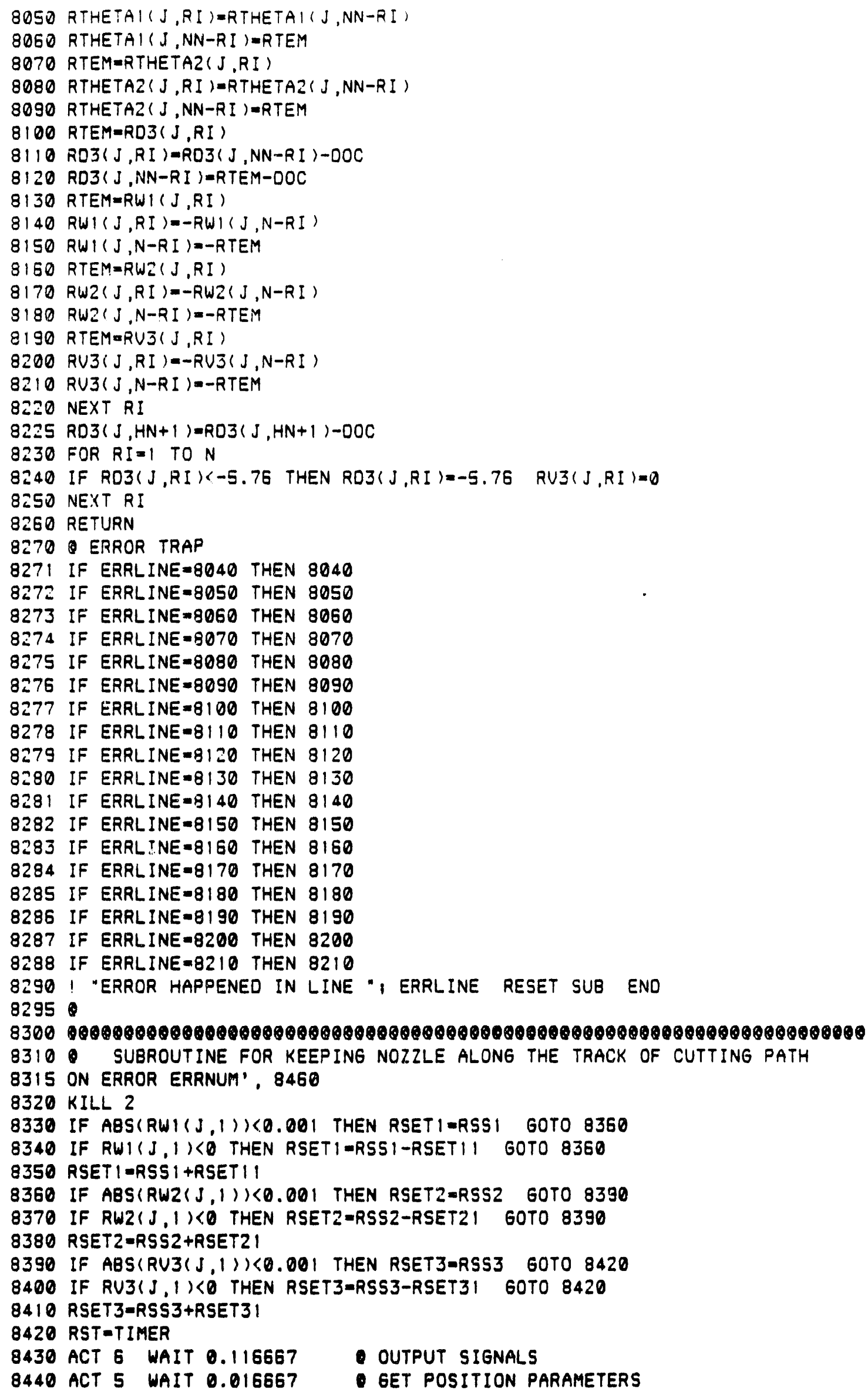


8450 RIO=RTHETAID+P4*RCI RID=RTHETAID+PS+RCI RJO=RDJD+PS*RCJ RTD=RT
8460 WAIT. I
8470 ACT 5 WAIT 0.016667 GET POSITION PARAMETERS

8480 RII=RTHETA10+P4*RCI R21=RTHETA20+P5*RC2 RJ1=RD30+PG*RCJ RTI=RT

8490 IF ABS $(R I 1-R T H E T A I(J, N))<H C$ AND ABS(RI)-RTHETAZ(J,N))

$J, N))<0.02$ THEN 8660

8500 RK $=I N T((R T)-R S T) / R D T(J)+1.5)$

8510 IF RK $>100$ THEN 8660

8520 RDR I =R 1 I-RTHETAI(J,RK) RDRI=R21-RTHETA2(J,RK) RDR3=R31-RO3(J,RK)

8530 RDT $=R T 1-R T 0$

$8540 R O W 1=(R 11-R 10) / R O T-R W 1(J, R K) \quad R D W 2=(R 21-R 20) / R O T-R W 2(J, R K)$

$R D \cup 3=(R 31-R 30) / R D T-R \cup 3(J, R K)$

8550 IF ABS(RDRI) $\angle H C$ AND ABS(RDW1) $<0.001$ THEN 8570

8560 RSETI $=R S E T I-R D R I / C * .02-R D W 1 / C * .02$

8570 IF ABSIRDRZ)(HC AND ABS(ROWZ) $<0.001$ THEN 8590

8530 RSETZ=RSETI-RORI/C*.0Z-ROWL/C*.0Z

8590 IF ABS(RDR3) .015 AND ABS(RDU3) 00.005 THEN 8610

8600 RSETJ $=$ RSET3-RORJ $* 0.5-R D U 3 \cdot 0.5$

8610 ACT $S$ WAIT 0.016667

$86: 0$ RIO=R11 RIO=R21 RJO=RJI RTO=RT1

8630 WAIT .05

9640 GOTO 8470

8650 TARGET REACHED, KEEP IT IN POSITION

8660 RALPHAI $=R T H E T A 1(J, N) \quad \operatorname{RALPHAZ}=\operatorname{RTHETAZ}(J, N) \quad \operatorname{RTRAN} 3=R D J(J, N)$

8670 TASK 2,7200 ACT 2

8680 RETURN

8690

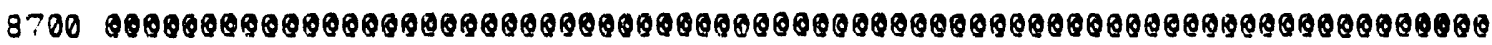

8710 SUBROUTINE FOR SHOWING THE RIGHT ARM

8720 COLOR O GOSUB 3200 WAIT 0.016667

8730 GOSUB 2930 COLOR 7 GOSUB 3200 SHOW

8740 RETURN

87500

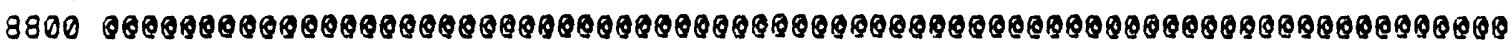

8810 TASK 6 FOR OUTPUTING RIGHT CONTROLLING SIGNALS

8820 AOT(RSLOT, OUT4)=RSET1 AOT(RSLOT, OUTS) $=$ RSET2 AOT(RSLOT, OUTE ) $=$ RSETJ

8830 SUSP SELF

8840 GOTO 8820

88500

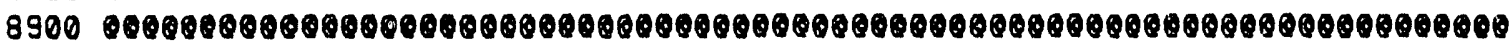

8910 TASK 5 FOR GETTING POSITION PARAMETERS FOR RIGHT ARM

8920 RT=TIMER $P 4=A I N(0$, IN4,0,0) P5=AIN $(0$, IN5,0,0) $\quad P G=A I N(0, I N G, 0,0)$

8930 SUSP SELF

8940 GOTO 8920

89500

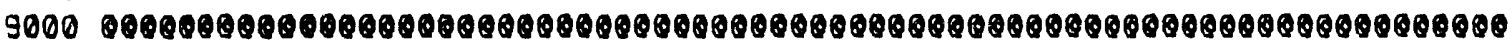

9010 ERROR TRAP

9020 IF ERLINE $<2860$ AND ERLINE $>2810$ THEN 2830

9030 IF ERLINE<2960 AND ERLINE $>2910$ THEN 2930

9040 IF ERLINE<3170 AND ERLINE $>3110$ THEN 3120

9050 IF ERLINE<3270 AND ERLINE $>3210$ THEN 3220

9060 1 "ERROR HAPPENED IN LINE " ERLINE RESET SUB END

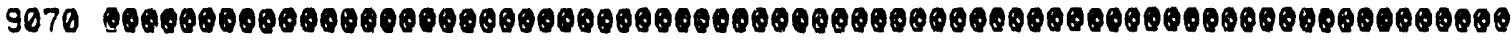

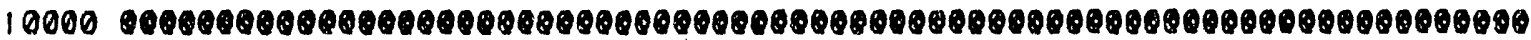

10010 SUBROUTINE FOR CONTROLLING THE ACTIONS OF CYLINDERS AND BOTTOM JETS IN THE HIGH PRESSURE WATERJET MINER

10020 GOSUB 10100 GET BASIC DATA FOR SCREEN CONTROL AND OUTPUT PORTS

10030 GOSUB 10400

- SET UP MENU FOR ACTIONS

10040 RETURN

10050 


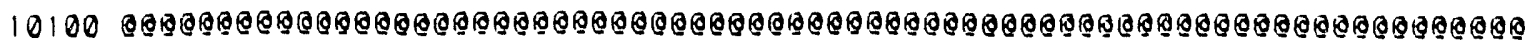
10110 SUBROUTINE FOR ENTERING BASIC DATA

10120 OSLOT $=3$

- OIGITAL I/O SLOT

10130 LU $=1 \quad L F=2 \quad B L=3 \quad$ RF $=4 \quad$ RU $=5 \quad$ CHANNELS FOR CYLINOERS

$10140 \quad L D=6 \quad L B=7 \quad B R=4 \quad R B=9 \quad R D=10$

10150 SCREEN CONTROL CONSTANTS

10160 ESC $=27 \quad E Q=61$

10170 NORMAL $=183$ REVERSE $=180 \quad$ BLINK $=181$

10180 BEEP $=7 \quad$ CR $=13$ LINE_OEL $=166$

10190 INU_CUR $=185$ UIS_CUR $=186$

10200 LEF $\bar{T}=8 \quad$ RIGHT $=12 \quad U P=11 \quad$ DOWN $=10 \quad$ SPACE $=32$

10210 STOP_ALL $=83$

10230 DOT $(\overline{3}, 14,15)=0$

10230 RETURN

10240

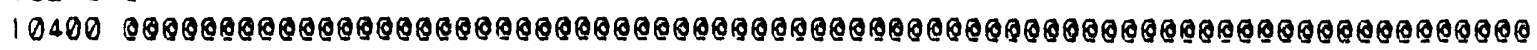

10410 SUBROUTINE FOR SETTING UP MENU AND TAKING ACTIONS

10420 DIM ACTION(10)

10430 DATA " LEFT UP" "LEFT FORWARD" "BOTTDM LEFT" "RIGHT FORWARD" " RIGHT UP" 10440 DATA "LEFT DOWN"," LEFT BACK", "BOTTOM RIGHT"," RIGHT BACK", "RIGHT DOWN" 


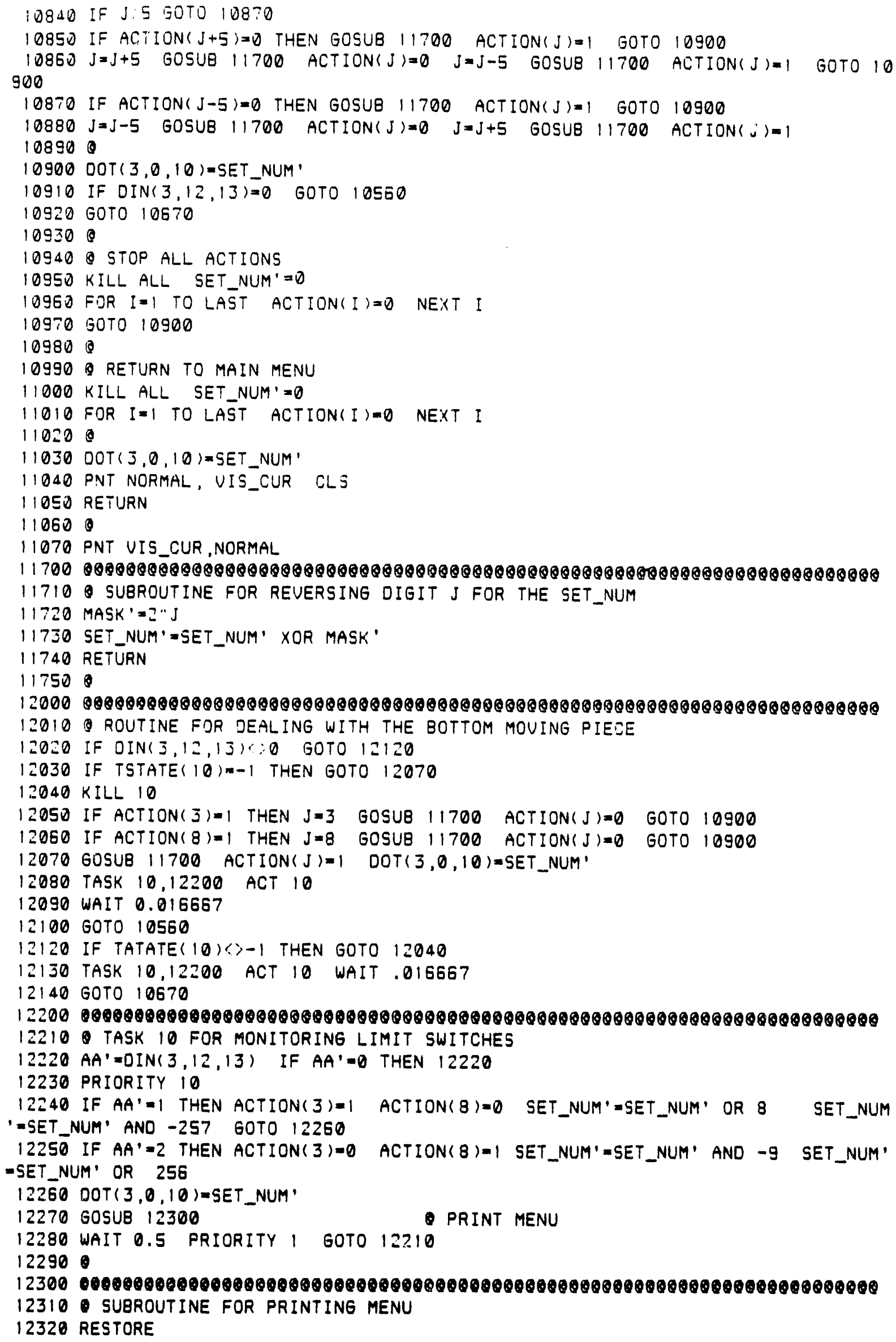




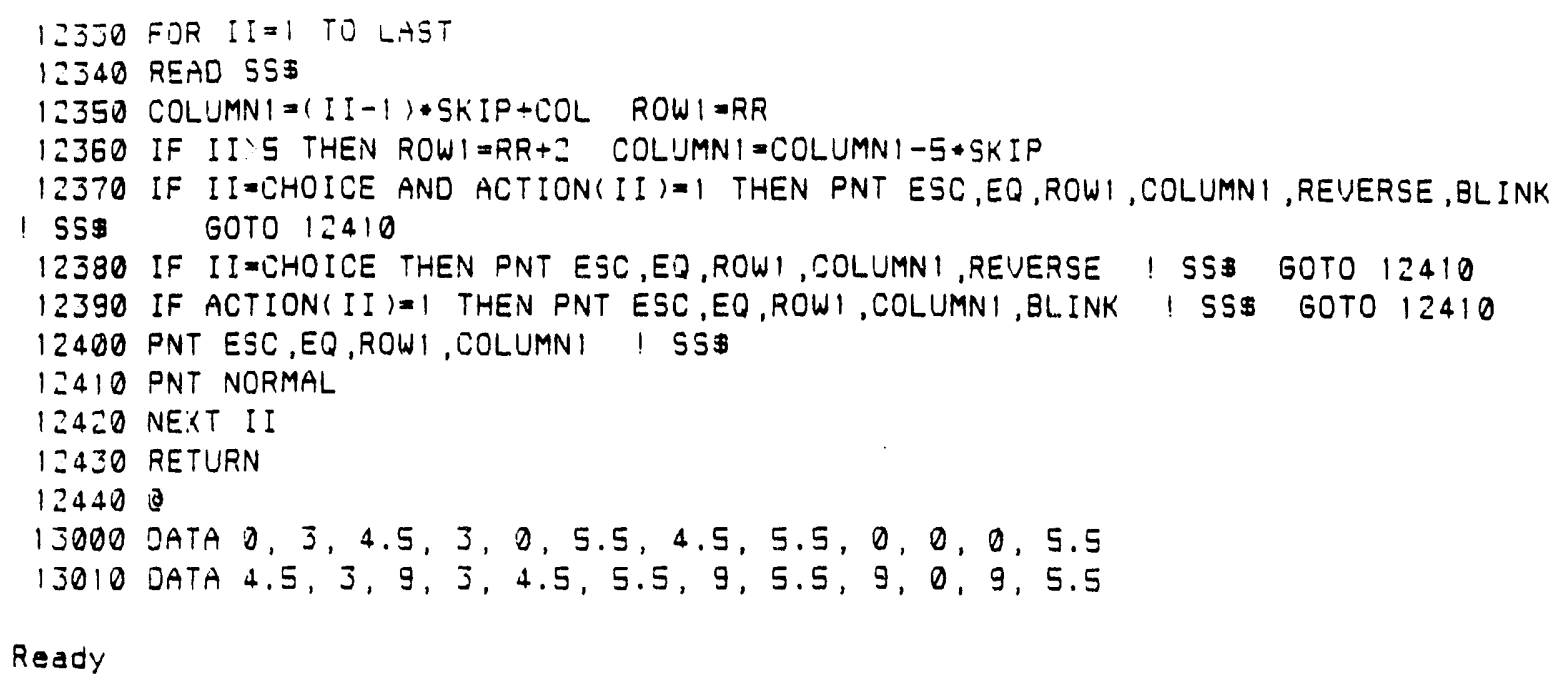



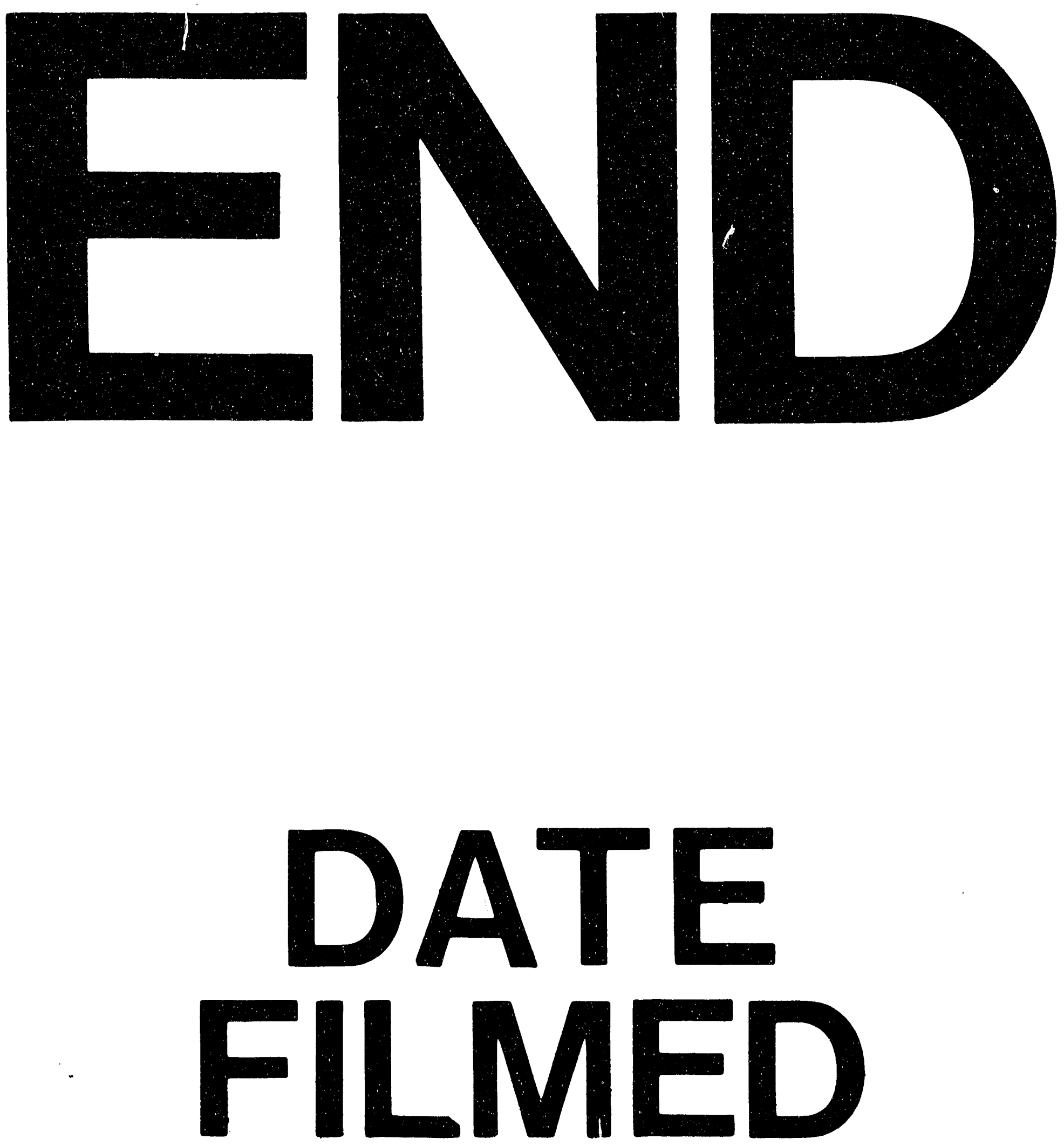

1

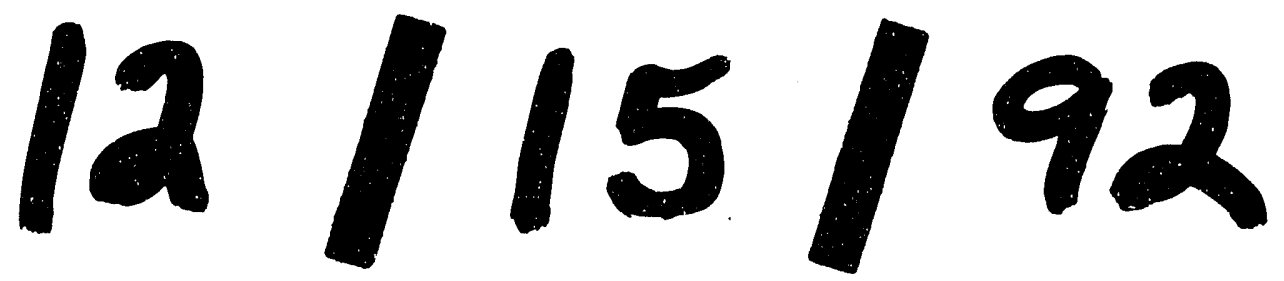


